\title{
Quadruplex turncoats: cation-dependent folding and stability of quadruplex-DNA double switches
}

Eric Largy, ${ }^{1,2,3}$ Adrien Marchand, ${ }^{1,2,3}$ Samir Amrane, ${ }^{1,2,3}$ Valérie Gabelica, ${ }^{1,2,3}$ Jean-Louis Mergny ${ }^{* 1,2,3}$

${ }^{1}$ Inserm, U1212, ARNA Laboratory, F-3300o Bordeaux, France.

${ }^{2}$ Univ. Bordeaux, IECB, ARNA laboratory, F-336oo Pessac, France.

${ }^{3}$ CNRS, UMR 7377, ARNA Laboratory, F-336oo Pessac, France.

\section{SUPPORTING INFORMATION}

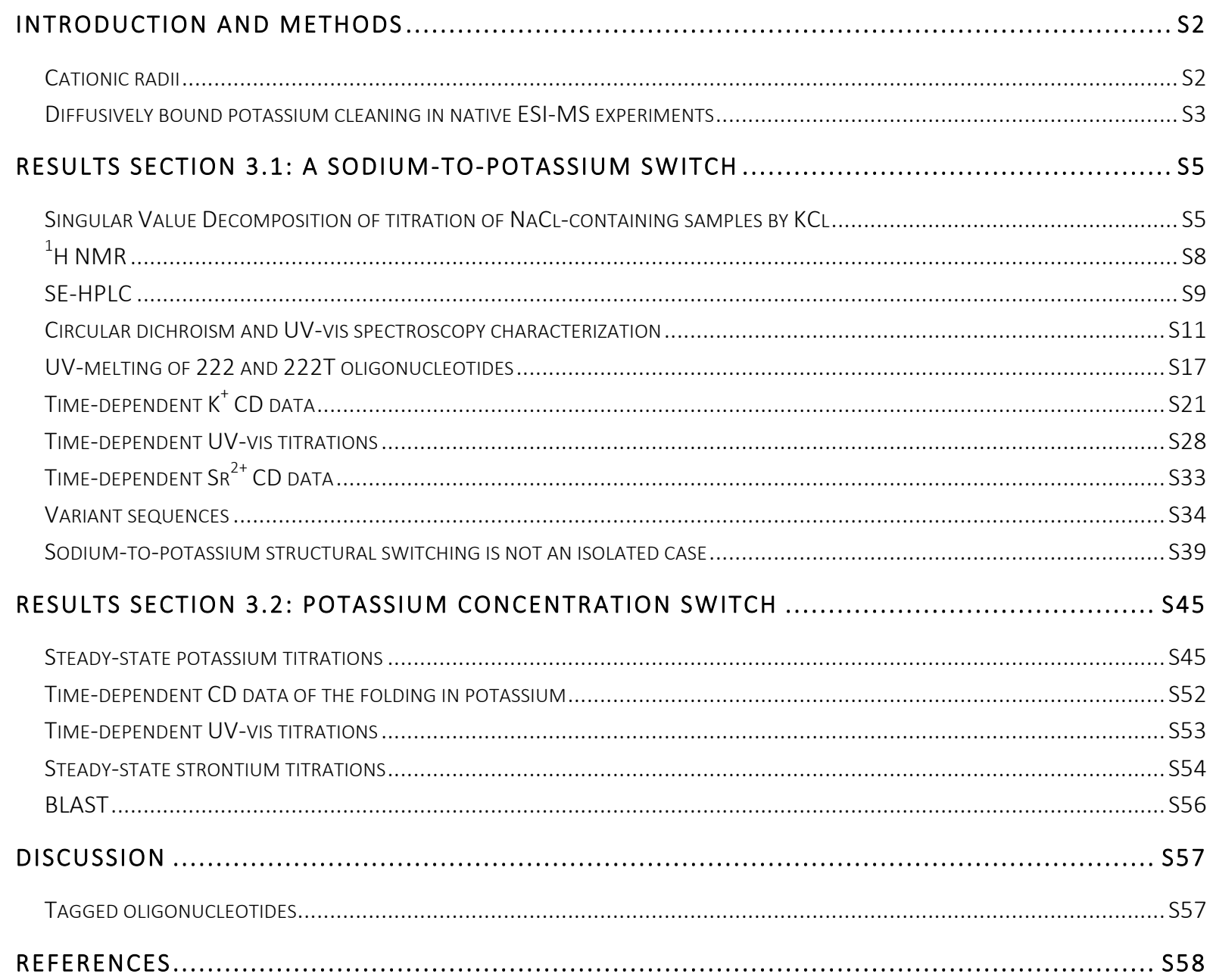




\section{INTRODUCTION AND METHODSS}

\section{CATIONIC RADII}

Below are given effective ionic radii for the cations investigated, assuming an octacoordination. Although the tetracoordination of $\mathrm{Na}^{+}$in the plane of quartets had been observed for $5^{\prime}$-GMP aggregates ${ }^{1}$, it must be noticed that in quadruplex structures, $\mathrm{Na}^{+}$cations can also be sandwiched between two tetrads, like potassium and other bulkier cations $\left(\mathrm{NH}_{4}^{+}, \mathrm{Ca}^{2+}, \mathrm{Sr}^{2+}\right)$, or adopt an intermediate location ${ }^{2}$.

Table S1. Revised effective ionic radii of some octacoordinated cations ${ }^{3}$.

\begin{tabular}{|c|c|c|}
\hline Cation & $\begin{array}{l}\text { Effective ionic radii } \\
\text { (Shannon) (A) }\end{array}$ & $\begin{array}{l}\text { Crystal radii } \\
(\AA)\end{array}$ \\
\hline $\mathrm{Mg}^{2+}$ & 0.89 & 1.03 \\
\hline$L i^{+}$ & 0.92 & 1.06 \\
\hline $\mathrm{Ca}^{2+}$ & 1.12 & 1.26 \\
\hline $\mathrm{Na}^{+}$ & 1.18 & 1.32 \\
\hline $\mathrm{Sr}^{2+}$ & 1.26 & 1.40 \\
\hline $\mathrm{NH}_{4}^{+}$ & 1.37 & 1.43 \\
\hline$K^{+}$ & 1.51 & 1.65 \\
\hline$R b^{+}$ & 1.61 & 1.75 \\
\hline
\end{tabular}




\section{DIFFUSIVELY BOUND POTASSIUM CLEANING IN NATIVE ESI-MS EXPERIMENTS}

The sequence d(TGCGTTGCGTTGCGTTGCG) was used as a non-quadruplex forming reference to obtain the non-specific $\mathrm{K}^{+}$distribution. It contains GCG repeats instead of GGG repeats to inhibit the quadruplex formation, linked by similar TT motifs. The use of an alternative sequence that only contains guanines and thymines gave similar results (GTGGTGTGTGGTGTGTGGT; not shown) We used the method described by Klassen's group in order to distinguish specific from non-specific adducts ${ }^{4}$. The following procedure has been used (Figure S1):

1. The integrals of the $\mathrm{K}^{+}$distribution for the non-G4 forming sequences were obtained

2. They were normalized according to the $0 \mathrm{~K}^{+}$stoichiometry

3. The values were used to reconstruct the specific $\mathrm{K}^{+}$stoichiometry thanks to the following formula:

$$
\begin{aligned}
& 0 K=i O K+i O K * x+i 0 K * y+i O K * z \\
& 1 K=\left(i 1 K-j 0 K^{*} x\right)+\left(i 1 K-i 0 K^{*} x\right) * x+\left(i 1 K-i 0 K^{*} x\right) * y+\left(i 1 K-i 0 K^{*} x\right) * z \\
& 2 K=\left(12 K-i 0 K^{*} y-\left(i 1 K-i 0 K^{*} x\right) * x\right)+\left(i 2 K-i 0 K^{*} y-\left(i 1 K-i 0 K^{*} x\right) * x\right) * x+(i 2 K-i 0 K * y-(i 1 K-i O K \\
& \left.* x)^{*} x\right) * y+\left(i 2 K-i 0 K^{*} y-\left(i 1 K-i 0 K^{*} x\right) * x\right) * z \\
& 3 K=\left(B K-i 0 K^{*} z-\left(i 1 K-i O K^{*} x\right) * y-\left(i 2 K-i O K^{*} y-\left(i 1 K-i O K^{*} x\right) * x\right) * x\right)+\left(B K-i O K^{*} z-(i 1 K-i O K\right. \\
& \left.* x) * y-\left(i 2 K-i O K^{*} y-\left(i 1 K-i O K^{*} x\right) * x\right) * x\right) * x+\left(i 3 K-i 0 K^{*} z-\left(i 1 K-i 0 K^{*} x\right) * y-(i 2 K-i O K *\right. \\
& \left.\left.y-\left(i 1 K-i 0 K^{*} x\right) * x\right) * x\right) * y+\left(B K-i 0 K^{*} z-(i 1 K-i O K * x) * y-(i 2 K-i 0 K * y-(i 1 K-i O K * x) * x)\right. \\
& * x) * z \\
& 4 K=\left(i 4 K-\left(i 1 K-i 0 K^{*} x\right) * z-\left(i 2 K-i 0 K^{*} y-\left(i 1 K-i 0 K^{*} x\right) * x\right) * y-\left(i 3 K-i 0 K^{*} z-\left(i 1 K-i 0 K^{*} x\right) * y-\right.\right. \\
& \left.\left.\left(i 2 K-i 0 K^{*} y-\left(i 1 K-i 0 K^{*} x\right) * x\right) * x\right) * x\right)+\left(i 4 K-\left(i 1 K-i 0 K^{*} x\right) * z-\left(i 2 K-i 0 K^{*} y-(i 1 K-i 0 K * x)\right.\right. \\
& * x) * y-(B K-i O K * z-(i 1 K-i O K * x) * y-(i 2 K-i O K * y-(i 1 K-i O K * x) * x) * x) * x) * x+(i 4 K- \\
& \left(i 1 K-i 0 K^{*} x\right) * z-(i 2 K-i O K * y-(i 1 K-i O K * x) * x) * y-(B K-i O K * z-(i 1 K-i O K * x) * y-(i 2 K- \\
& \left.\left.\left.i 0 K^{*} y-\left(i 1 K-i 0 K^{*} x\right) * x\right)^{*} x\right) * x\right) * y+\left(i 4 K-\left(i 1 K-i 0 K^{*} x\right) * z-\left(i 2 K-i 0 K^{*} y-\left(i 1 K-i 0 K^{*} x\right) *\right.\right. \\
& x) * y-(B K-i O K * z-(i 1 K-i O K * x) * y-(i 2 K-i O K * y-(i 1 K-i O K * x) * x) * x) * x) * z
\end{aligned}
$$

Where $O K, 1 K, 2 K, 3 K, 4 K$ and $5 K$ reflect the specific $K^{+}$distribution. $x, y$ and $z$ are the values of the normalized integrals of the 1,2 and 3 non-specific $K^{+} .10 K, i 1 K, i 2 K, i 3 K, i 4 K$ and $i 5 K$ are the initial integrals for the $0,1,2,3,4$ and $5 \mathrm{~K}^{+}$stoichiometries. The specific $\mathrm{K}^{+}$intensity is therefore equal to the 
total area of the peak for this stoichiometry minus the non-specific adducts of the peaks with lower $\mathrm{K}^{+}$ stoichiometries plus the non-specific adducts on the considered peak.

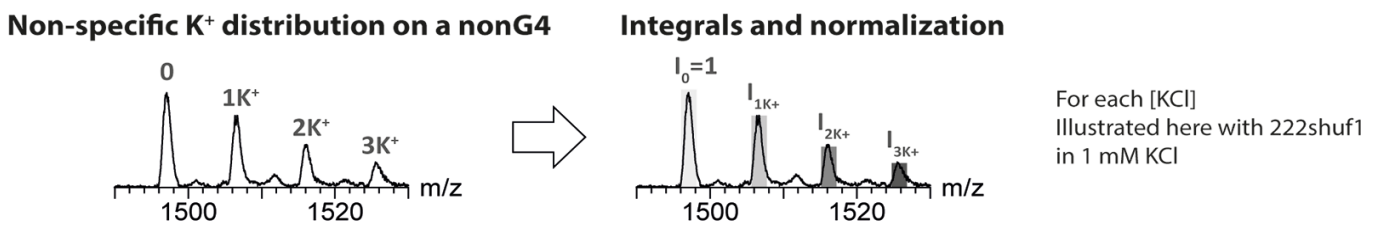

Raw $\mathrm{K}^{+}$distribution of 222 in $1 \mathrm{mM} \mathrm{KCl}$

Specific $\mathbf{K}^{+}$distribution
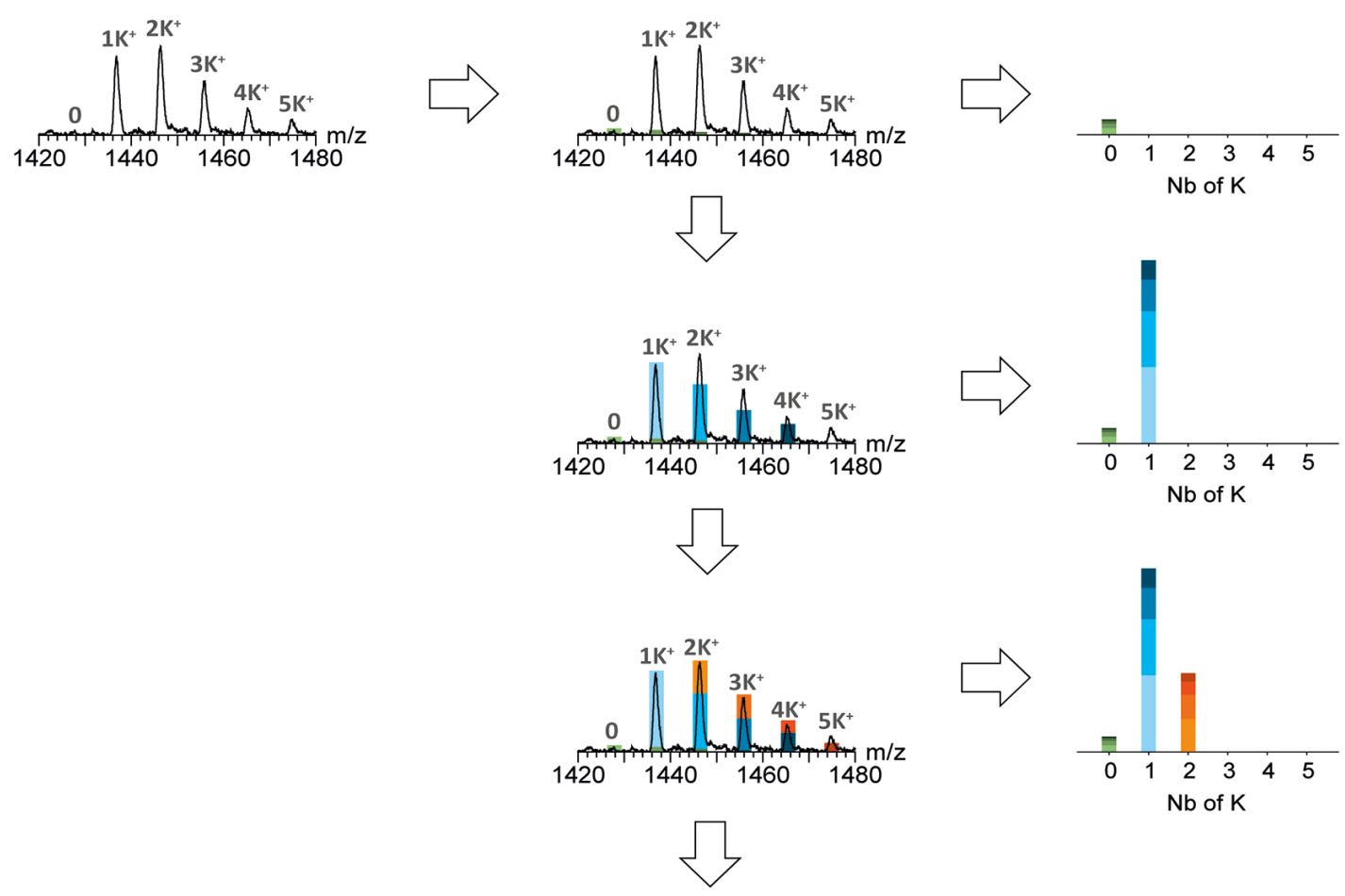

Figure S1. Scheme of the principle applied herein for the cleaning of non-specific adducts of potassium on G4-DNA for ESI-MS experiments. 


\section{RESULTS SECTION 3.1: A SODIUM-TO-POTASSIUM SWITCH}

Singular Value Decomposition of titration of NaCl-CONTAining SAMPLES by KCL Singular Value Decomposition (SVD) was adapted from the protocol of Gray and Chaires ${ }^{5}$ in Wolfram Mathematica 10. Raw data of potassium concentration-dependent or time-dependent experiments (matrix D) were decomposed into three matrices $\mathrm{U}$ (basis spectra), $\mathrm{S}$ (singular values) and $\mathrm{V}$ (amplitude vectors as a function of potassium concentration or time, respectively).

$D=$ USV

The scree plots (a chart associating the components to their singular value) were generated for the ten highest singular values, and the corresponding percentages of total variance were obtained from the relative variance $(\mathrm{RV})$ of singular values $\mathrm{s}_{\mathrm{i}}$ :

$R V=\frac{s_{i}^{2}}{\sum_{i} s_{i}^{2}}$

In a first approach, the significant components were selected so that the sum of their contribution reaches at least $99.75 \%$ of the total variance. 
A

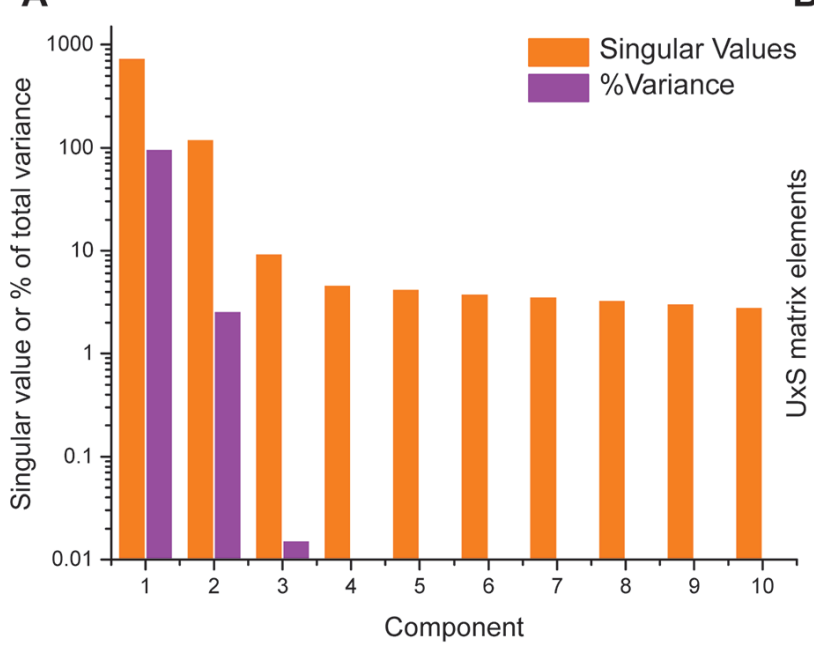

C

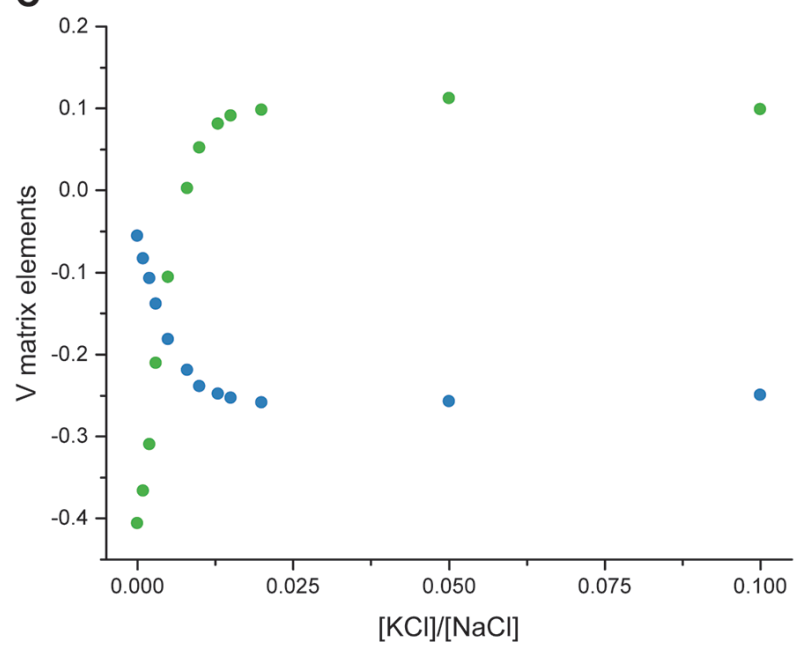

B

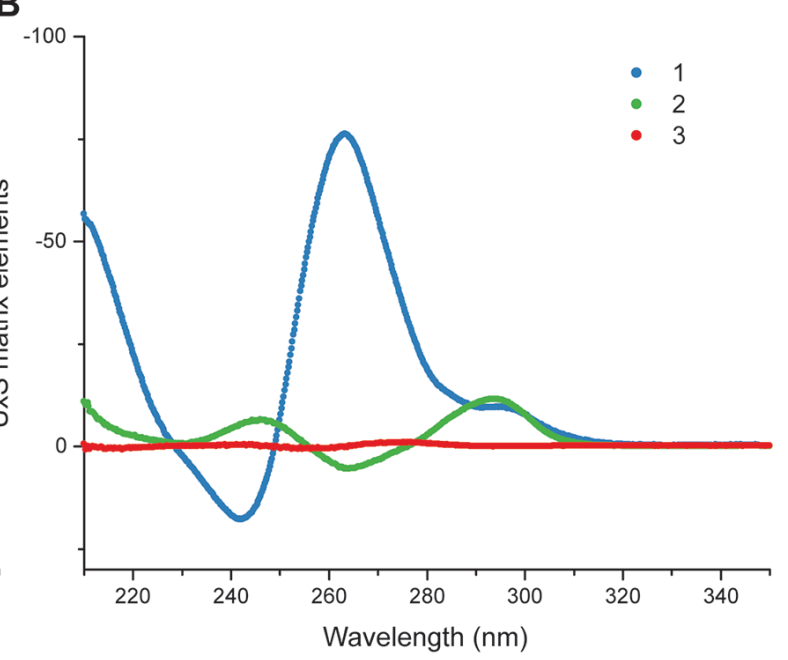

Figure S2. SVD results of the titration of 222-100 $\mathrm{mM} \mathrm{Na}^{+}$by increasing amounts of $\mathrm{KCl}$. Panel $\mathrm{A}$ is a bar chart showing the first ten singular values and their corresponding relative variance. The three first basis spectra and the first two $V$ matrix elements as a function of potassium concentration are shown in panels $B$ and $C$, respectively. 
A

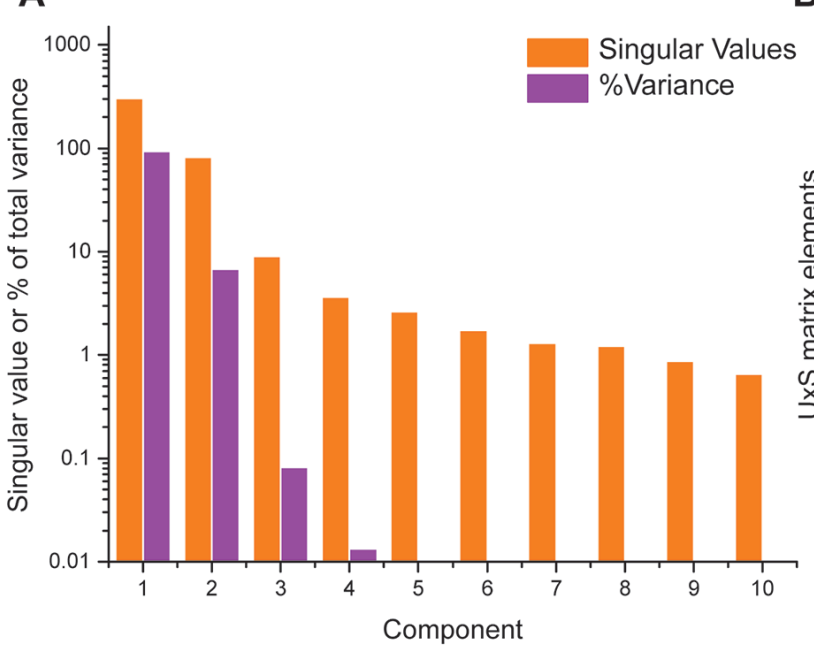

C

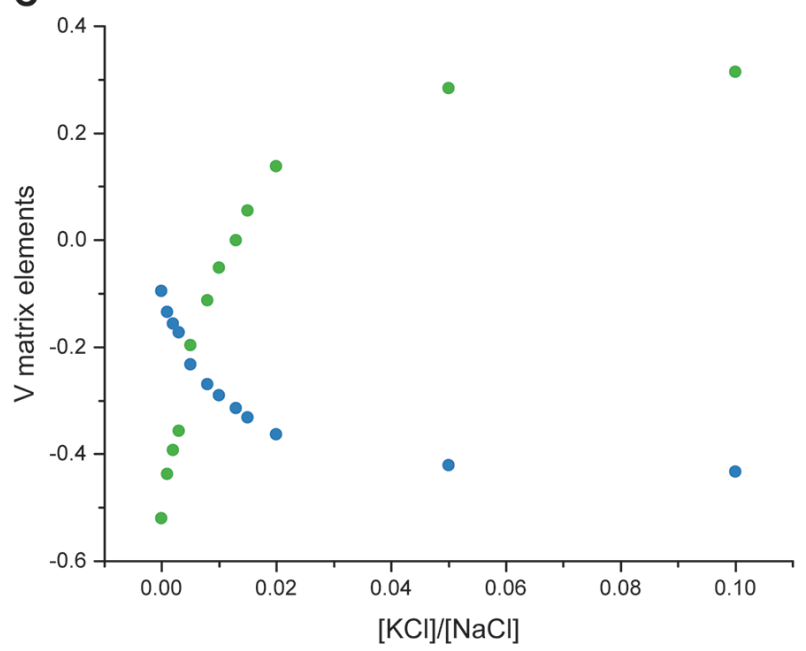

B

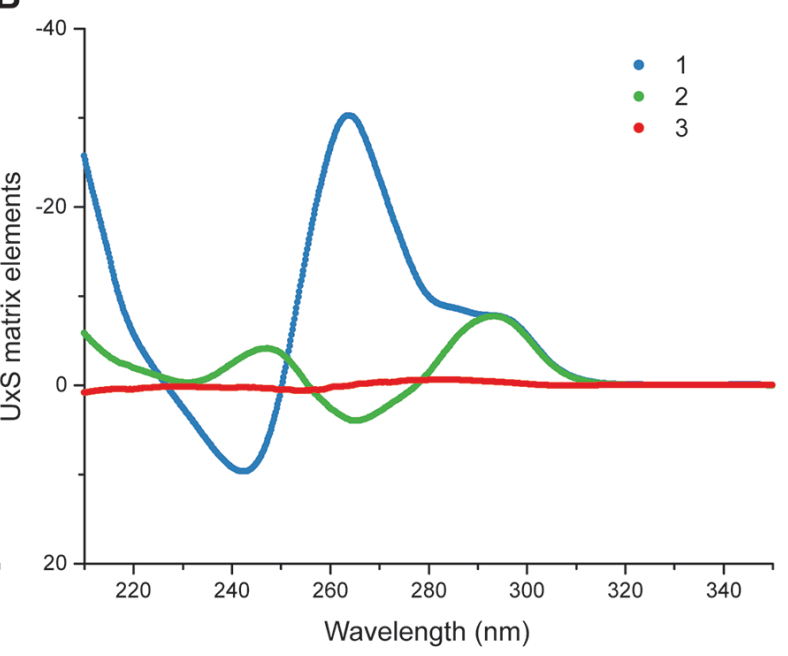

Figure S3. SVD results of the titration of $222 \mathrm{~T}-100 \mathrm{mM} \mathrm{Na}{ }^{+}$by increasing amounts of $\mathrm{KCl}$. Panel A is a bar chart showing the first ten singular values and their corresponding relative variance. The three first basis spectra and the first two $V$ matrix elements as a function of potassium concentration are shown in panels $B$ and $C$, respectively. 


\section{${ }^{1} \mathrm{H} N M R$}

$1 H$ NMR experiments were performed on a $700 \mathrm{MHz} N M R$ Bruker spectrometer, at $20{ }^{\circ} \mathrm{C}$, on $300-\mu \mathrm{M}$ oligonucleotide samples. The jump-and-return method $\left(1 \mathrm{D}{ }^{1} \mathrm{H} J \mathrm{R}\right)$ was used for water suppression in 1D spectrum acquisition.

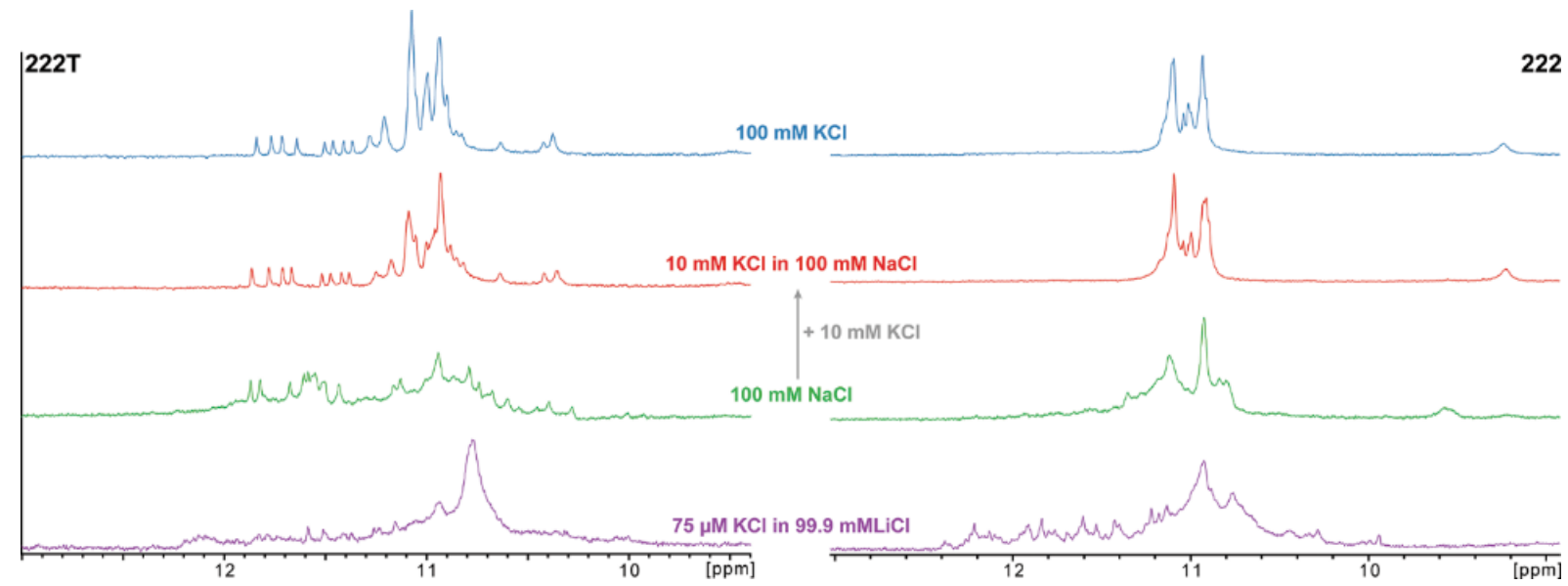

Figure S4. ${ }^{1} \mathrm{H}$ NMR spectra of $222 \mathrm{~T}$ (left) and 222 (right) in water, supplemented with $75 \mu \mathrm{M} \mathrm{KCl}$ and $99.9 \mathrm{mM} \mathrm{LiCl}$ (purple), $100 \mathrm{mM} \mathrm{KCl}$ (blue), $100 \mathrm{mM} \mathrm{NaCl}$ (green), and after addition of $10 \mathrm{mM} \mathrm{KCl}$ to the previous sample (red, incubation time $<10 \mathrm{~min}$ at room temperature). 


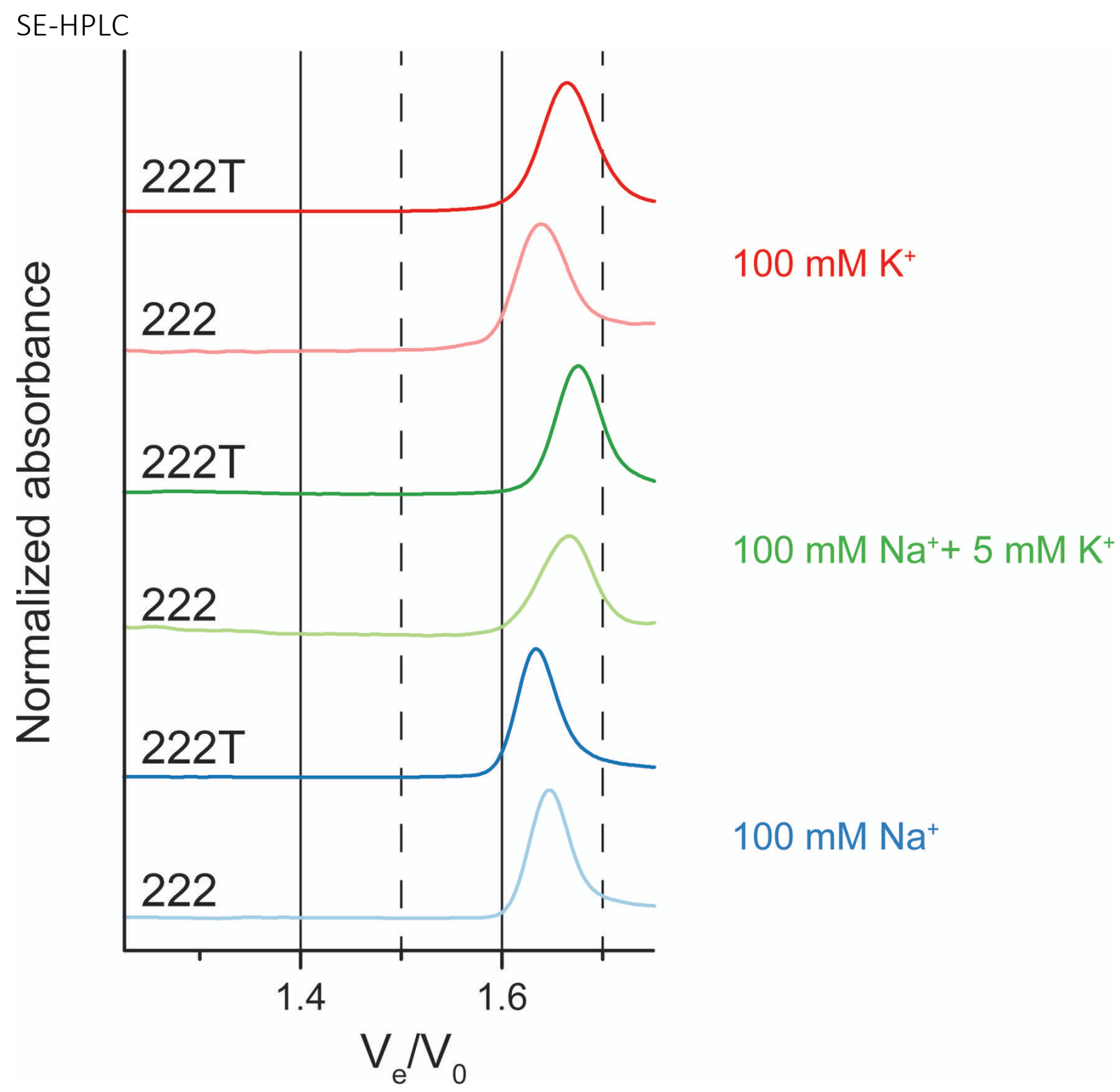

Figure S5. SE-HPLC profile $(260 \mathrm{~nm})$ of 222 and $222 \mathrm{~T}$ at low strand concentration $(10 \mu \mathrm{M})$, in various buffers (see legend). 
Supporting Information - page S10

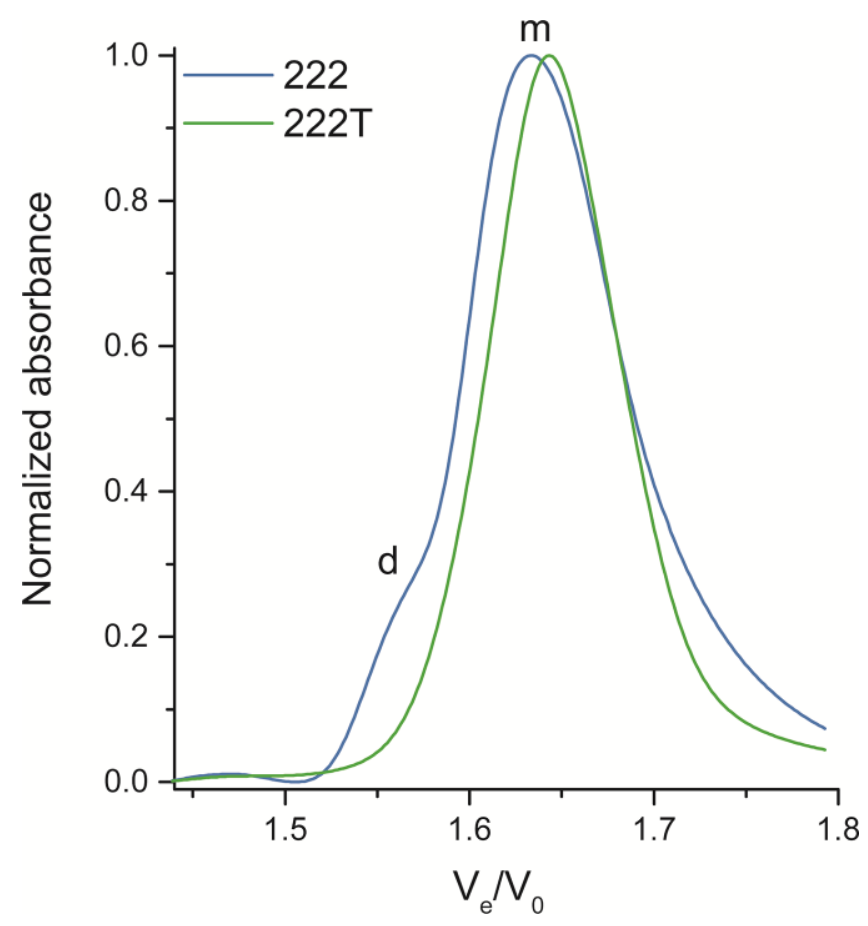

Figure S6. SE-HPLC profile $(260 \mathrm{~nm})$ of 222 and $222 \mathrm{~T}$ at high strand concentration $(250 \mu \mathrm{M})$, in a 100 $m \mathrm{M} \mathrm{KCl}$ containing buffer. Monomer peaks are indicated by $m$, dimers by $d$. 


\section{CIRCULAR DICHROISM AND UV-VIS SPECTROSCOPY CHARACTERIZATION}

Circular Dichroism (CD) experiments were performed with a JASCO J-815 spectropolarimeter equipped with a JASCO CDF-426S Peltier temperature controller, using quartz cells of $2 \mathrm{~mm}$ path length. The scans were recorded at $20^{\circ} \mathrm{C}$ or $4{ }^{\circ} \mathrm{C}$, from 210 to $350 \mathrm{~nm}$ with the following parameters: $0.2 \mathrm{~nm}$ data pitch, $2 \mathrm{~nm}$ bandwidth, $0.5 \mathrm{~s}$ response, $50 \mathrm{~nm} \mathrm{m^{-1 }}$ scanning speed, and are the result of three accumulations (except for time-dependent experiments where single scans are acquired at $200 \mathrm{~nm}$ $\left.\mathrm{min}^{-1}\right)$. Solutions were prepared by diluting the annealed oligonucleotide samples at $10 \mu \mathrm{M}$ in lithium cacodylate $(20 \mathrm{mM}, \mathrm{pH}$ 7.2), supplemented with various concentrations of group 1 or 2 cation chlorides. The CD data were blank-subtracted and normalized to molar dichroic absorption $(\Delta \varepsilon)$ based on nucleoside concentration using Equation 1 , with $\theta$ the ellipticity in millidegrees, $c$ the nucleoside concentration in $\mathrm{mol} \mathrm{L}^{-1}$, and / the path length in $\mathrm{cm}$.

$\Delta \varepsilon=\theta /(32980 \times c \times)$

Thermal Difference Spectra (TDS) were obtained by subtraction of the UV-spectra ( $\lambda=210-350 \mathrm{~nm}$ ) of a given sample in lithium cacodylate $(20 \mathrm{mM}, \mathrm{pH} 7.2)$ supplemented with chloride salts of a group 1 or 2 cation $(100 \mathrm{mM})$, acquired at $95^{\circ} \mathrm{C}$ and $4{ }^{\circ} \mathrm{C}^{6}$.

Isothermal difference spectra (IDS) were calculated by subtraction of the UV-spectra of a given sample acquired in absence or presence (100 or $0 \mathrm{mM}$ for steady state measurements, and $5 \mathrm{mM}$ added for time-dependent experiments) of monovalent or divalent cations, at $2{ }^{\circ} \mathrm{C}$. IDS are not strictly identical to TDS because the absorbance spectra of the unfolded and folded species are temperaturedependent. 
Table S2. Spectroscopic characterization of 222 and $222 \mathrm{~T}$ in presence of a variety of cations.

\begin{tabular}{|c|c|c|c|c|c|c|c|c|c|c|c|c|c|c|}
\hline & & \multicolumn{3}{|c|}{$C D^{\mathrm{a}}$} & \multicolumn{4}{|c|}{$T D S^{b}$} & \multicolumn{5}{|c|}{$\underline{I D S^{b}}$} & \multirow[b]{2}{*}{ ratio vs. $\mathrm{Na}^{+}$} \\
\hline & $\lambda$ & $\begin{array}{l}240 \\
\mathrm{~nm}\end{array}$ & $\begin{array}{l}260 \\
\mathrm{~nm}\end{array}$ & $\begin{array}{l}295 \\
\mathrm{~nm}\end{array}$ & $\begin{array}{l}240 \\
\mathrm{~nm}\end{array}$ & $\begin{array}{l}255 \\
\mathrm{~nm}\end{array}$ & $\begin{array}{l}275 \\
\mathrm{~nm}\end{array}$ & $\begin{array}{l}295 \\
\mathrm{~nm}\end{array}$ & $\begin{array}{l}240 \\
\mathrm{~nm}\end{array}$ & $\begin{array}{l}255 \\
\mathrm{~nm}\end{array}$ & $\begin{array}{l}275 \\
\mathrm{~nm}\end{array}$ & $\begin{array}{l}295 \\
\mathrm{~nm}\end{array}$ & $\begin{array}{c}240 \mathrm{~nm}^{\mathrm{s}} \\
/ 295 \mathrm{~nm}^{\mathrm{c}}\end{array}$ & \\
\hline \multirow{9}{*}{222} & $\mathrm{~K}^{+}$ & - & + & no & 0.13 & 0.08 & 0.20 & -0.12 & 0.08 & 0.01 & 0.03 & -0.07 & 1.03 & 2.9 \\
\hline & $\mathrm{Na}^{+}$ & + & - & + & 0.11 & 0.06 & 0.22 & -0.14 & 0.05 & -0.07 & 0.03 & -0.13 & 0.35 & 1.0 \\
\hline & $\mathrm{Ca}^{2+}$ & - & + & no & 0.13 & 0.15 & 0.27 & -0.16 & 0.15 & 0.14 & 0.15 & -0.14 & 1.12 & 3.2 \\
\hline & $\mathrm{Sr}^{2+}$ & - & + & no & 0.02 & 0.04 & 0.15 & -0.09 & 0.10 & 0.06 & 0.11 & -0.20 & 0.50 & 1.4 \\
\hline & & & & & & & & & & & & & & \\
\hline & $\mathrm{NH}_{4}^{+}$ & - & + & + & 0.09 & 0.07 & 0.17 & -0.14 & 0.05 & -0.01 & 0.02 & -0.12 & 0.40 & 1.1 \\
\hline & $\mathrm{Rb}^{+}$ & $(-)$ & + & + & 0.09 & 0.04 & 0.17 & -0.15 & 0.05 & -0.04 & 0.00 & -0.13 & 0.35 & 1.0 \\
\hline & $\mathrm{Li}^{+}$ & no & no & no & 0.05 & 0.10 & 0.16 & -0.02 & -0.02 & -0.01 & -0.01 & 0.00 & no $G 4$ & no $G 4$ \\
\hline & $\mathrm{Mg}^{2+}$ & no & no & no & 0.07 & 0.12 & 0.22 & -0.08 & -0.01 & -0.01 & -0.01 & -0.03 & no $G 4$ & no $G 4$ \\
\hline \multirow{8}{*}{$\begin{array}{c}222 \\
T\end{array}$} & $\mathrm{~K}^{+}$ & - & + & no & 0.12 & 0.03 & 0.13 & -0.11 & 0.16 & 0.02 & 0.02 & -0.11 & 1.45 & 3.0 \\
\hline & $\mathrm{Na}^{+}$ & + & - & + & 0.08 & 0.02 & 0.16 & -0.16 & 0.09 & -0.04 & 0.02 & -0.18 & 0.48 & 1.0 \\
\hline & $\mathrm{Ca}^{2+}$ & - & + & $(+)$ & 0.10 & 0.12 & 0.23 & -0.12 & 0.09 & 0.04 & 0.05 & -0.15 & 0.62 & 1.3 \\
\hline & $\mathrm{Sr}^{2+}$ & - & + & $(+)$ & 0.05 & 0.04 & 0.16 & -0.12 & 0.10 & 0.04 & 0.07 & -0.22 & 0.47 & 1.0 \\
\hline & $\mathrm{NH}_{4}^{+}$ & $(-)$ & + & + & 0.08 & -0.01 & 0.11 & -0.15 & 0.06 & -0.09 & -0.04 & -0.17 & 0.35 & 0.7 \\
\hline & $\mathrm{Rb}^{+}$ & - & + & no & 0.08 & -0.01 & 0.10 & -0.14 & 0.16 & 0.03 & 0.03 & -0.12 & 1.32 & 2.7 \\
\hline & $\mathrm{Li}^{+}$ & no & no & no & 0.09 & 0.03 & 0.12 & -0.09 & 0.01 & 0.02 & 0.01 & -0.01 & no $G 4$ & no $G 4$ \\
\hline & $\mathrm{Mg}^{2+}$ & no & no & no & 0.04 & 0.13 & 0.19 & -0.02 & 0.04 & 0.07 & 0.03 & -0.03 & no $G 4$ & no $G 4$ \\
\hline \multicolumn{15}{|c|}{ a Positive "+" or negative "-" dichroic bands. Brackets indicate a low intensity. } \\
\hline \multicolumn{15}{|c|}{$\begin{array}{l}\text { bable of the } \Delta \mathrm{A} \text {, values calculated from } \operatorname{TDS}\left(A_{95^{\circ} \mathrm{C}}-A_{4^{\circ} \mathrm{C}}\right) \text { and } \\
{ }^{\mathrm{C}} \text { IDS factor defined by the absolute value of } \Delta A_{240 \mathrm{~nm}} / \Delta A_{295 \mathrm{~nm}} \text {. } \\
\text { d } \\
{ }^{\mathrm{d}} \text { Ratio of the IDS factor vs. the sodium IDS factor. }\end{array}$} \\
\hline
\end{tabular}
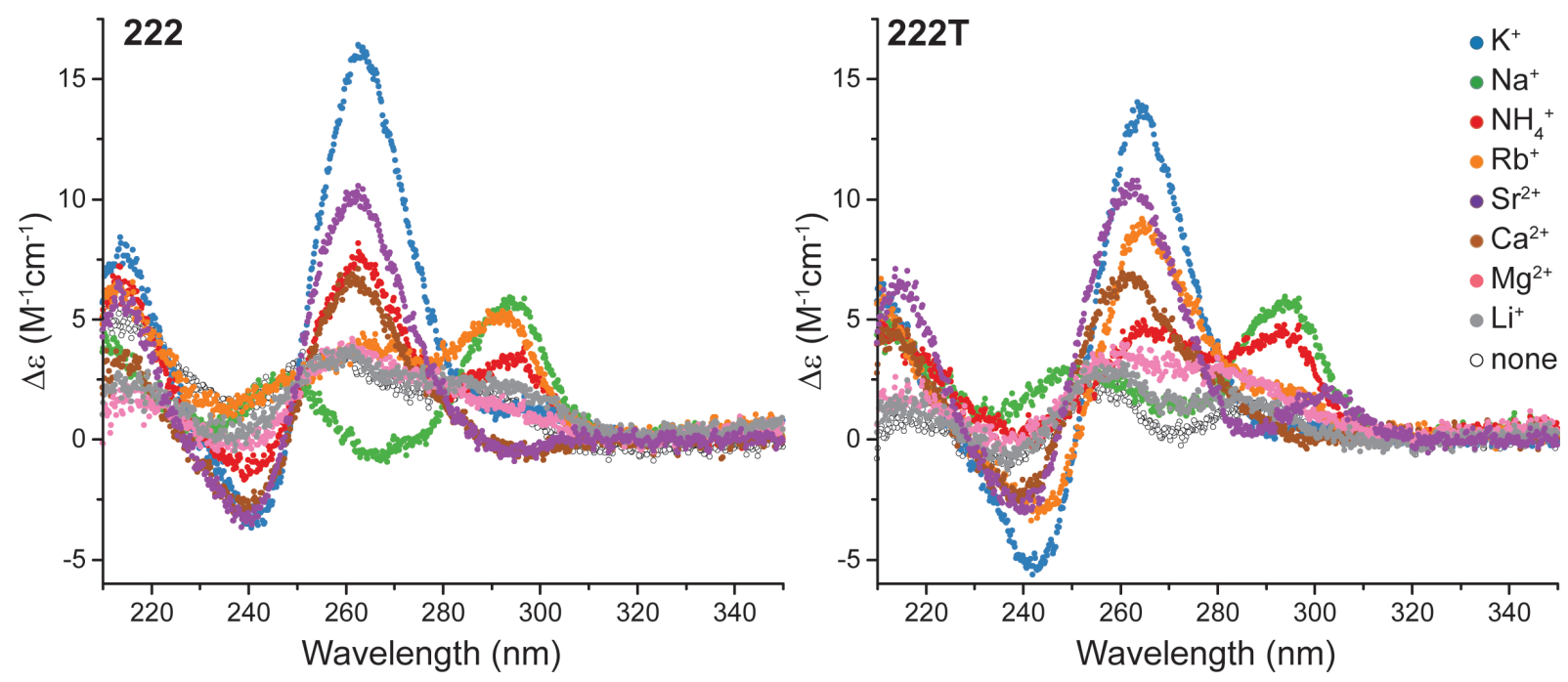

Figure S7. CD spectra of 222 and $222 \mathrm{~T}(10 \mu \mathrm{M})$ incubated with $100 \mathrm{mM}$ cation (see legend on figure; "none" refers to a 120-mM TMAA solution without additional cation). 

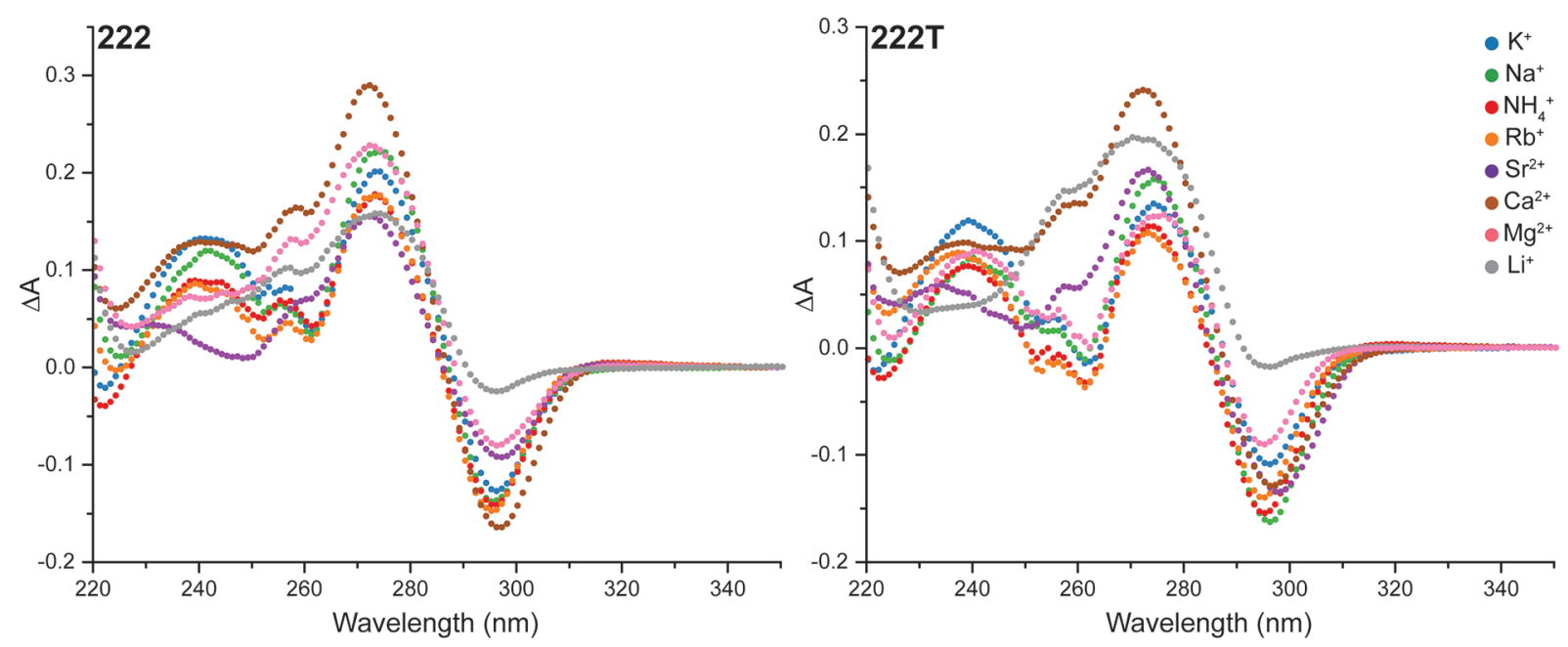

Figure S8. TDS signature of 222 and $222 \mathrm{~T}$ in presence of various cations $(100 \mathrm{mM})$, inferred from UV spectra at 4 and $95{ }^{\circ} \mathrm{C}$ (Figure S9 and Figure S10). 
Supporting Information - page S14
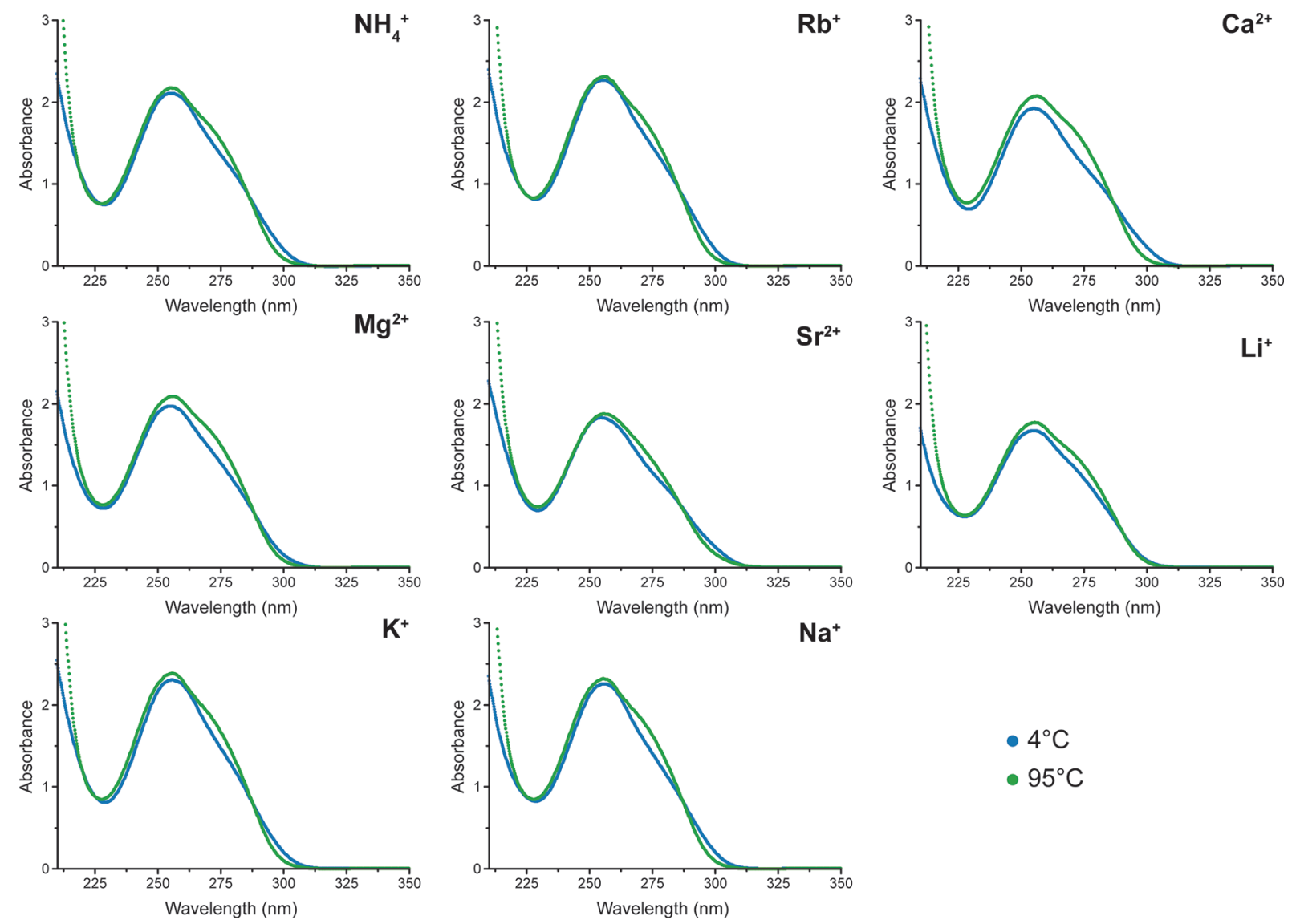

Figure S9. UV -spectra of 222 in presence of $100 \mathrm{mM}$ cations, at $4^{\circ} \mathrm{C}$ and $95^{\circ} \mathrm{C}$.

S14 
Supporting Information - page S15
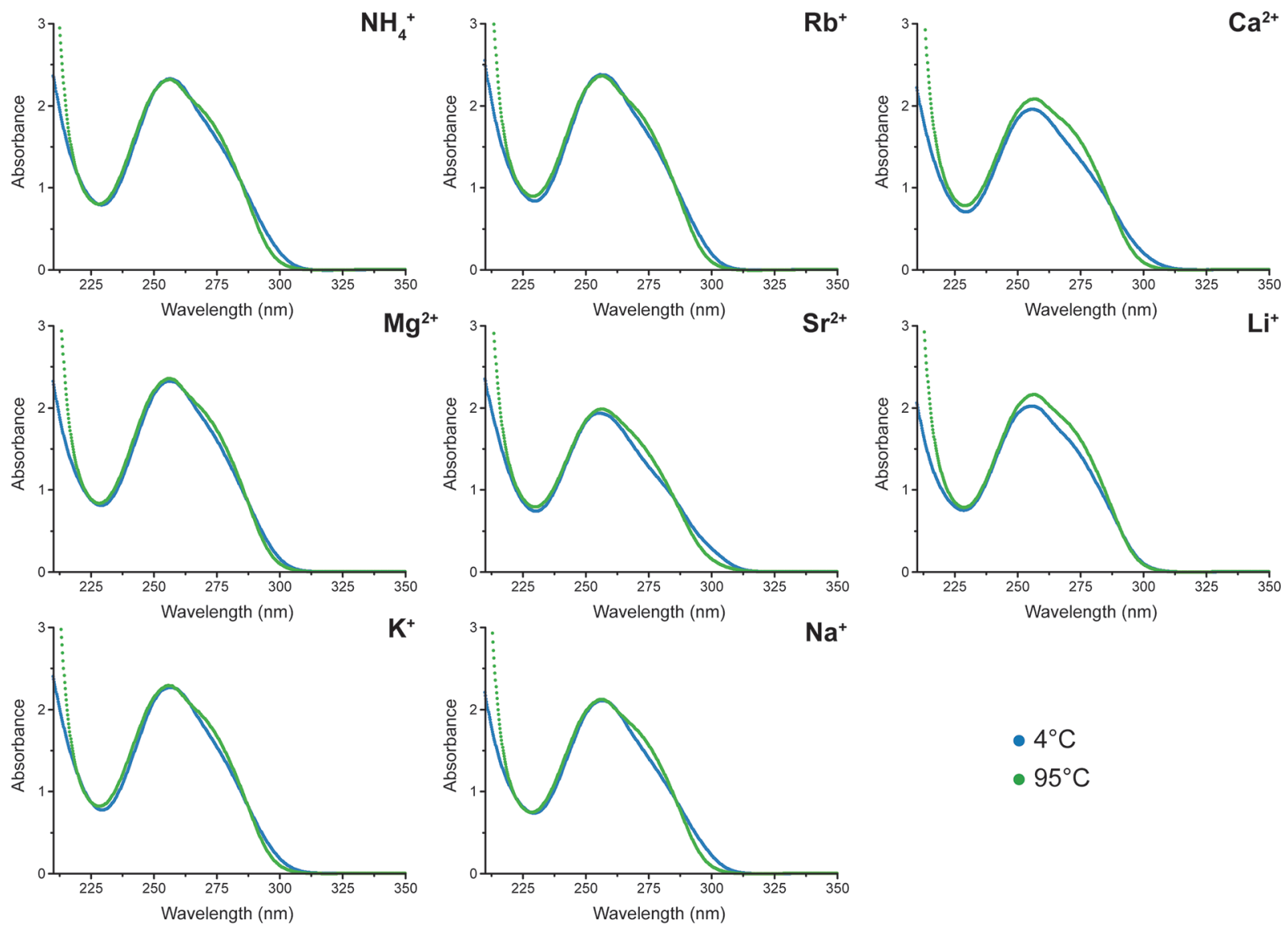

Figure S10. UV -spectra of $222 \mathrm{~T}$ in presence of $100 \mathrm{mM}$ cations, at $4^{\circ} \mathrm{C}$ and $95{ }^{\circ} \mathrm{C}$.

S15 

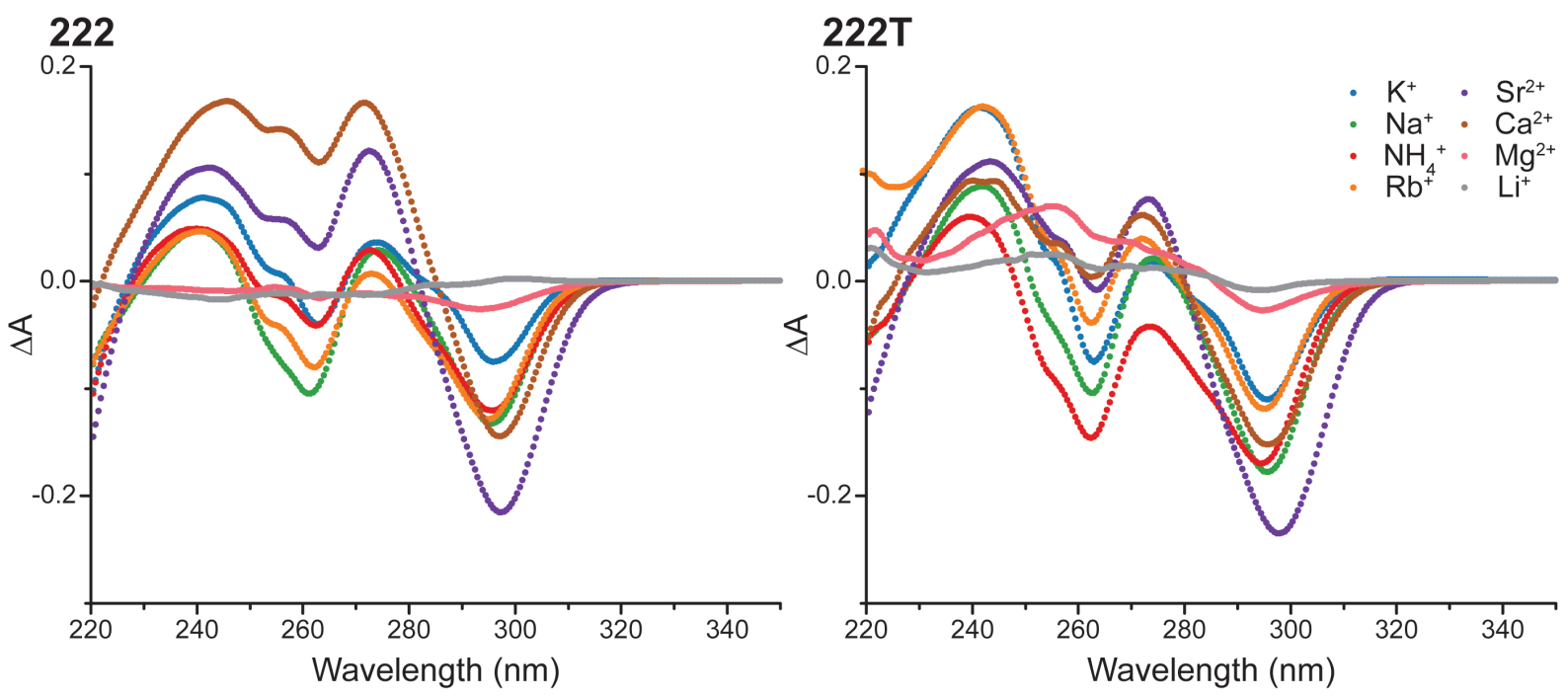

Figure S11. IDS signature of 222 and $222 \mathrm{~T}$ at $20^{\circ} \mathrm{C}$, inferred from UV spectra acquired in presence or absence of various cations (100 mM). 


\section{UV-MELTING OF 222 AND 222T OLIGONUCLEOTIDES}

UV-melting. Melting temperatures were examined by measuring the changes in absorbance at $295 \mathrm{~nm}$ as a function of the temperature, using a UVmc2 double-beam spectrophotometer (SAFAS, Monte Carlo, Monaco) equipped with a high-performance Peltier temperature controller and a thermostatable ten-cell holder. The samples containing the oligonucleotide in cacodylate buffer (20 $\mathrm{mM} \mathrm{LiAsMe} \mathrm{O}_{2}, \mathrm{pH}$ 7.2), supplemented by various concentrations of chloride salts of a group 1 or 2 cation and lithium chloride (q.s. for a $120 \mathrm{mM}$ salt concentration), were first heated to $95^{\circ} \mathrm{C}$, then the absorbance was monitored at 260, 295 and $350 \mathrm{~nm}$ on a cycle composed of a cooling down to $4{ }^{\circ} \mathrm{C}$ at a rate of $0.2^{\circ} \mathrm{C} \mathrm{min}^{-1}$, then heating back up at $95^{\circ} \mathrm{C}$ at the same rate. Raw data were blank subtracted, and melting temperatures were subsequently obtained by determining the maximum of the first derivative data, assuming only two thermodynamic states. Thermodynamic parameters were determined from the data restricted to a $10{ }^{\circ} \mathrm{C}$ temperature window centered on the melting temperature. The association constant $K_{\mathrm{a}}$ of the folding reaction (unfolded single strand $\rightarrow>$ folded quadruplex) is calculated for each data point assuming the association of two cations with one DNA molecule, unless otherwise specified. Subsequently, $\Delta G^{\circ}$ is calculated for each point using the equation below ${ }^{7}$. The enthalpy $\Delta H^{\circ}$ and entropy $\Delta S^{\circ}$ are extracted from the intersect and slope, respectively, of the $\Delta G^{\circ}$ versus $T$ plot.

$\Delta G^{\circ}=-R T \ln \left(K_{a}\right)=\Delta H^{\circ}-T \cdot \Delta S^{\circ}$
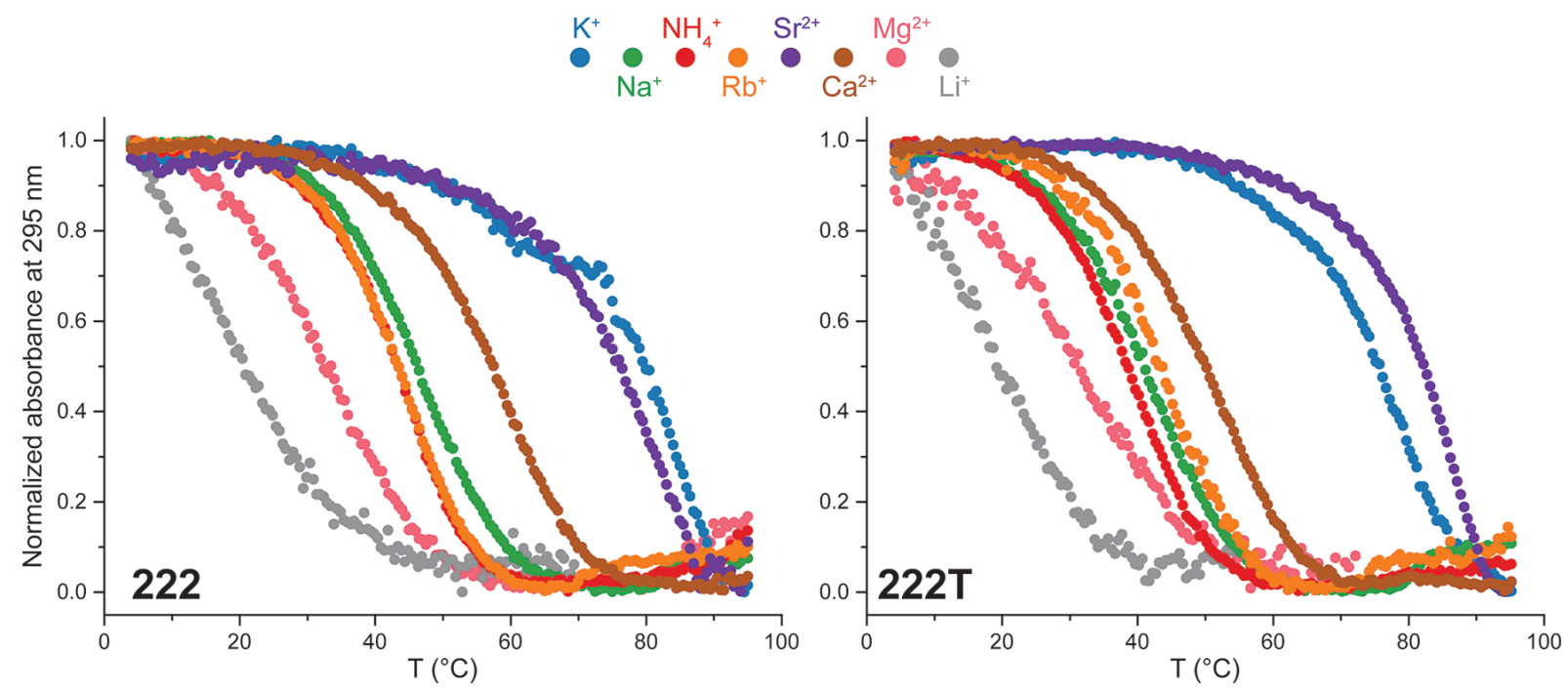

Figure S12. Normalized UV-melting curves at $295 \mathrm{~nm}$ of 222 (left) and 222T (right), at a $10 \mu \mathrm{M}$ strand concentration, in presence of $100 \mathrm{mM}$ cation (see color code on figure) and $20 \mathrm{mM}$ lithium cacodylate ( $\mathrm{pH}$ 7.2). In the case of lithium, the pre-melting baseline is not visible and hence the normalization is subject to caution. 
Table S3. Model-dependent thermodynamic parameters of 222/222T folding in a variety of cationic conditions. To determine these parameters, it was assumed that only two species are present in solution (fully folded and fully unfolded), and hypothesized that $\triangle C p^{\circ}=0$ around $T=T_{\mathrm{m}}$.

\begin{tabular}{|c|c|c|c|c|c|c|}
\hline DNA & $\begin{array}{c}\text { Catio } \\
\mathrm{n}\end{array}$ & $\begin{array}{c}\text { Concentratio } \\
\mathrm{n}(\mathrm{mM})\end{array}$ & $T_{\mathrm{m}}\left({ }^{\circ} \mathrm{C}\right)^{\mathrm{b}}$ & $\Delta H_{\text {folding }}^{\circ}(\mathrm{kJ} / \mathrm{mol})$ & $\Delta S_{\text {folding }}^{\circ}(\mathrm{J} / \mathrm{mol})$ & $\begin{array}{c}\Delta G_{\text {folding }\left(20^{\circ} \mathrm{C}\right)} \\
(\mathrm{kJ} / \mathrm{mol})\end{array}$ \\
\hline \multirow{18}{*}{222} & \multirow{8}{*}{$\mathrm{K}^{+}$} & 100 & $84.9 \pm 0.2$ & -254 & -678 & -55.0 \\
\hline & & 10 & $67.7 \pm 0.2$ & -269 & -723 & -57.4 \\
\hline & & 5 & $62.1 \pm 0.6$ & -267 & -715 & -57.4 \\
\hline & & 1 & $44.5 \pm 0.7$ & -221 & -585 & -49.5 \\
\hline & & 0.5 & $36.4 \pm 0.1$ & -183 & -464 & -46.9 \\
\hline & & 0.4 & $35.4 \pm 0.4$ & -170 & -421 & -46.4 \\
\hline & & 0.3 & $33.3 \pm 0.2$ & -164 & -401 & -46.3 \\
\hline & & 0.2 & $29.3 \pm 0.1$ & -147 & -342 & -46.1 \\
\hline & \multirow[t]{2}{*}{$\mathrm{Sr}^{2+}$} & 100 & $>85.0$ & n.d. & n.d. & n.d. \\
\hline & & $1^{a}$ & $68.7 \pm 0.6$ & -126 & -255 & -50.9 \\
\hline & $\mathrm{Na}^{+}$ & 100 & $47.5 \pm 0.9$ & -132 & -376 & -22.1 \\
\hline & \multirow{2}{*}{$\mathrm{Na}^{+} / \mathrm{K}^{+}$} & $95 / 5$ & $58.0 \pm 0.3$ & -263 & -710 & -54.6 \\
\hline & & $90 / 10$ & $64.3 \pm 0.6$ & -288 & -787 & -57.8 \\
\hline & $\mathrm{Ca}^{2+}$ & 100 & $63.0 \pm 3.5$ & -154 & -428 & -28.7 \\
\hline & $\mathrm{NH}_{4}^{+}$ & 100 & $45.7 \pm 0.1$ & -161 & -472 & -23.1 \\
\hline & $\mathrm{Rb}^{+}$ & 100 & $45.0 \pm 0.1$ & -156 & -453 & -22.7 \\
\hline & $\mathrm{Mg}^{2+}$ & 100 & $37.2 \pm 2.4$ & -112 & -326 & -16.0 \\
\hline & $\mathrm{Li}^{+}$ & 100 & $<14.0$ & n.d. & n.d. & n.d. \\
\hline \multirow{18}{*}{$222 \mathrm{~T}$} & \multirow{8}{*}{$\mathrm{K}^{+}$} & 100 & $77.0 \pm 0.3$ & -218 & -575 & -49.4 \\
\hline & & 10 & $59.0 \pm 0.0$ & -211 & -552 & -49.1 \\
\hline & & 5 & $52.7 \pm 0.5$ & -208 & -538 & -50.3 \\
\hline & & 1 & $36.4 \pm 0.5$ & -197 & -515 & -46.0 \\
\hline & & 0.5 & $35.5 \pm 0.2$ & -167 & -452 & -46.0 \\
\hline & & 0.4 & $34.8 \pm 0.1$ & -175 & -442 & -45.4 \\
\hline & & 0.3 & $33.0 \pm 0.4$ & -177 & -441 & -46.1 \\
\hline & & 0.2 & $27.8 \pm 0.1$ & -178 & -415 & -45.5 \\
\hline & \multirow[t]{2}{*}{$\mathrm{Sr}^{2+}$} & 100 & $>86.5$ & n.d. & n.d. & n.d. \\
\hline & & $1^{a}$ & $62.7 \pm 1.2$ & -154 & -348 & -52.4 \\
\hline & $\mathrm{Na}^{+}$ & 100 & $42.5 \pm 0.7$ & -128 & -369 & -19.8 \\
\hline & \multirow{2}{*}{$\mathrm{Na}^{+} / \mathrm{K}^{+}$} & $95 / 5$ & $52.7 \pm 0.2$ & -169 & -432 & -42.2 \\
\hline & & $90 / 10$ & $58.1 \pm 0.2$ & -235 & -634 & -48.9 \\
\hline & $\mathrm{Ca}^{2+}$ & 100 & $55.7 \pm 3.2$ & -150 & -426 & -25.4 \\
\hline & $\mathrm{NH}_{4}^{+}$ & 100 & $39.8 \pm 0.5$ & -132 & -387 & -19.1 \\
\hline & $\mathrm{Rb}^{+}$ & 100 & $43.5 \pm 0.3$ & -142 & -411 & -21.7 \\
\hline & $\mathrm{Mg}^{2+}$ & 100 & $38.0 \pm 2.3$ & -79 & -222 & -14.0 \\
\hline & $\mathrm{Li}^{+}$ & 100 & $<18.2$ & n.d. & n.d. & n.d. \\
\hline \multicolumn{7}{|c|}{${ }^{a}$ Calculated assuming binding of only one cation } \\
\hline \multicolumn{7}{|c|}{${ }^{\mathrm{b}}$ Average of two experiments. } \\
\hline
\end{tabular}



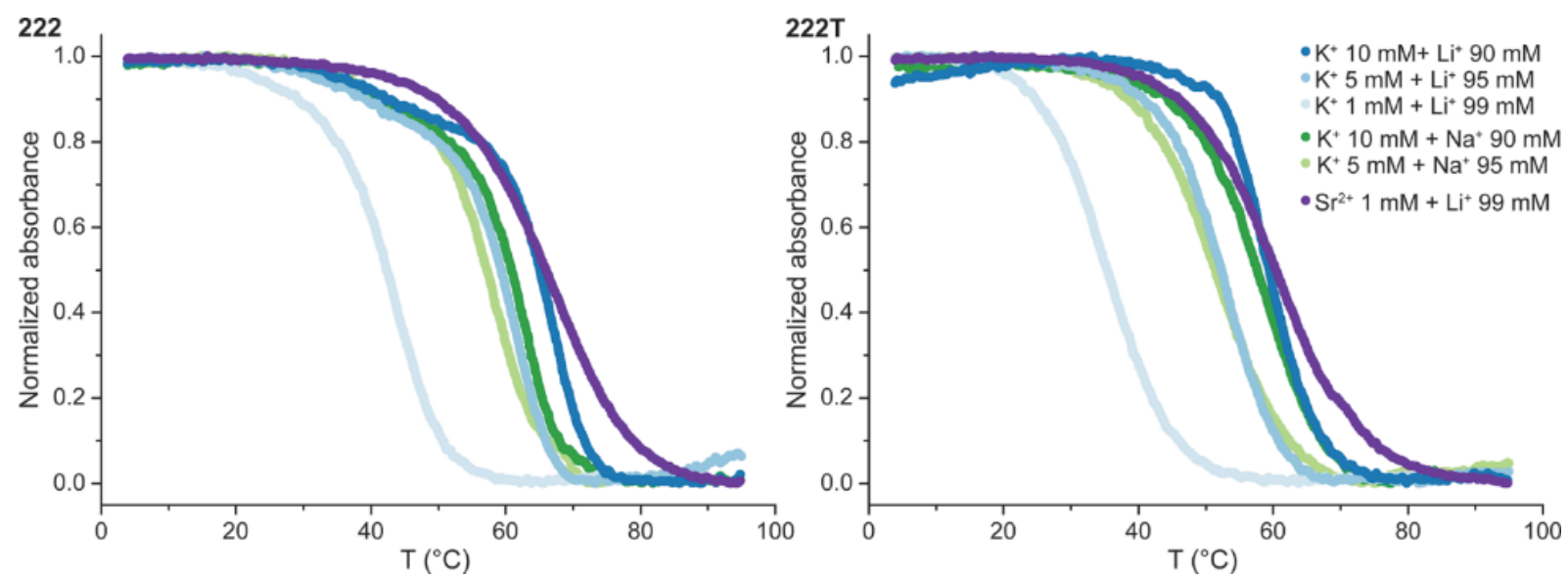

Figure S13. UV-melting curves at $295 \mathrm{~nm}$ of 222 (left) and $222 \mathrm{~T}$ (right), at a $10 \mu \mathrm{M}$ strand concentration, in presence of various concentrations of $\mathrm{KCl}, \mathrm{NaCl}$, and $\mathrm{SrCl}_{2}$, in lithium cacodylate $(20 \mathrm{mM}, \mathrm{pH} 7.2)$, and $\mathrm{LiCl}$ (q.s. for a $120 \mathrm{mM}$ salt concentration) (see color code on figure). 
222
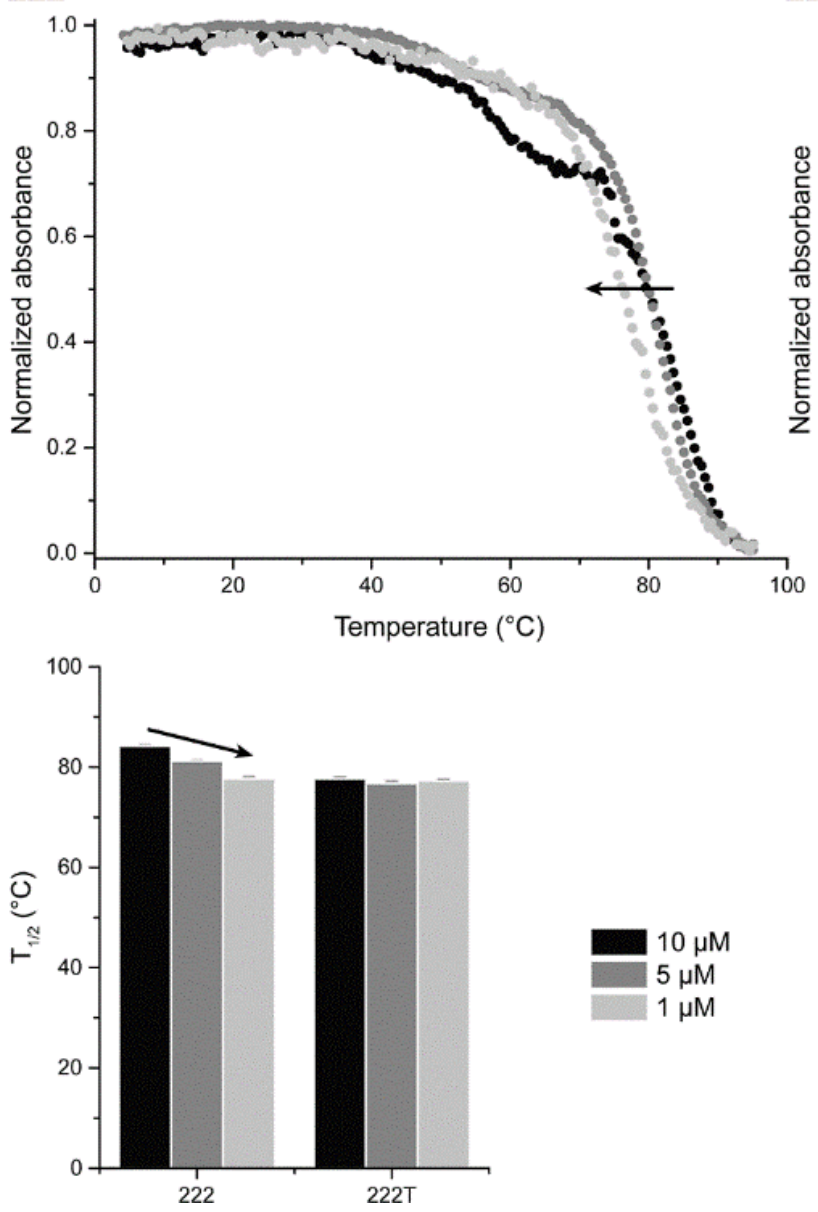

222T

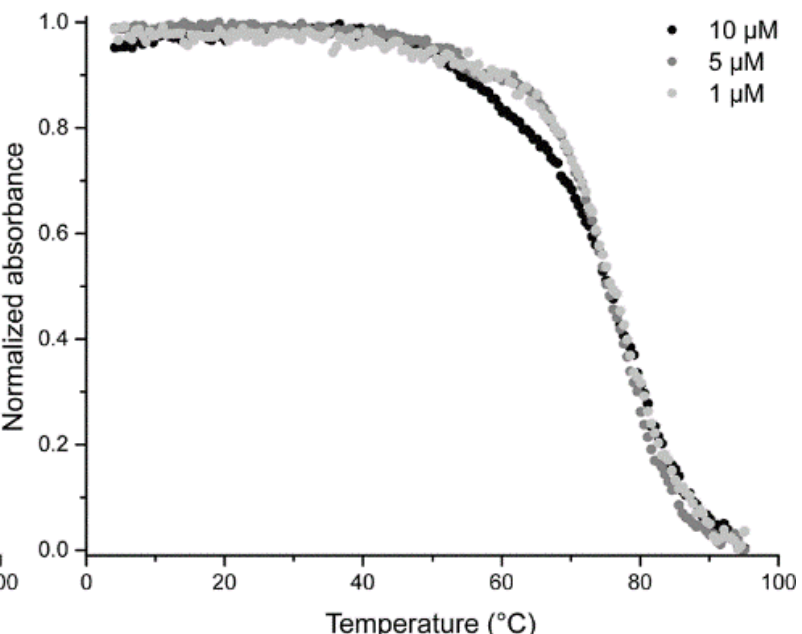

Figure S14. Top: melting curves of 222 (left) and $222 \mathrm{~T}$ (right) in $100 \mathrm{mM} \mathrm{KCl}$ at a 10, 5, or 1- $\mu \mathrm{M}$ strand concentration. Bottom: corresponding melting temperatures. 


\section{TIME-DEPENDENT $\mathrm{K}^{+}$CD DATA}

In time-dependent experiments, plots at 3 characteristic wavelengths (typically around 240, 260, and $295 \mathrm{~nm}$ ) were simultaneously fitted with single $(j=1)$ and double exponential $(j=2)$ models (equation below), where $\Delta \varepsilon_{0}$ is the offset, $A_{i}$ and $k_{i}$ are respectively the span and the rate constant of the process $i$, and are shared parameters during the fitting process.

$\Delta \varepsilon=\Delta \varepsilon_{0}+\sum_{i=1}^{j}\left[A_{i} \times \exp \left(-k_{i} \times t\right)\right]$

The relative quality of both models was assessed for all data sets using the corrected Akaike information criterion (AICC) and the extra sum-of-squares $F$ tests. The double exponential model was selected in each case as the most relevant.

Half-life $t_{1 / 2}$ and time constant $\tau$ were calculated following their classical definition:

$t_{1 / 2}^{i}=\ln (2) / k_{i}$

$\tau_{i}=1 / k_{i}$
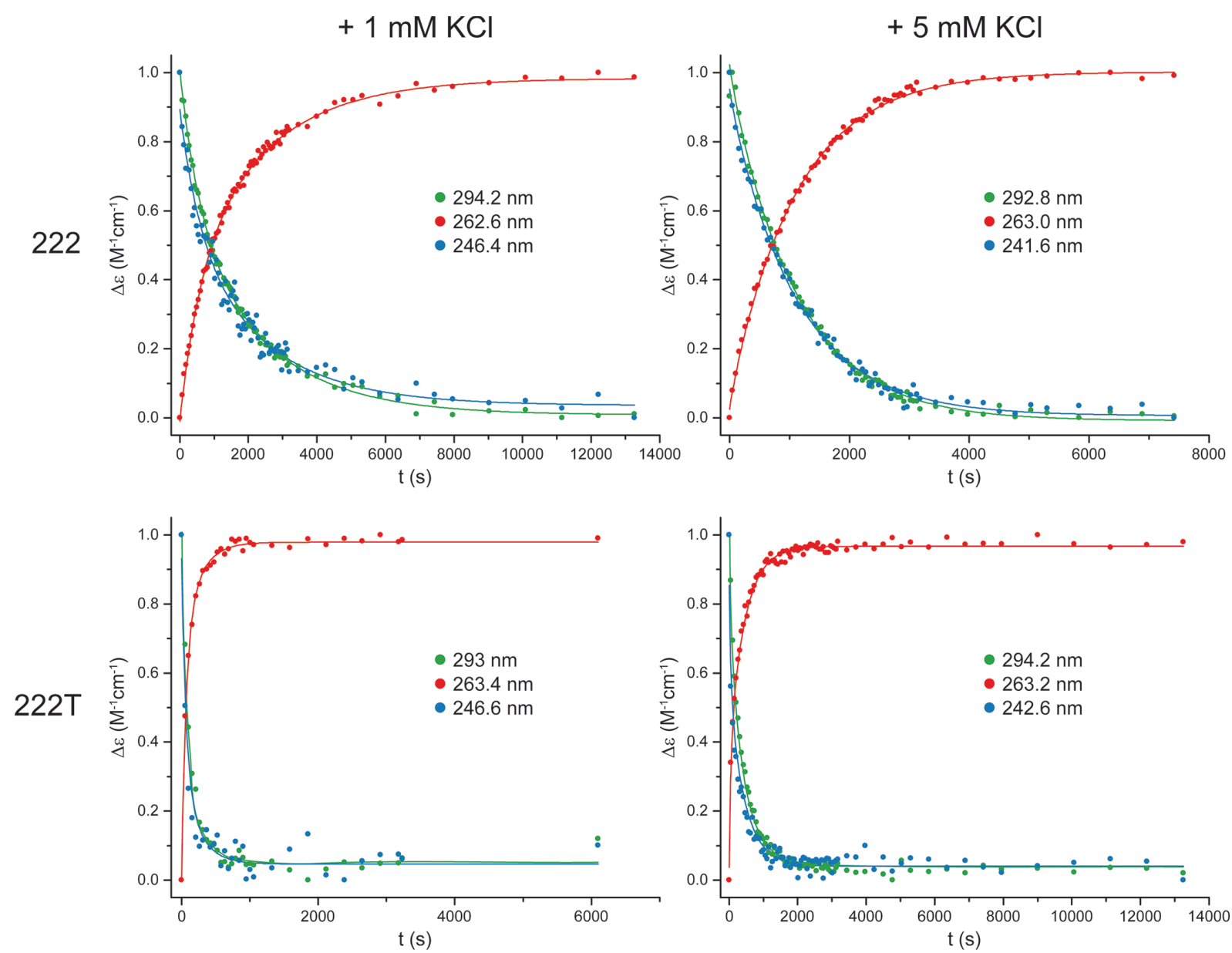

Figure S15. Time-dependence of the major bands (exact wavelengths reported on figure) with global fit using a double-exponential model. Molar ellipticity is normalized in the $[0 ; 1]$ range. 
Table S4. Kinetics parameters from time-dependent $C D$ measured at $4{ }^{\circ} \mathrm{C}$.

\begin{tabular}{ccccccccc}
\hline & $C_{\mathrm{KCl}}(\mathrm{mM})$ & $k_{1}\left(\mathrm{~ms}^{-1}\right)$ & $k_{2}\left(\mathrm{~ms}^{-1}\right)$ & $t_{1 / 2}{ }^{1}(\mathrm{~s})$ & $t_{1 / 2}{ }^{2}(\mathrm{~s})$ & $\tau_{1}(\mathrm{~s})$ & $\tau_{2}(\mathrm{~s})$ & $R^{2}$ (global) \\
\hline 222 & 1 & $1.8 \pm 0.2$ & $0.44 \pm 0.04$ & 396 & 1579 & 572 & 2278 & 0.9944 \\
& 5 & $11 \pm 1$ & $0.90 \pm 0.01$ & 63 & 771 & 90 & 1113 & 0.9978 \\
& 1 & $16 \pm 3$ & $5 \pm 1$ & 44 & 161 & 63 & 233 & 0.9942 \\
$222 T$ & 5 & $19 \pm 3$ & $2.21 \pm 0.09$ & 37 & 314 & 53 & 453 & 0.9969 \\
\hline
\end{tabular}


Supporting Information - page S23
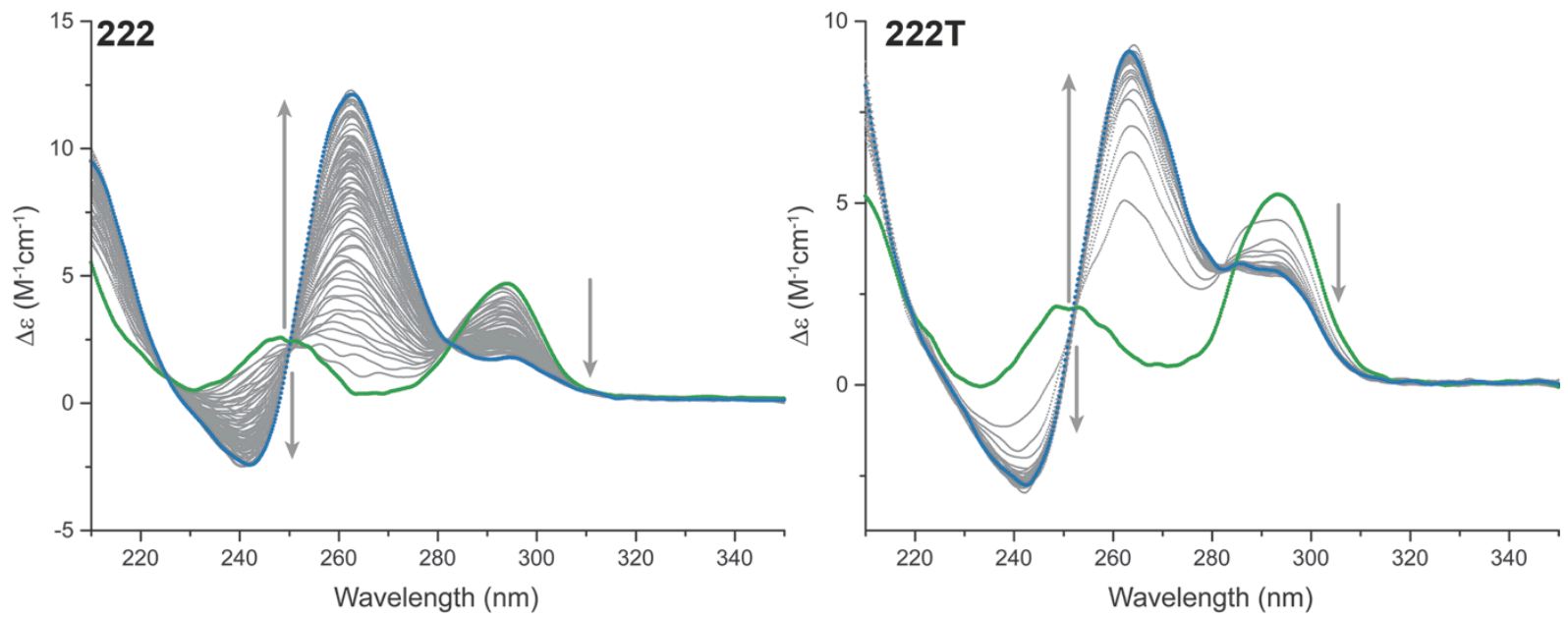

Figure S16. Time-dependent CD of 222 and $222 \mathrm{~T}$ in $100 \mathrm{mM} \mathrm{Na}^{+}$(green) after addition of $1 \mathrm{mM} \mathrm{KCl}$ (final spectrum after 125 minutes: blue), at $4{ }^{\circ} \mathrm{C}$. Arrows indicate the time evolution of the CD signal.

S23 

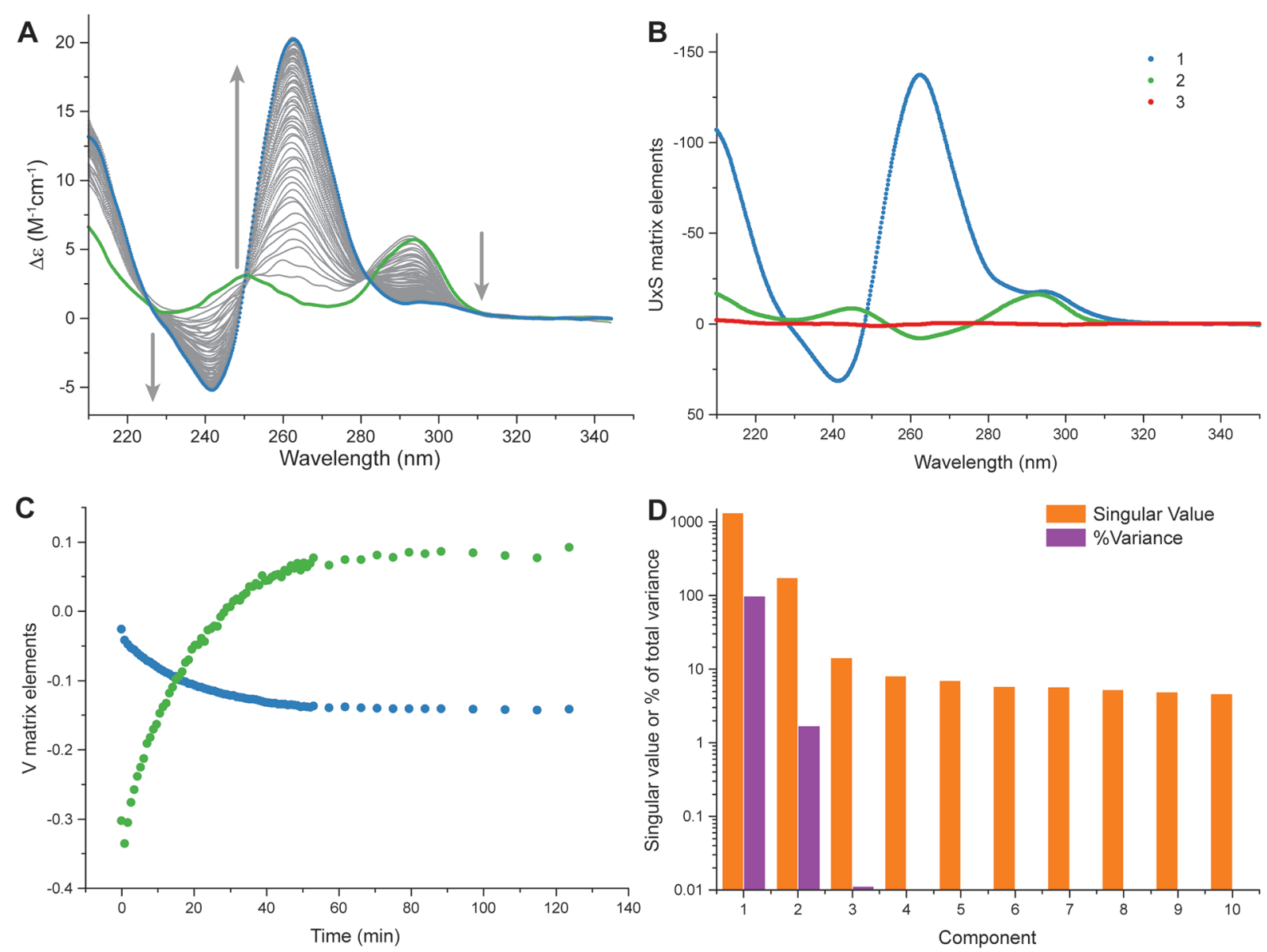

Figure S17. Time-dependent CD of 222 in $\mathrm{Na}^{+}$(green) after addition of $5 \mathrm{mM} \mathrm{KCl}$ (final spectra: blue) (panel A), at $4{ }^{\circ} \mathrm{C}$. Arrows indicate the time evolution of the CD signal. The two first basis spectra and the corresponding $V$ matrix elements as a function of time, obtained by SVD, are shown in panels $B$ and $C$, respectively. Panel $D$ is a bar chart showing the first ten singular values and their corresponding relative variance. 
A

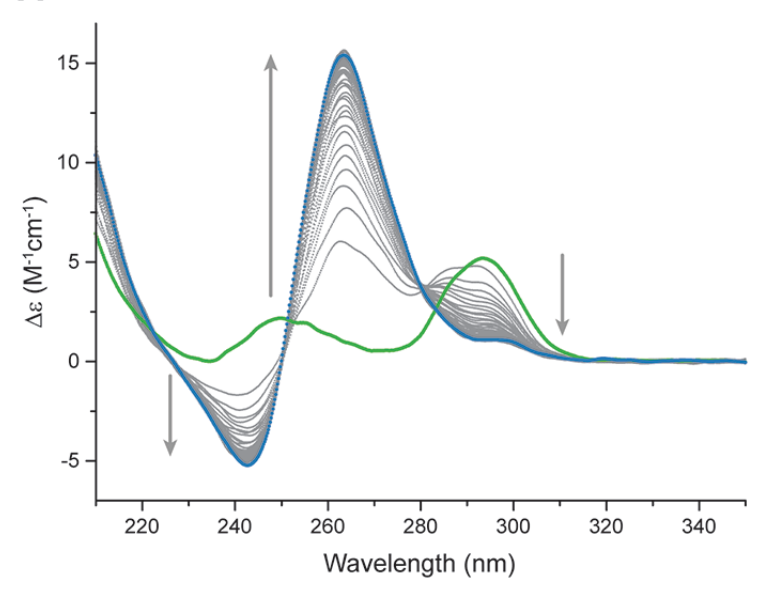

C

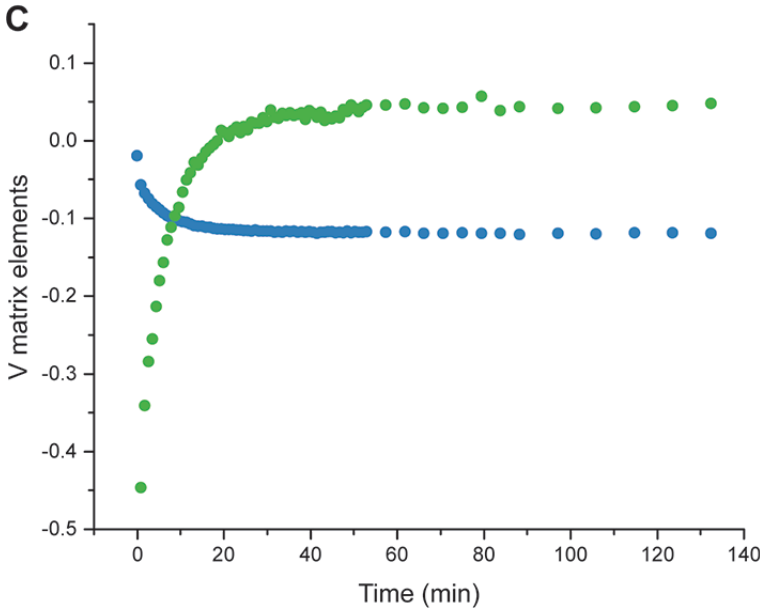

B
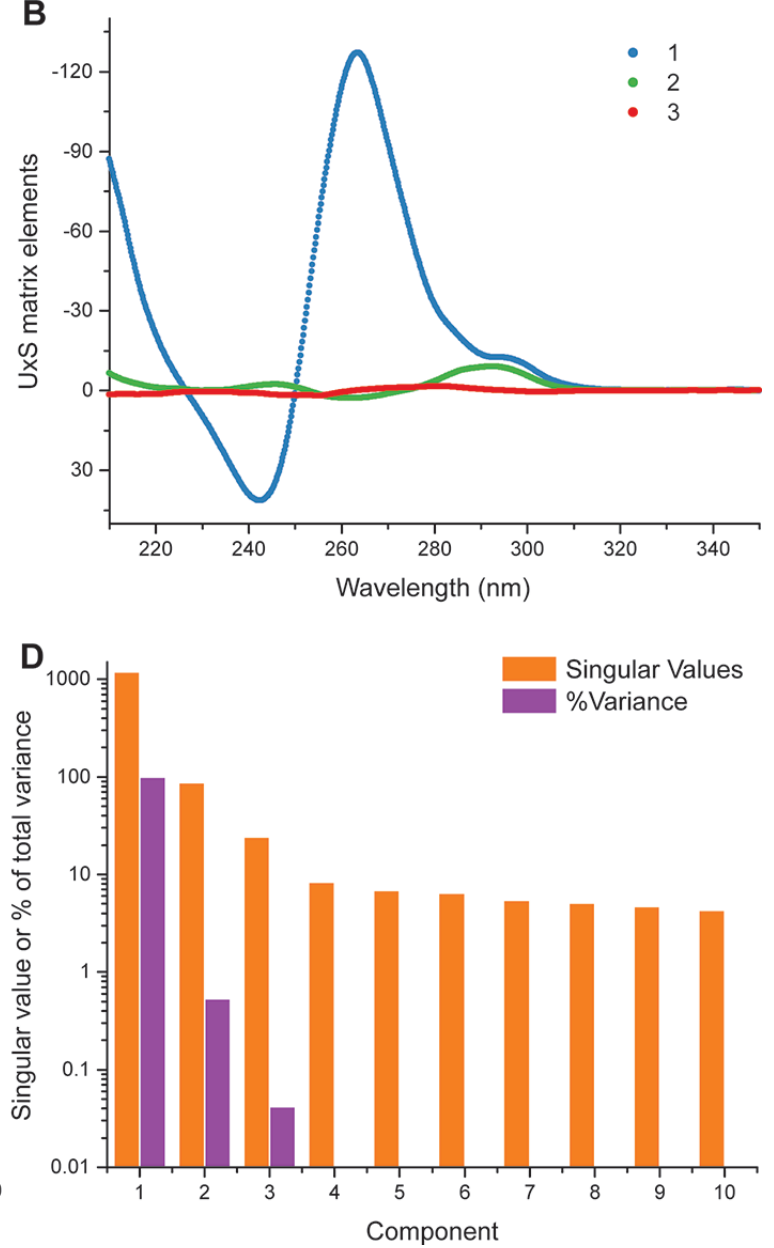

Figure S18. Time-dependent CD of $222 \mathrm{~T}_{\text {in }} \mathrm{Na}^{+}$(green) after addition of $5 \mathrm{mM} \mathrm{KCl}$ (final spectrum: blue) (panel A), at $4{ }^{\circ} \mathrm{C}$. Arrows indicate the time evolution of the CD signal. The two first basis spectra and the corresponding $V$ matrix elements as a function of time, obtained by SVD, are shown in panels $B$ and $C$, respectively. Panel $D$ is a bar chart showing the first ten singular values and their corresponding relative variance. 
Dual wavelength parametric test of the two state model ( "Wallimann plots" ${ }^{8}$ ) were constructed by plotting the CD intensity at a given wavelength versus the CD intensity at another wavelength, then performing a linear regression on the data set. Three wavelengths were used (around 240, 260 and $295 \mathrm{~nm}$ ). Linearity of the plot suggests a 2-state model, while deviation from the linearity indicates the presence of at least 3 species.
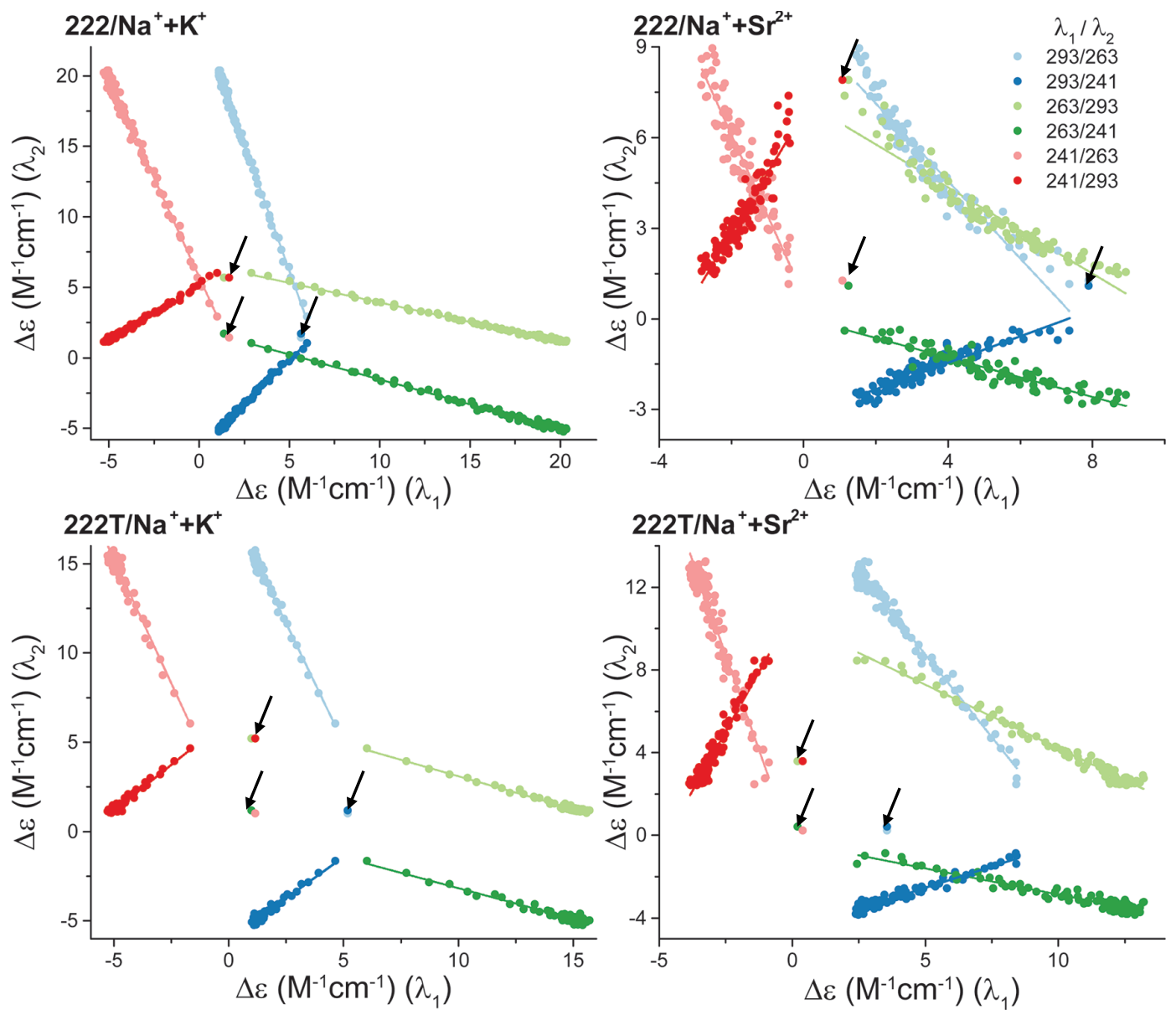

Figure S19. Wallimann plots of the time dependent CD experiments, where $5 \mathrm{mM} \mathrm{KCl}$ or SrCl${ }_{2}$ are added to 222 or $222 \mathrm{~T}$ in $100 \mathrm{mM} \mathrm{NaCl}$, at $4{ }^{\circ} \mathrm{C}$. Linear regressions were performed on all the points but the first ones (pointed by arrows), for various characteristic wavelength combinations. 
Table S5. Adjusted coefficient of determination for the above linear regressions.

\begin{tabular}{c|cc} 
& $\lambda_{1} / \lambda_{2}(\mathrm{~nm})$ & Adj. R-Square \\
\hline \multirow{3}{*}{$222 / \mathrm{NaCl}+\mathrm{KCl}$} & $293 / 263$ & 0.99599 \\
& $293 / 241$ & 0.99261 \\
& $263 / 241$ & 0.99303 \\
\hline \multirow{3}{*}{$222 / \mathrm{NaCl}+\mathrm{SrCl}_{2}$} & $293 / 263$ & 0.91186 \\
& $293 / 241$ & 0.87065 \\
& $263 / 241$ & 0.86404 \\
\hline \multirow{3}{*}{$222 \mathrm{~T} / \mathrm{NaCl}+\mathrm{KCl}$} & $293 / 263$ & 0.98616 \\
& $293 / 241$ & 0.95596 \\
& $263 / 241$ & 0.95830 \\
\hline \multirow{3}{*}{$222 \mathrm{~T} / \mathrm{NaCl}+\mathrm{SrCl}_{2}$} & $293 / 263$ & 0.98297 \\
& $293 / 241$ & 0.94592 \\
& $263 / 241$ & 0.92390
\end{tabular}




\section{TIME-DEPENDENT UV-VIS TITRATIONS}

Time-dependent IDS were performed by addition of $5 \mathrm{mM} \mathrm{KCl}$ to a DNA sample monitored by a scan every 25 seconds ( $\lambda=220-330 \mathrm{~nm}, 1.0 \mathrm{~nm}$ step, and $0.1 \mathrm{~s}$ integration time). Rate constants $k$ were determined by non-linear fitting of the time evolution of the absorbance at $295 \mathrm{~nm}$, with an exponential model, discarding the first point. The linearized Arrhenius equation where $R$ is the gas constant and $A$ is the pre-exponential factor was used to determine the activation energy $E_{\mathrm{a}}$ by plotting $\ln (k)$ versus $1 / T$, where the slope is $-E_{a} / R$.

$\ln (k)=\frac{-E_{a}}{R} \cdot \frac{1}{T}+\ln (A)$

Similarly, the Gibbs free energy of activation is determined with the Eyring-Polanyi equation:

$k=\frac{k_{B} T}{h} e^{-\frac{\Delta G^{\ddagger}}{R T}}$

Where $\Delta \mathrm{G}^{\ddagger}$ is the Gibbs energy of activation, $k_{\mathrm{B}}$ is Boltzmann's constant, and $h$ is Planck's constant; linearized as follows:

$\ln \frac{k}{T}=\frac{-\Delta H^{\ddagger}}{R} \cdot \frac{1}{T}+\ln \frac{k_{B}}{h}+\frac{\Delta S^{\ddagger}}{R}$

Where $\Delta H^{\ddagger}$ is the enthalpy of activation and $\Delta S^{\ddagger}$ is the entropy of activation. Plotting $\ln (k / T)$ versus $1 / T$ gives access to $\Delta H^{\ddagger}$ and $\Delta S^{\ddagger}$ via the slope $\left(-\Delta H^{\ddagger} / R\right)$ and intercept $\left(\Delta S^{\ddagger} / R+\ln \left(k_{\mathrm{B}} / h\right)\right)$. 
$1^{\circ} \mathrm{C}$
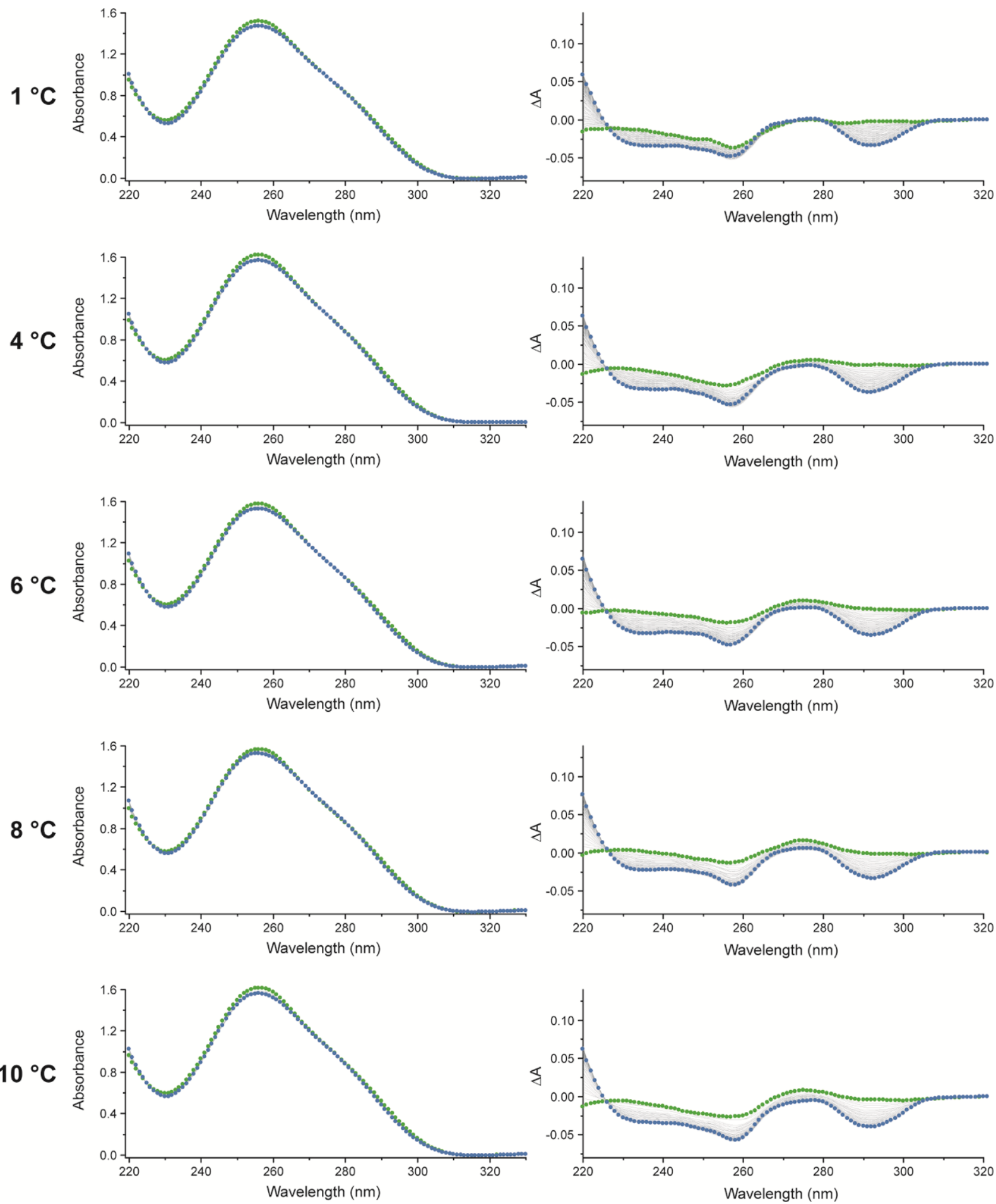

Figure S20. Time-dependent (0-100 $\mathrm{min})$ UV-vis spectra of 222 in 100-mM Na (green) after addition of $5 \mathrm{mM} \mathrm{KCl}$ (final spectra: blue), at various temperatures (left), and the corresponding IDS signatures (right). The first IDS shown, in green, is obtained after addition of potassium and 15 seconds experimental dead time. 
$1{ }^{\circ} \mathrm{C}$

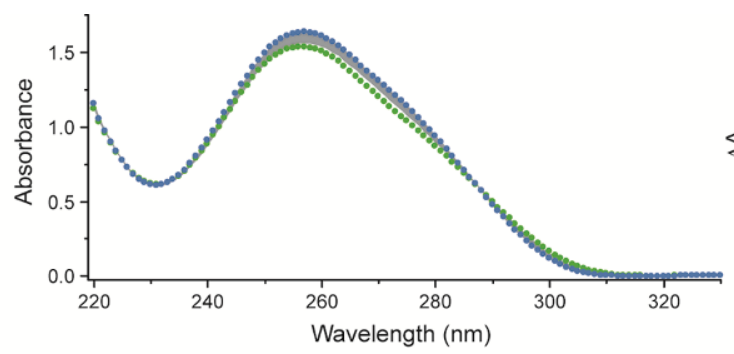

$4{ }^{\circ} \mathrm{C}$

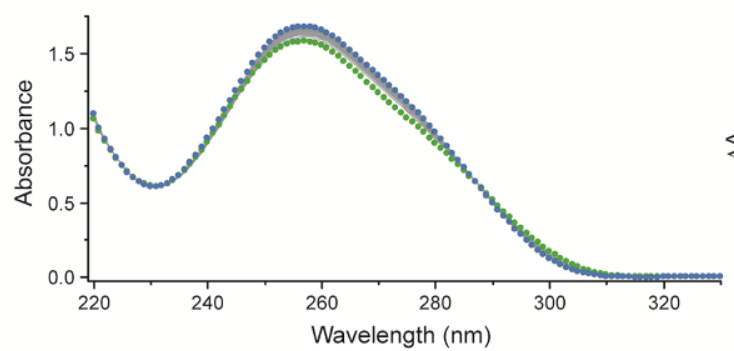

$6{ }^{\circ} \mathrm{C}$

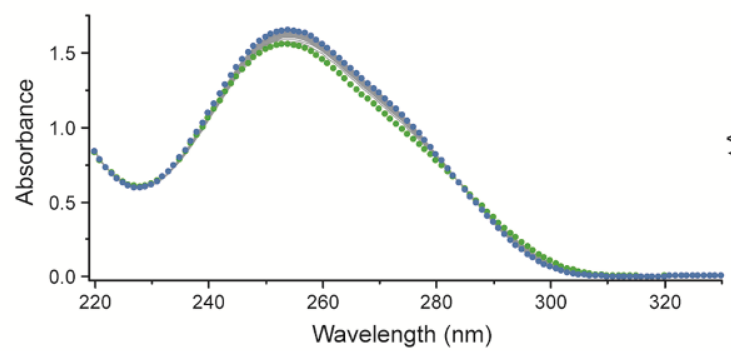

$8{ }^{\circ} \mathrm{C}$

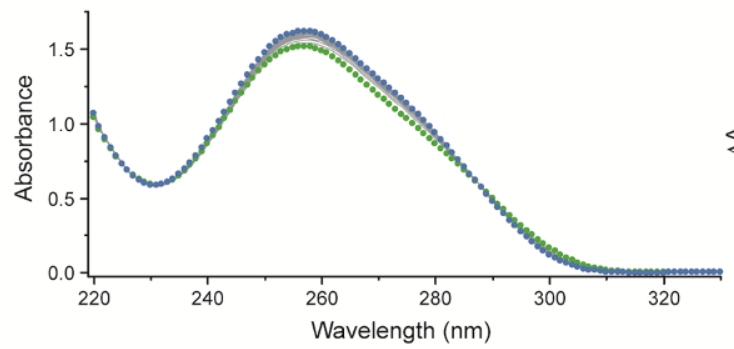

$10^{\circ} \mathrm{C}$

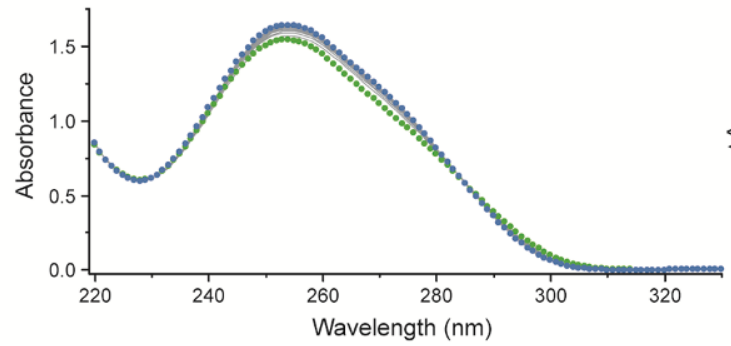

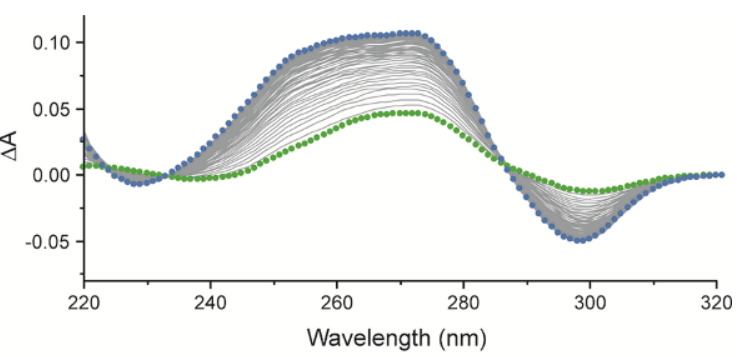
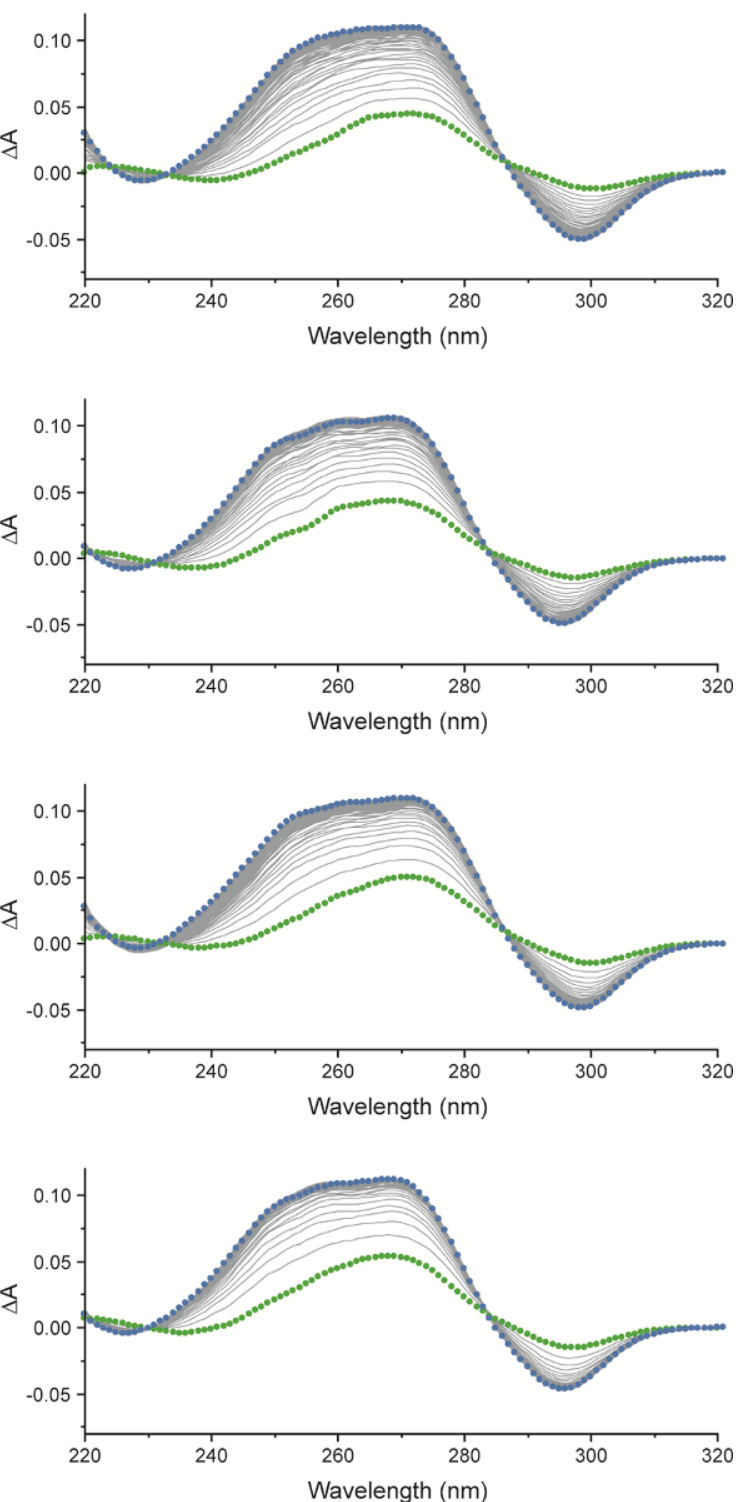

Figure S21. Time-dependent (0-100 min) UV-vis spectra of $222 \mathrm{~T}$ in 100- $\mathrm{mM} \mathrm{Na}^{+}$(green) after addition of $5 \mathrm{mM} \mathrm{KCl}$ (final spectra: blue), at various temperatures (left), and the corresponding IDS signatures (right). The first IDS shown, in green, is obtained after addition of potassium and 15 seconds experimental dead time. 

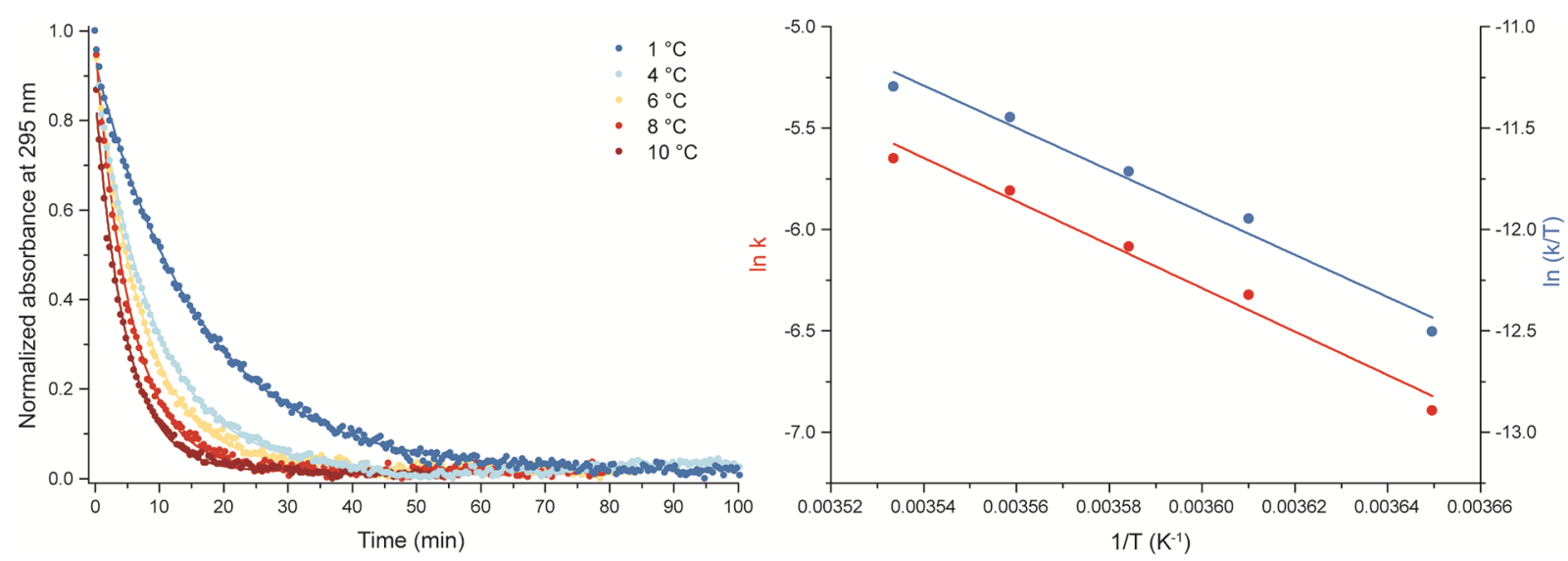

Figure S22. Time-dependent UV-vis absorbance of 222 in 100- $\mathrm{mM} \mathrm{Na}^{+}$after addition of $5 \mathrm{mM} \mathrm{KCl:} \mathrm{time-}$ evolution of the absorbance at $295 \mathrm{~nm}$ at various temperatures (left), and plots (right) verifying the Arrhenius (red) and Eyring-Polanyi equations (b/ue). 

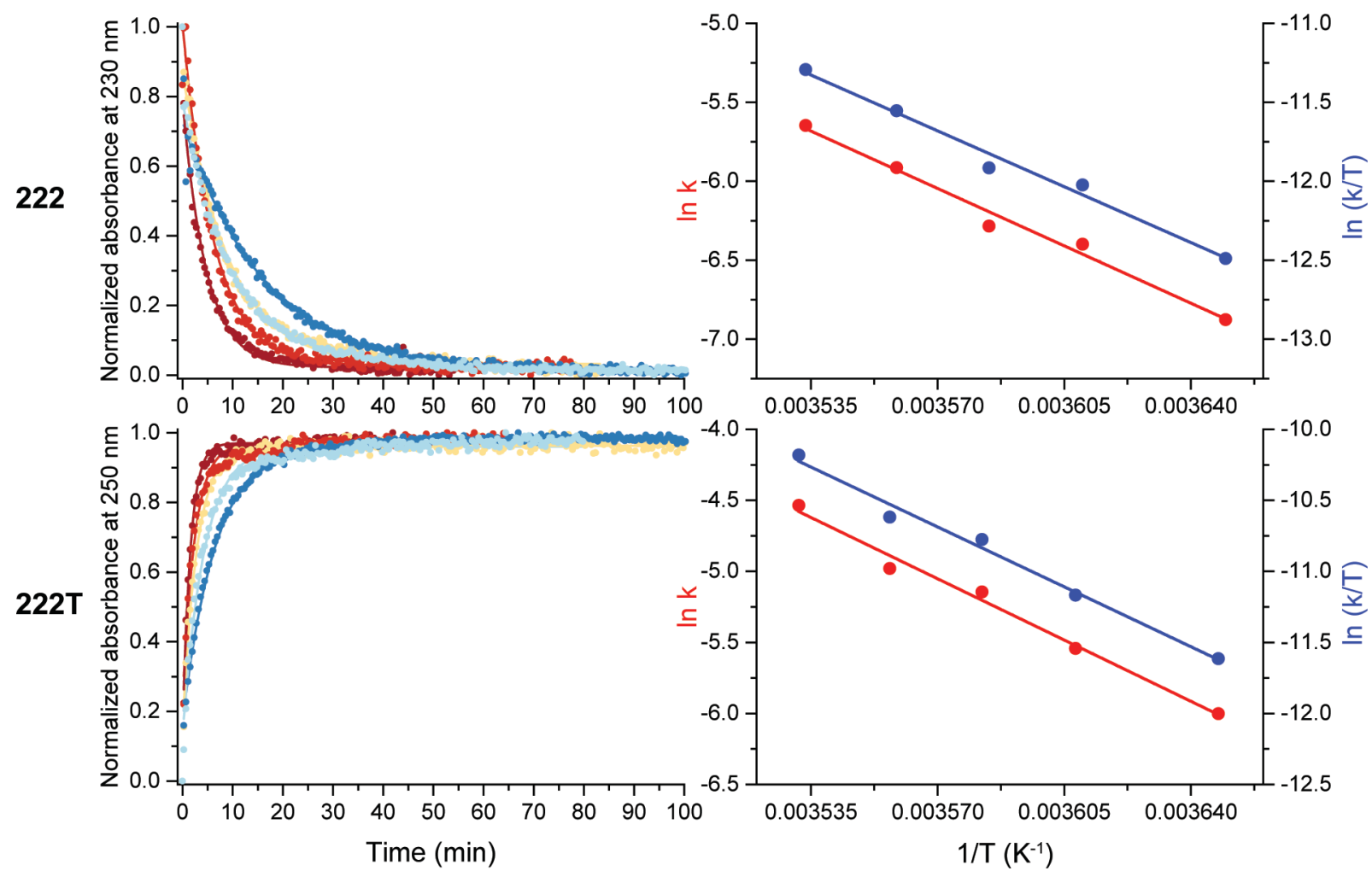

Figure S23. Time-dependent UV-vis absorbance of 222 (top) and $222 \mathrm{~T}$ (bottom) in 100-mM Na ${ }^{+}$after addition of $5 \mathrm{mM} \mathrm{KCl}$ : time-evolution of the absorbance at 230 and $250 \mathrm{~nm}$, respectively, at various temperatures (left), and plots (right) verifying the Arrhenius (red) and Eyring-Polanyi equations (b/ue). 
TIME-DEPENDENT $S R^{2+}$ CD DATA
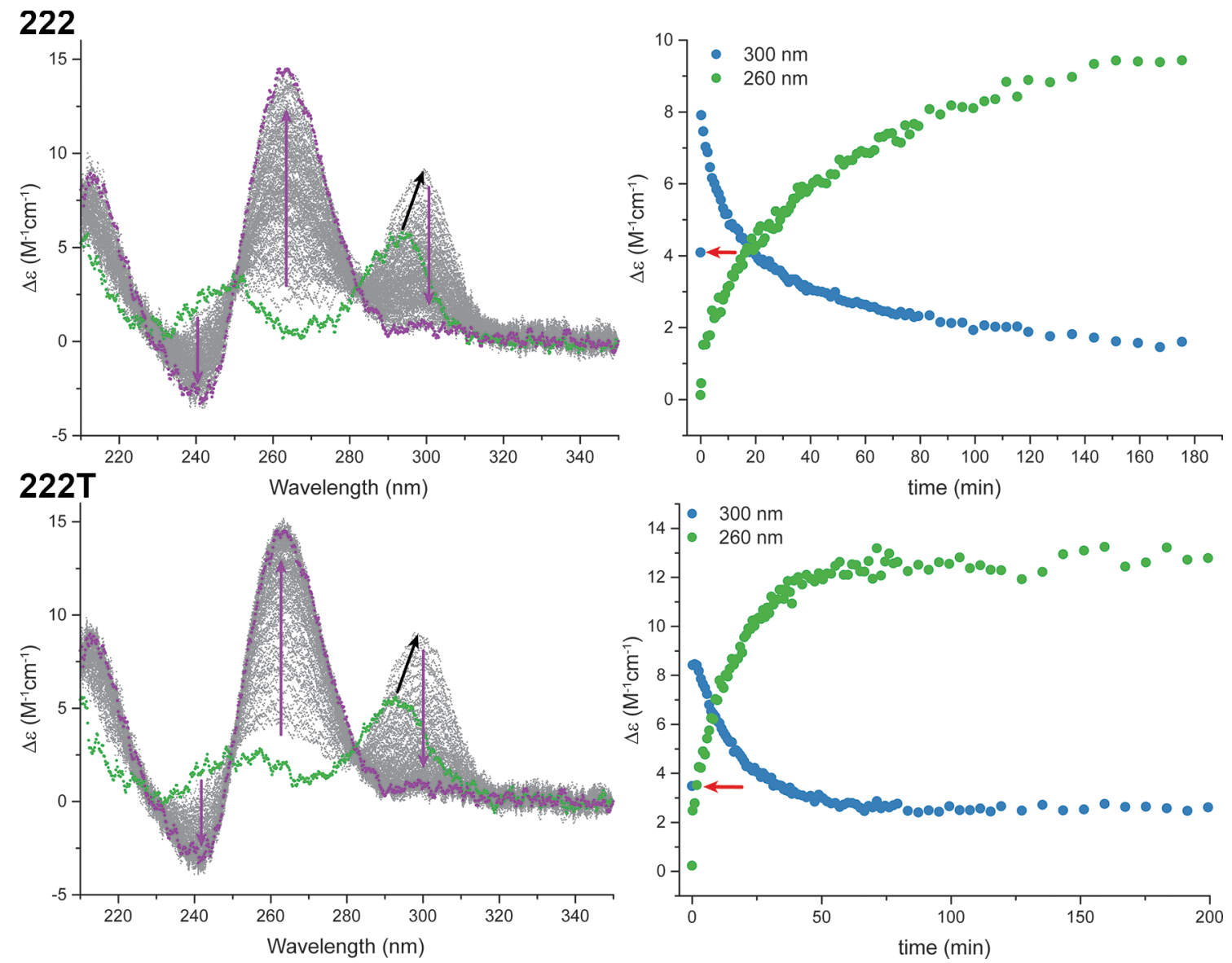

Figure S24. Time-dependent CD of 222 (top) and $222 \mathrm{~T}$ (bottom) in $\mathrm{Na}^{+}$(green) after addition of $5 \mathrm{mM}$ $\mathrm{SrCl}_{2}$ at $20{ }^{\circ} \mathrm{C}$ (final spectra after 180 minutes: purple) (left) and the plot at two characteristic wavelengths (right). The red arrow highlights the initial point at $t=0$, for $\lambda=300 \mathrm{~nm}$. 


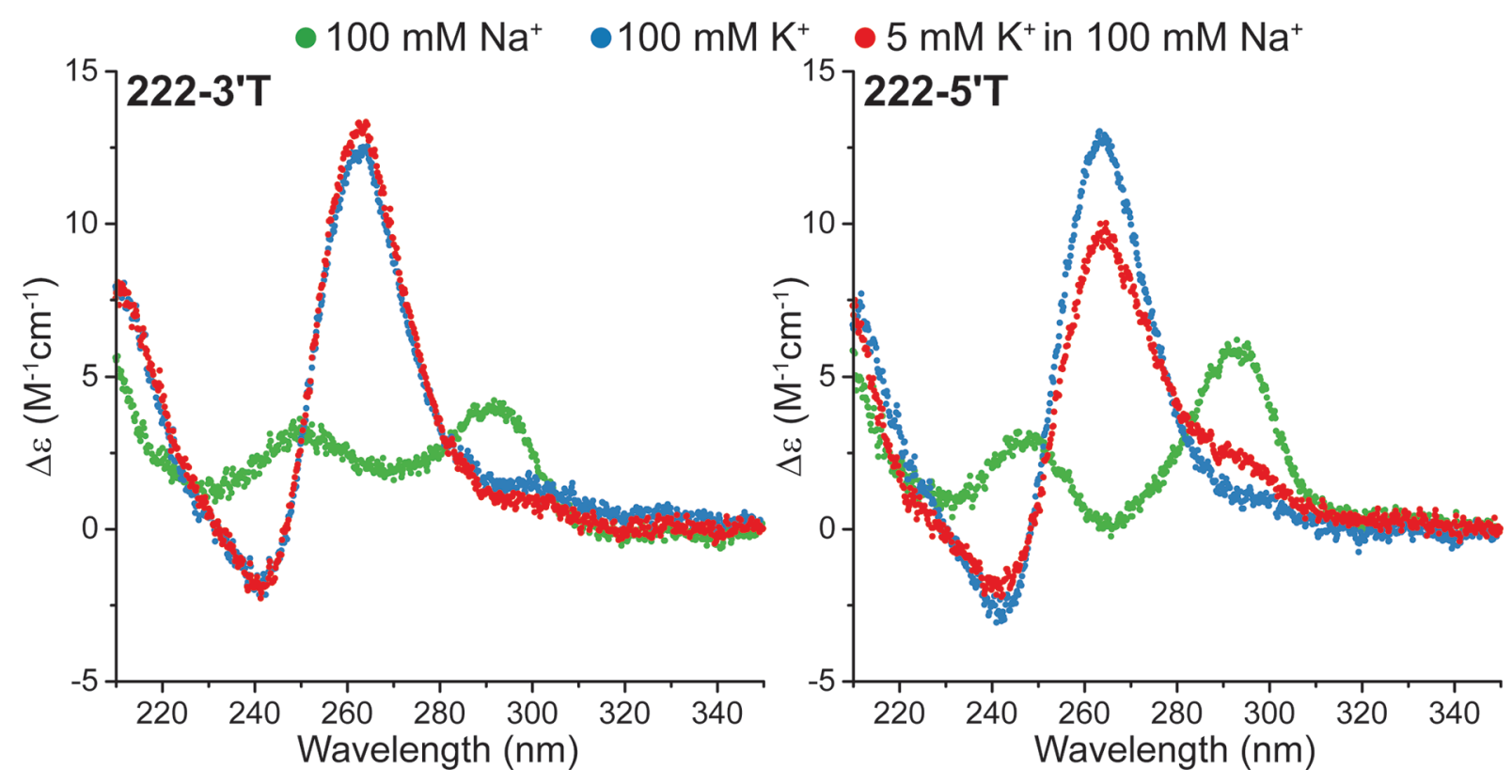

Figure S25. Variants of the 222 sequence $(10 \mu \mathrm{M})$ in presence of $100 \mathrm{mM}$ of $\mathrm{Na}^{+}$(green), $100 \mathrm{mM} \mathrm{K}^{+}$ (blue), or $5 \mathrm{mM} \mathrm{K}^{+}$added in a $100 \mathrm{mM} \mathrm{Na}^{+}$solution (red). 
A

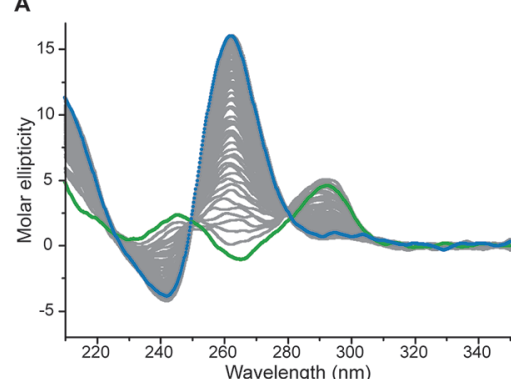

D

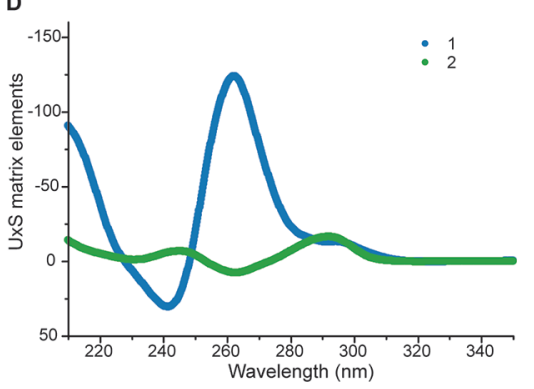

B

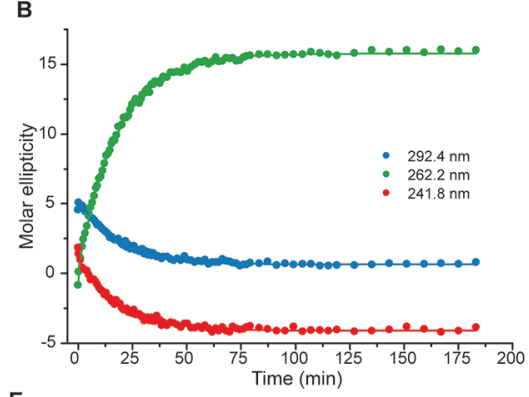

E

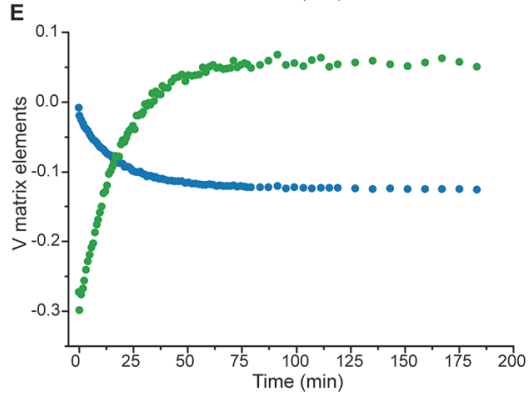

C

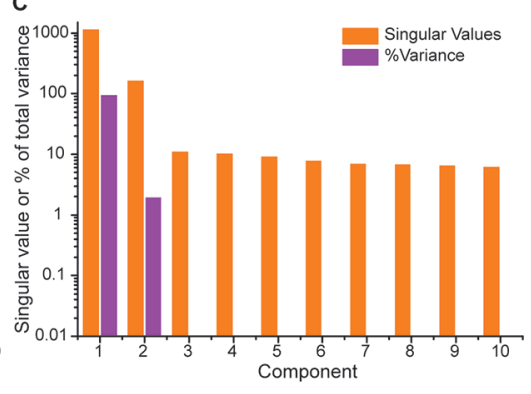

Figure S26. Time-dependent CD of 222-3'T prepared in TMAA (20 mM) supplemented with $100 \mathrm{mM} \mathrm{NaCl}$ (green) after addition of $5 \mathrm{mM} \mathrm{KCl}$, at $4{ }^{\circ} \mathrm{C}$ (final spectrum: blue) (panel A). Corresponding plots of the normalized ellipticity at three characteristic wavelengths are shown in panel $B$. Panel $C$ is a bar chart showing the first ten singular values and their corresponding relative variance, obtained by SVD. The first two basis spectra, and the corresponding $V$ matrix elements as a function of time, are shown in panels $D$ and $E$, respectively. 
A
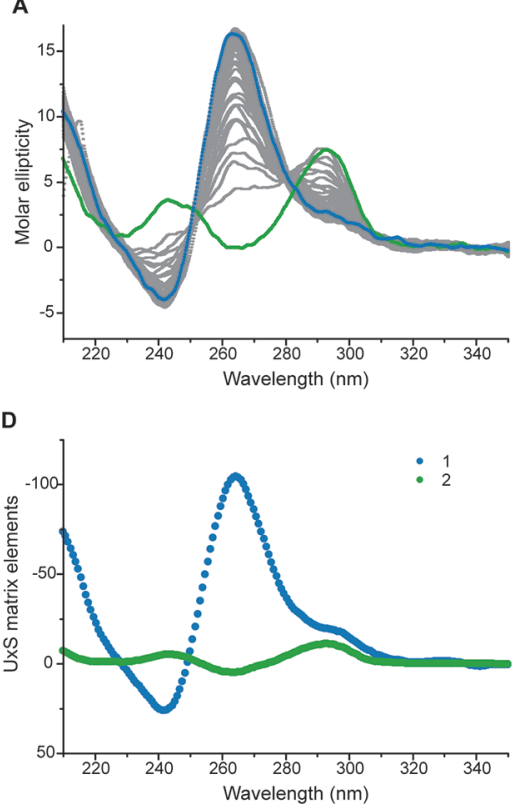

B
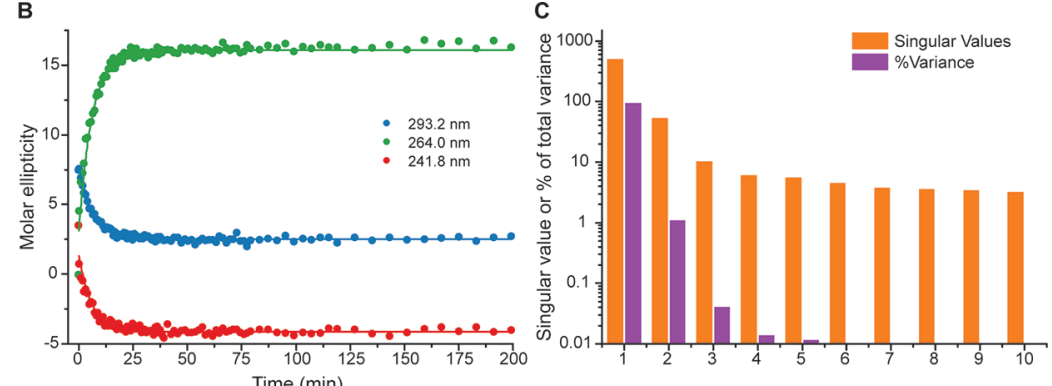

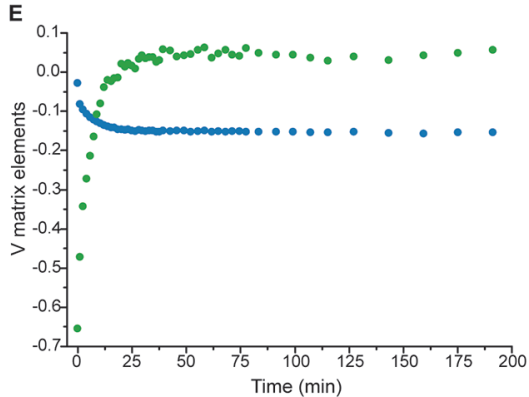

Figure S27. Time-dependent CD of 222-5'T prepared in TMAA (20 mM) supplemented with $100 \mathrm{mM} \mathrm{NaCl}$ (green) after addition of $5 \mathrm{mM} \mathrm{KCl}$, at $4{ }^{\circ} \mathrm{C}$ (final spectrum: blue) (panel A). Corresponding plots of the normalized ellipticity at three characteristic wavelengths are shown in panel $B$. Panel $C$ is a bar chart showing the first ten singular values and their corresponding relative variance, obtained by SVD. The first two basis spectra, and the corresponding $V$ matrix elements as a function of time, are shown in panels $D$ and $E$, respectively. 

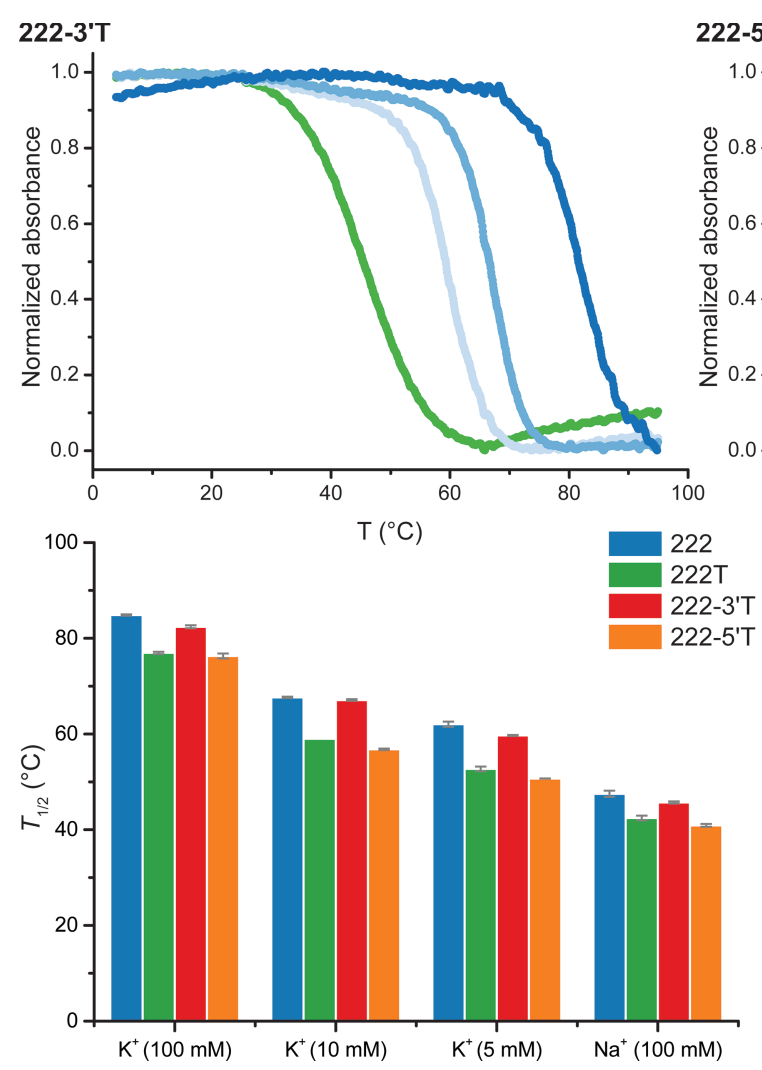

222-5'T

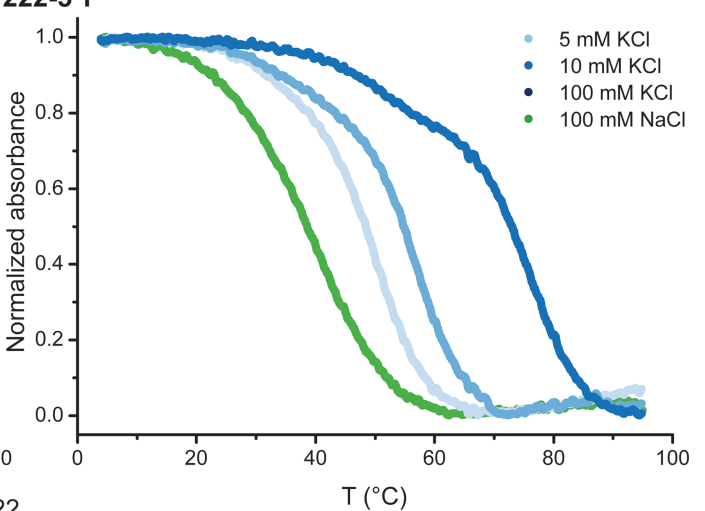

Figure S28. Top panels: UV-melting curves of 222-3'T (left) and 222-5'T (right), at a $10 \mu \mathrm{M}$ strand concentration, in presence of various concentrations of $\mathrm{KCl}$ and/or $\mathrm{NaCl}$, lithium cacodylate $(20 \mathrm{mM}, \mathrm{pH}$ 7.2), and $\mathrm{LiCl}$ (q.s. for a $120 \mathrm{mM}$ salt concentration) (see color code on figure). Bottom panel: Corresponding melting temperatures, compared to 222 and $222 \mathrm{~T}$. 

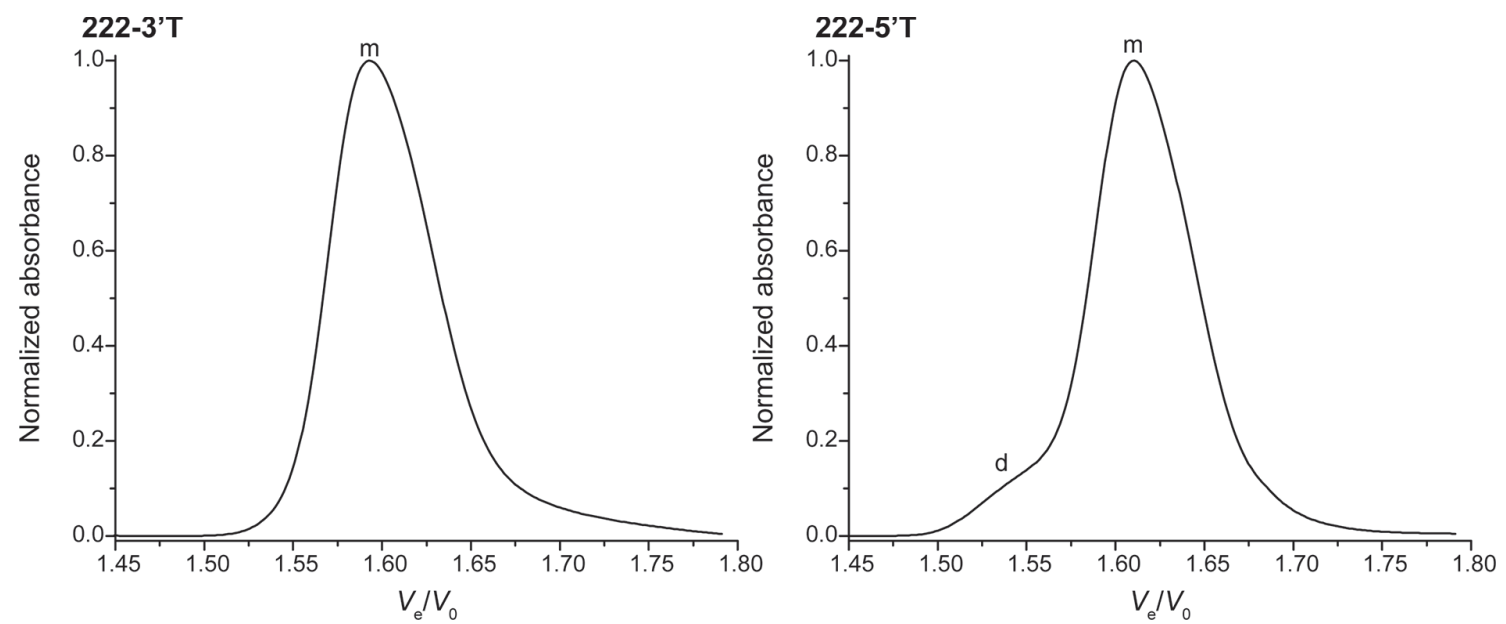

Figure S29. SE-HPLC profile (260 nm) of 222-5'T and 222-3'T at high strand concentration (250 $\mu \mathrm{M})$, in a $100 \mathrm{mM} \mathrm{KCl}$ containing buffer. Monomer peaks are indicated by $\mathrm{m}$, dimers by $d$. 


\section{SODIUM-TO-POTASSIUM STRUCTURAL SWITCHING IS NOT AN ISOLATED CASE}

In CD screening experiments, spectra were acquired in lithium cacodylate supplemented with $100 \mathrm{mM}$ of either $\mathrm{KCl}$ or $\mathrm{NaCl}$ to assess whether the sequences display distinct topologies in sodium- and potassium-rich conditions. Then, $\mathrm{KCl}(100 \mathrm{mM})$ was added to the $\mathrm{Na}^{+}$-containing sample (without additional annealing) and a CD spectrum was acquired 3-4 hours later. In titration experiments of $\mathrm{Na}^{+}$ samples in lithium cacodylate, spectra were recorded after a 3-min incubation period following $\mathrm{KCl}$ or $\mathrm{SrCl}_{2}$ addition. Titrations of unfolded samples were performed with independent solutions prepared in TMAA, and incubated overnight. 
Table S6. Other sequences screened by circular dichroism. All sequences are listed $5^{\prime}$ to $3^{\prime}$ and correspond to oligodeoxynucleotides. Synthetic constructs named by numbers only all share the same template of four tracts of three guanines linked by three thymine-only loops whose length is indicated by the three numbers composing the name.

\begin{tabular}{|c|c|c|c|}
\hline Name & Sequence & Description & Reference \\
\hline 331 & $\underline{\text { GGGTTTGGGTTTGGGTGGG }}$ & Synthetic construct & 9 \\
\hline 233 & $\underline{\text { GGGTTGGGTTTGGGTTTGGG }}$ & Synthetic construct & 9 \\
\hline 223 & $\underline{\text { GGGTTGGGTTGGGTTTGGG }}$ & Synthetic construct & 9 \\
\hline 161 & $\underline{\text { GGGTGGGTTTTTTGGGTGGG }}$ & Synthetic construct & 9 \\
\hline $161 T$ & TGGGTGGGTTTTTTGGGTGGGT & Synthetic construct & 9 \\
\hline $161 T \mathrm{~T}$ & TTGGGTGGGTTTTTT $\underline{\text { GGGTGGGTT }}$ & Synthetic construct & 9 \\
\hline 322 & $\underline{\text { GGGTTTGGGTTGGGTTGGG }}$ & Synthetic construct & 9 \\
\hline 232 & $\underline{\text { GGGTTGGGTTTGGGTTGGG }}$ & Synthetic construct & 9 \\
\hline 133 & $\underline{\text { GGGTGGGTTTGGGTTTGGG }}$ & Synthetic construct & 9 \\
\hline G5T2 & $\underline{\text { GGGGGTTGGGGGTTGGGGGTTGGGGGTT }}$ & Synthetic construct & 10 \\
\hline H-Bi-G4 & $\underline{\text { GGGACGTAGTGGG }}$ & Synthetic construct & 11 \\
\hline Ara24 & $\underline{\text { GGGTTTAGGGTTTAGGGTTTAGGG }}$ & Arabidopsis telomere & 12 \\
\hline Tom24 & $\underline{\text { GGGTTAAGGGTTAAGGGTTAAGGG }}$ & L. esculentum telomere & 12 \\
\hline Tet22 & $\underline{\text { GGGGTTGGGGTTGGGGTTGGGG }}$ & Tetrahymena telomere & 12 \\
\hline Chla27 & $\underline{\text { GGGTTTTAGGGTTTTAGGGTTTTAGGG }}$ & Chlamydomonas telomere & 12 \\
\hline Scer21 & $\underline{\text { GGGTGTGGGTGTGGGTGTGGG }}$ & S. cerevisiae telomere & 12 \\
\hline Par21 & $\underline{\text { GGGTTTGGGTTTGGGTTTGGG }}$ & Paramecium telomere & 12 \\
\hline Gla26 & $\underline{\text { GGGGTCTGGGTGCTGTGGGGTCTGGG }}$ & C. glabrata telomere & 12 \\
\hline $0 x y 28$ & $\underline{\text { GGGGTTTTGGGGTTTTGGGGTTTTGGGG }}$ & Oxytricha telomere & 13 \\
\hline Oxy 30 & TGGGGTTTTGGGGTTTTGGGGTTTTGGGGT & Oxytricha telomere & 14,15 \\
\hline K-ras 35B1 & AGGGCGGTGTGGGAAGAGGGAAGAGGGGGAGGCAG & K-ras promoter & 15 \\
\hline K-ras 35B3 & AGGGCGGTGTGGGAAGAGGGAAGAGGGGGAGG & K-ras promoter & 14,15 \\
\hline c-kit1 & $\underline{\text { GGGAGGGCGCTGGGAGGAGGG }}$ & c-kit promoter & 14,16 \\
\hline c-kit87-up & $\underline{\text { AGGGAGGGCGCTGGGAGGAGGG }}$ & c-kit promoter & 17 \\
\hline c-kit2 & CGGGCGGGCGCTAGGGAGGGT & c-kit promoter & 18 \\
\hline c-kit2GG & $\underline{\text { GGGCGGGCGCTAGGGAGGG }}$ & c-kit promoter & 16 \\
\hline B-raf & 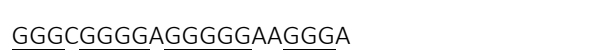 & B-raf promoter & 19 \\
\hline
\end{tabular}



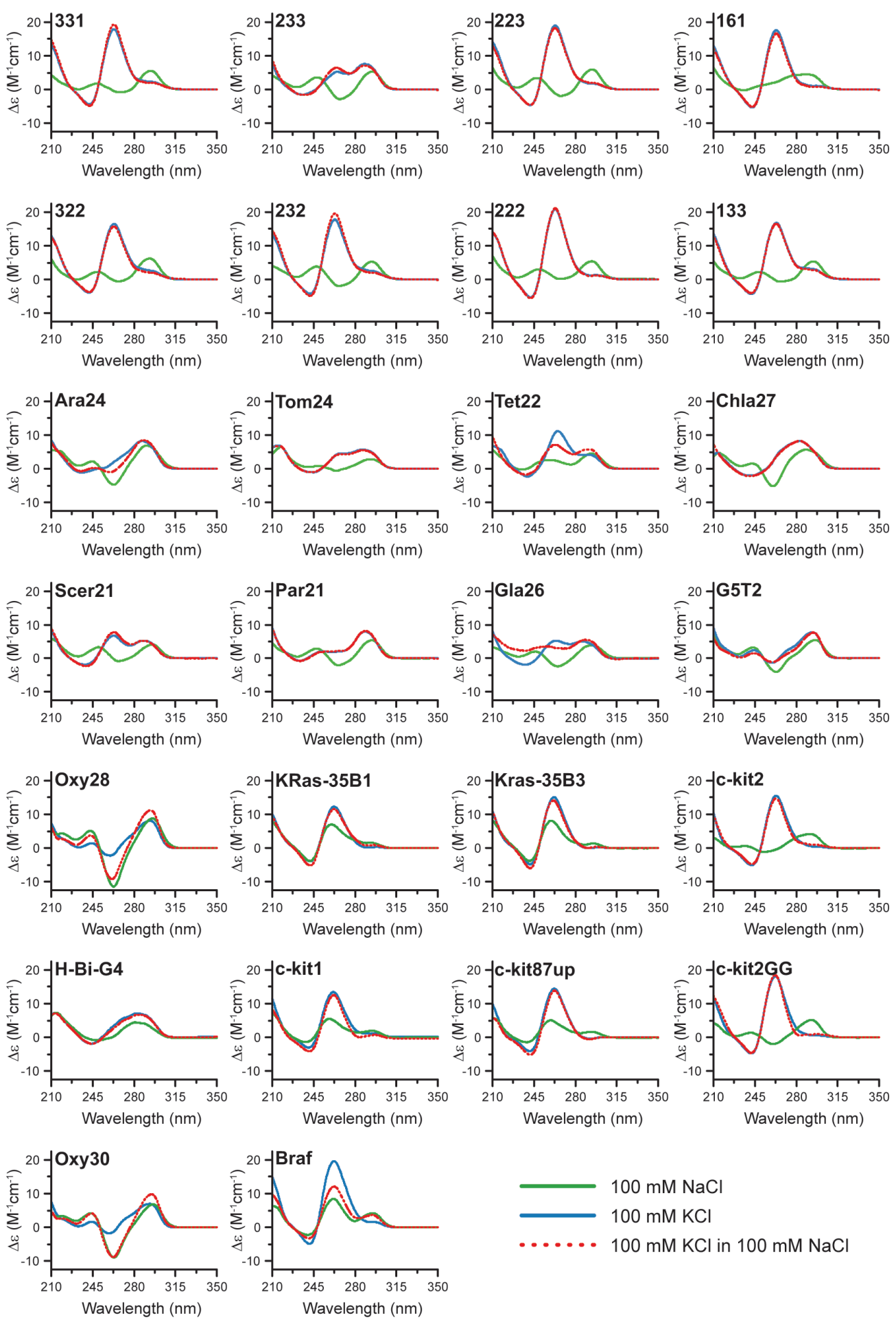

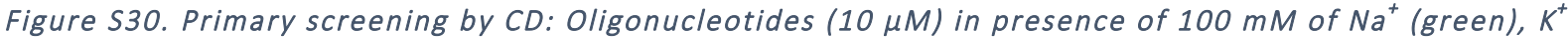
(blue), or $\mathrm{K}^{+}$added in a $\mathrm{Na}^{+}$solution (red). 222 is shown for reference.

Note that H-Bi-G4 forms a particular quadruplex whose loops form short hairpins. The CD signal is thus a combination of G4 and B-DNA contributions. It is likely that the difference between the $\mathrm{Na}^{+}$and $\mathrm{K}^{+}$spectra arises from the fairly low stability of the structures, the expected lower stability in sodium leading to a weaker CD signal. 

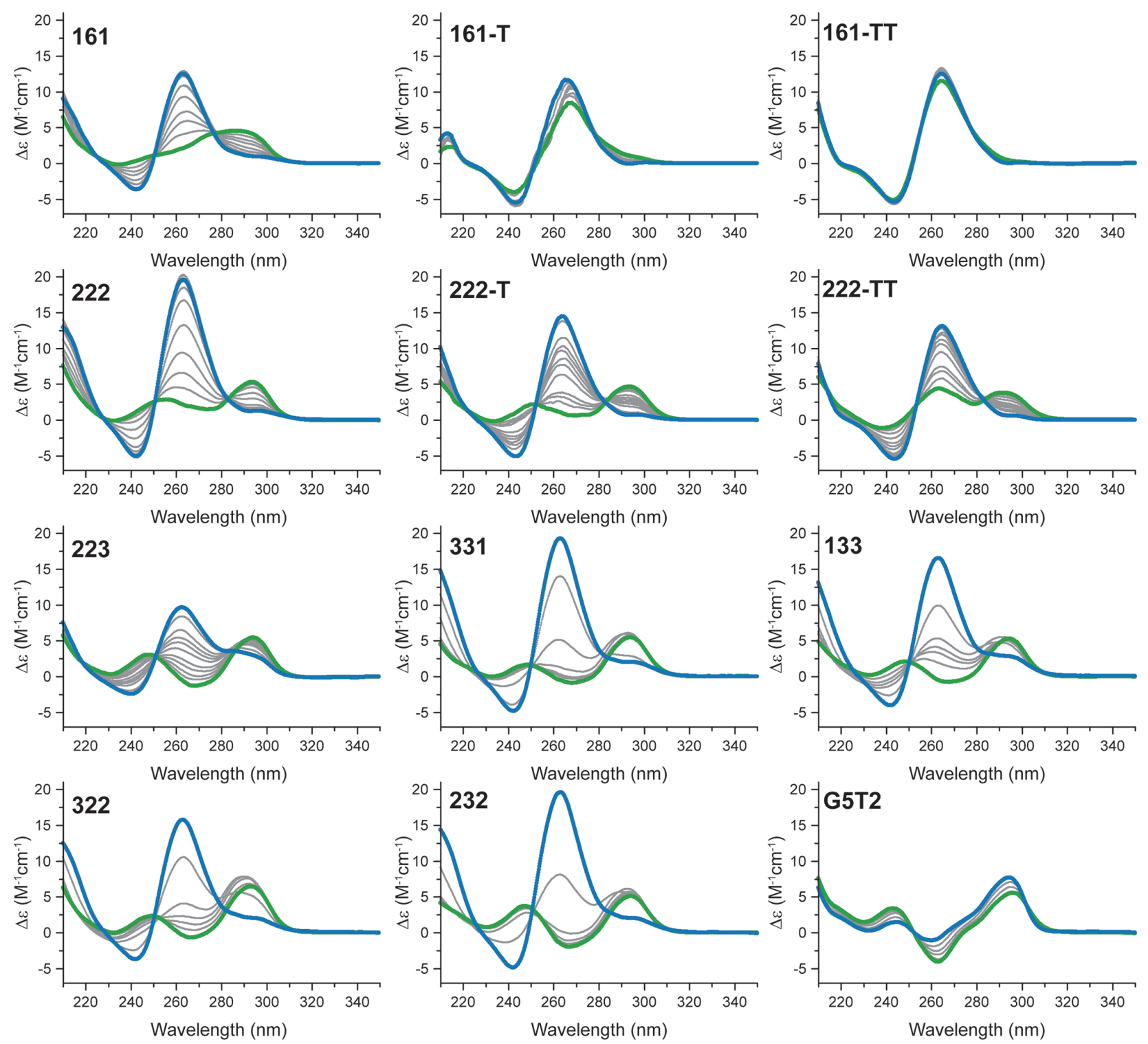

Figure S31. CD titration of a variety of oligonucleotides $(10 \mu \mathrm{M})$ in $100 \mathrm{mM} \mathrm{NaCl}$ solution by $\mathrm{KCl}(0,0.1$, $0.2,0.3,0.5,0.75,1.0,1.25,1.5,2,5$, and $10 \mathrm{mM}$, from green to blue). 222 and $222 \mathrm{~T}$ are shown for reference. 

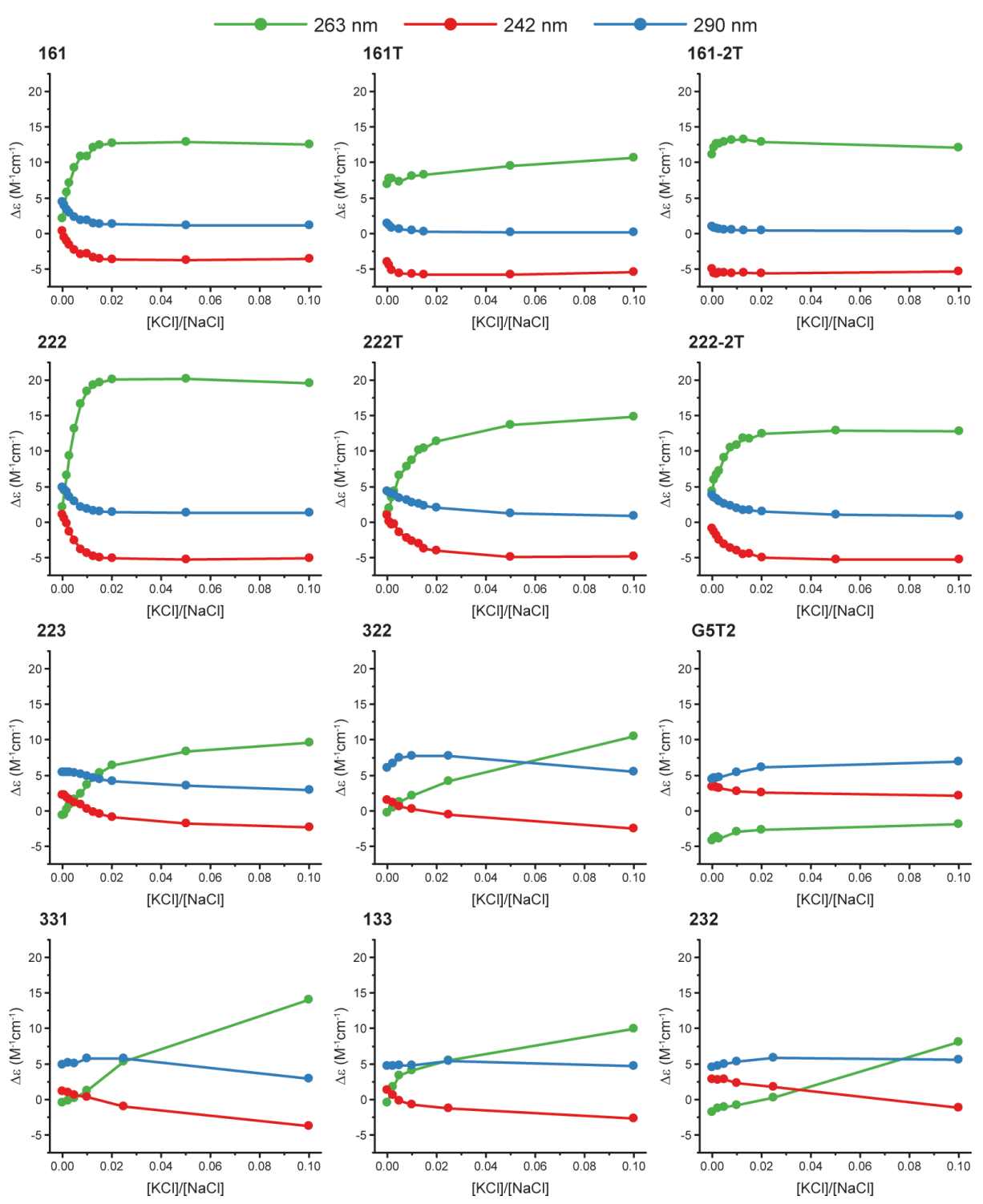

Figure S32. Potassium-dependency plotted from CD titrations at characteristic wavelengths. 222 and $222 T$ are shown for reference. 

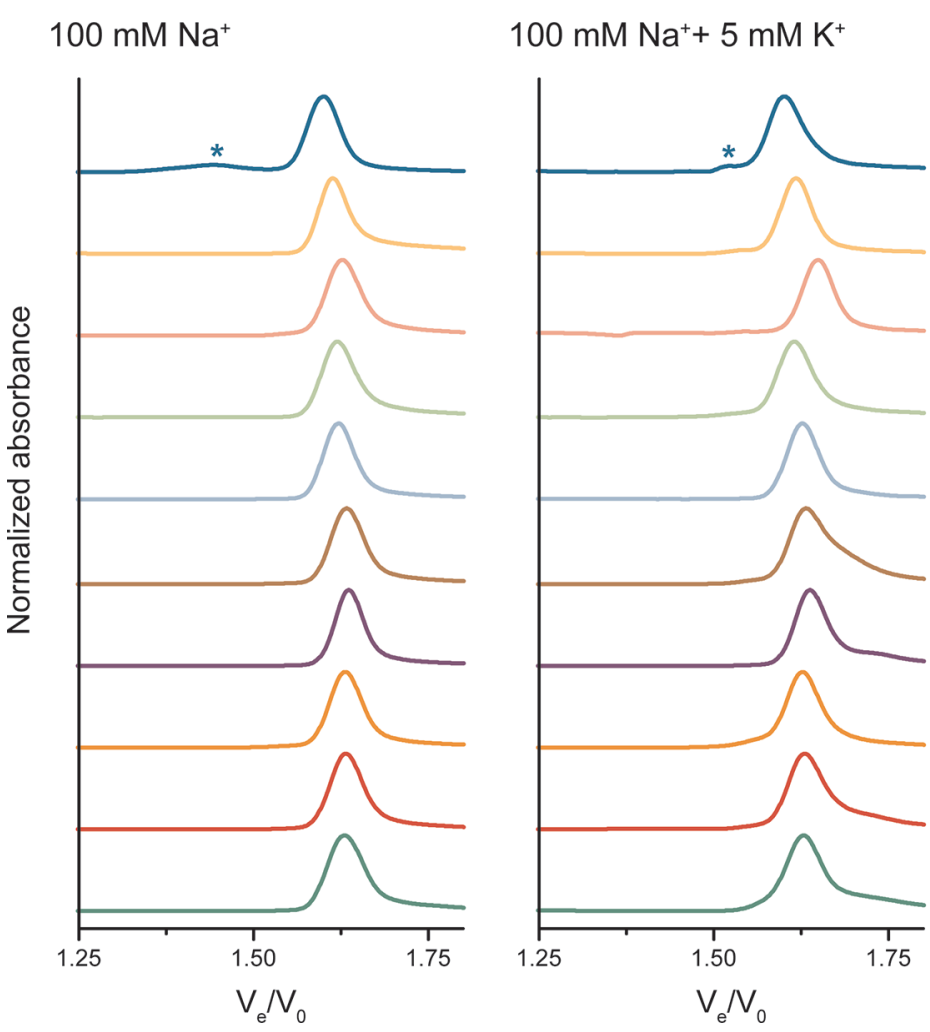

$100 \mathrm{mM} \mathrm{K}^{+}$

Figure S33. SE-HPLC profile $(260 \mathrm{~nm})$ for a selection of oligonucleotides (10- $\mu \mathrm{M}$ strand concentration) in different buffer conditions. Asterisks indicate the presence of multimolecular species. 


\section{RESULTS SECTION 3.2: POTASSIUM CONCENTRATION SWITCH}

STEADY-STATE POTASSIUM TITRATIONS

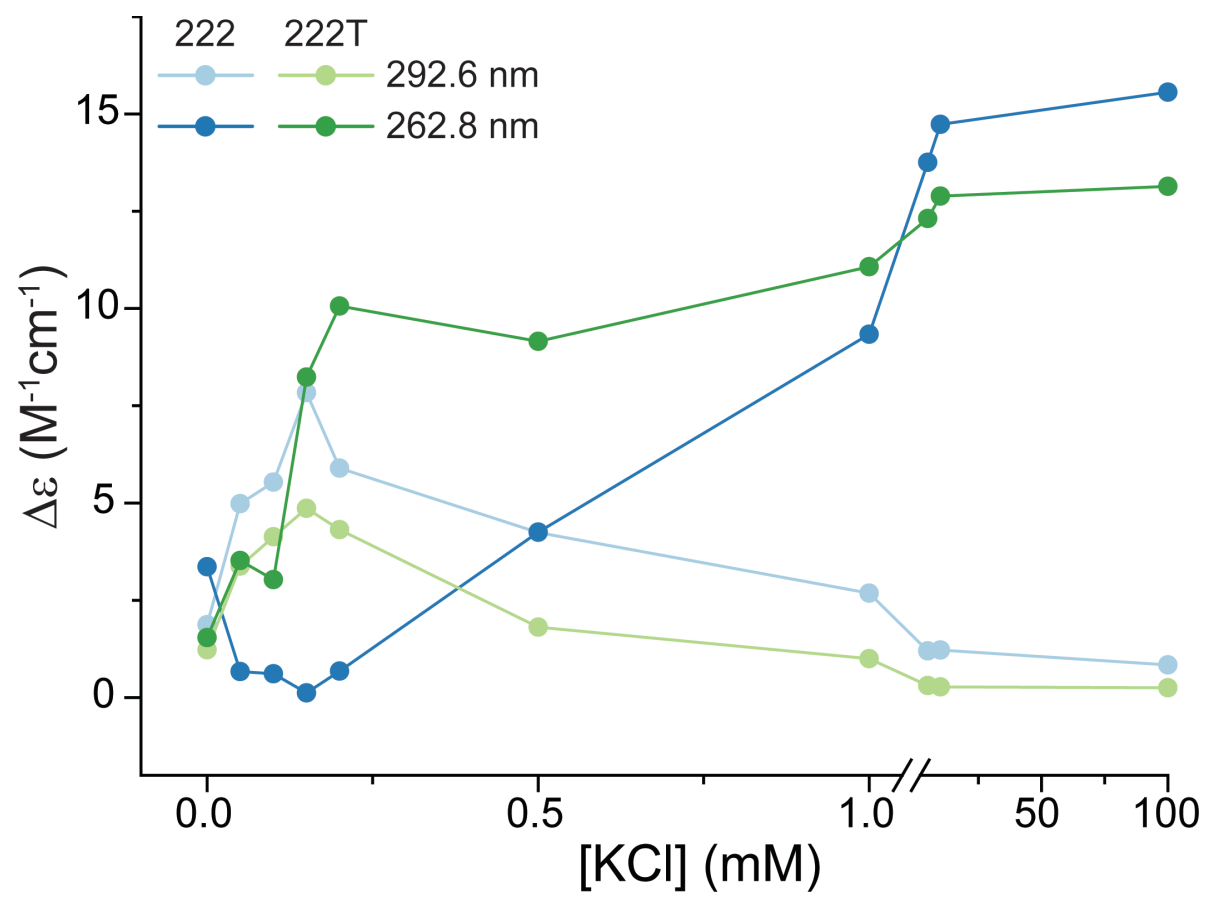

Figure S34. Plot of the molar ellipticity at two characteristic wavelengths as a function of the concentration in potassium cations. 
222
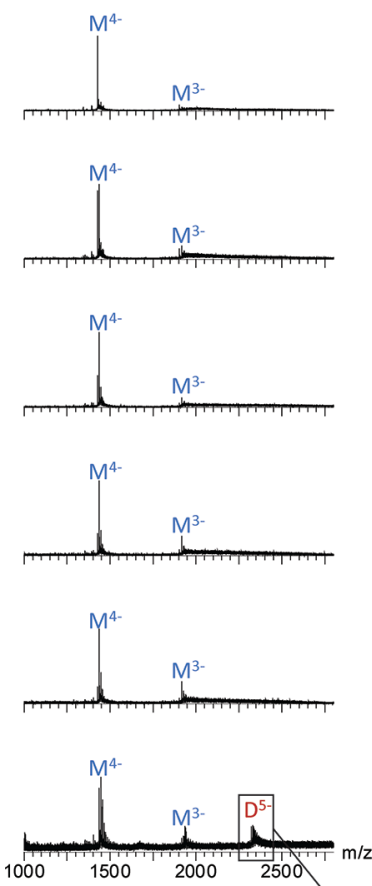

$\overbrace{}^{\min }$
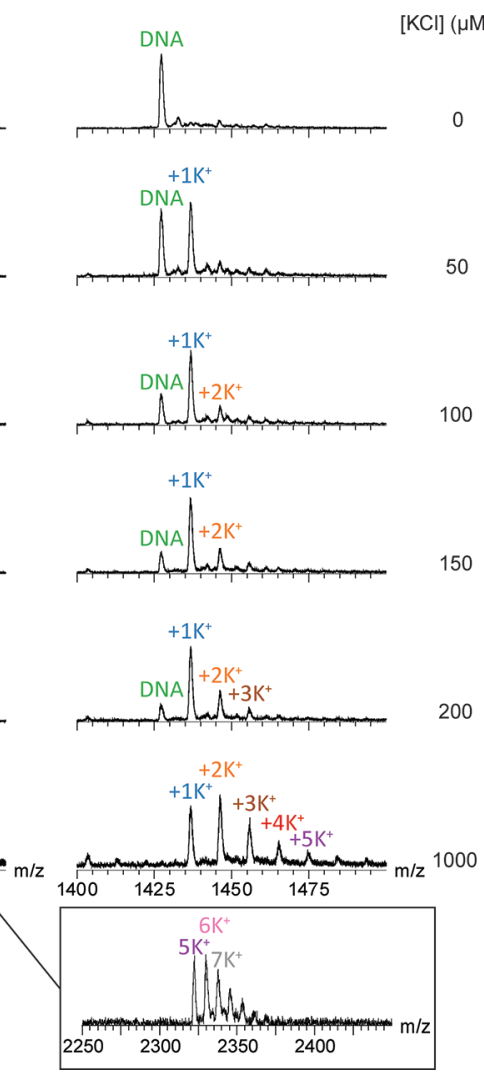

50
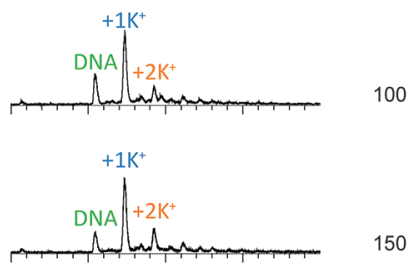

150

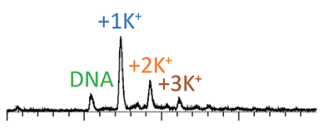

200
222T
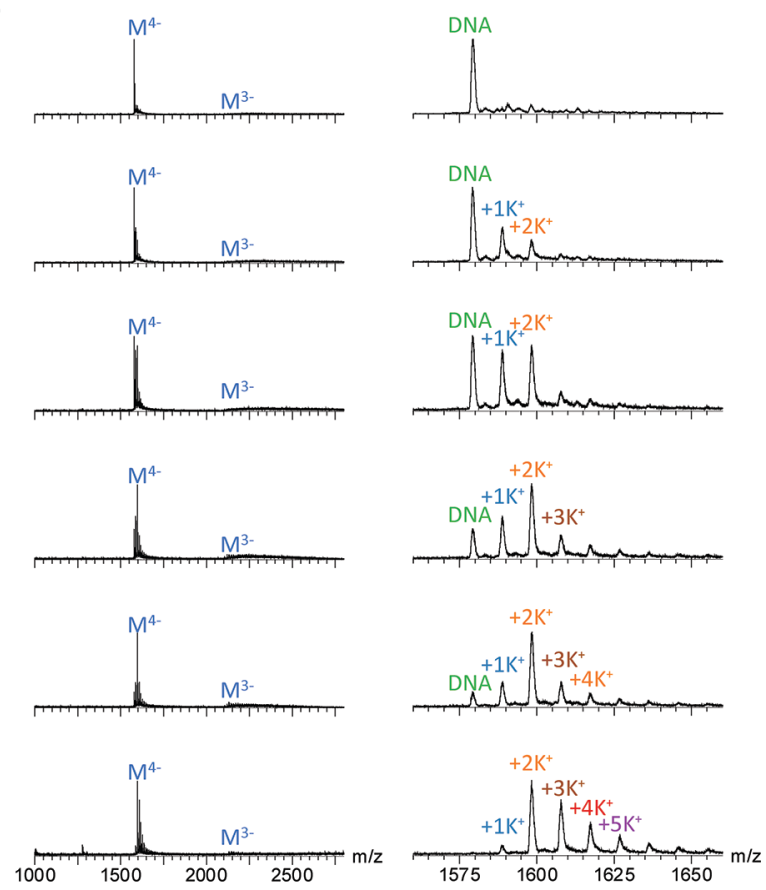

Figure S35. Titration of 222 (left) and $222 \mathrm{~T}$ (right) by $\mathrm{KCl}(0-1000 \mu \mathrm{M})$, at a $10-\mu \mathrm{M}$ strand concentration, by native ESI-MS (data before non-specific adduct subtraction). For each oligonucleotide, the left spectra show the $1000-2750 \mathrm{~m} / \mathrm{z}$ range, and the right spectra are focused on the 4-charge state, and 5-for the dimer (insert). $M$ stands for monomer and $D$ for dimer. The number of potassium adduct is indicated above the corresponding peaks. 

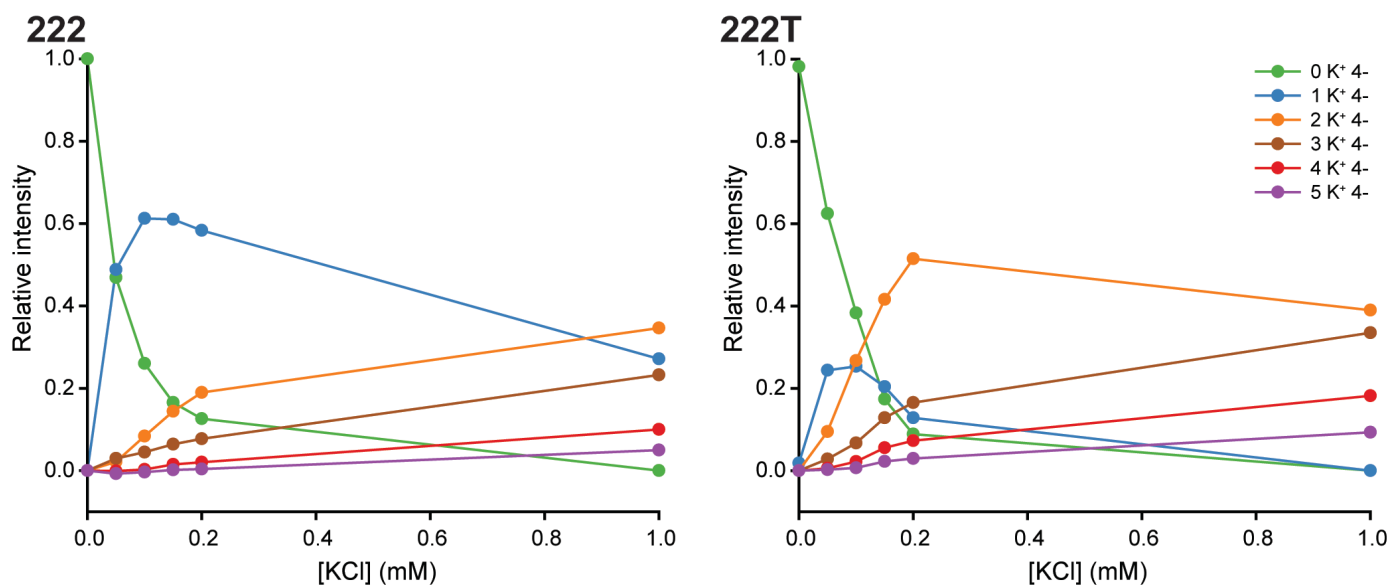

Figure S36. Relative amounts of each potassium adducts (normalized to [0,1]) as a function of the potassium concentration, prior to non-specific adduct cleaning. Only the 4-charge state is considered. 


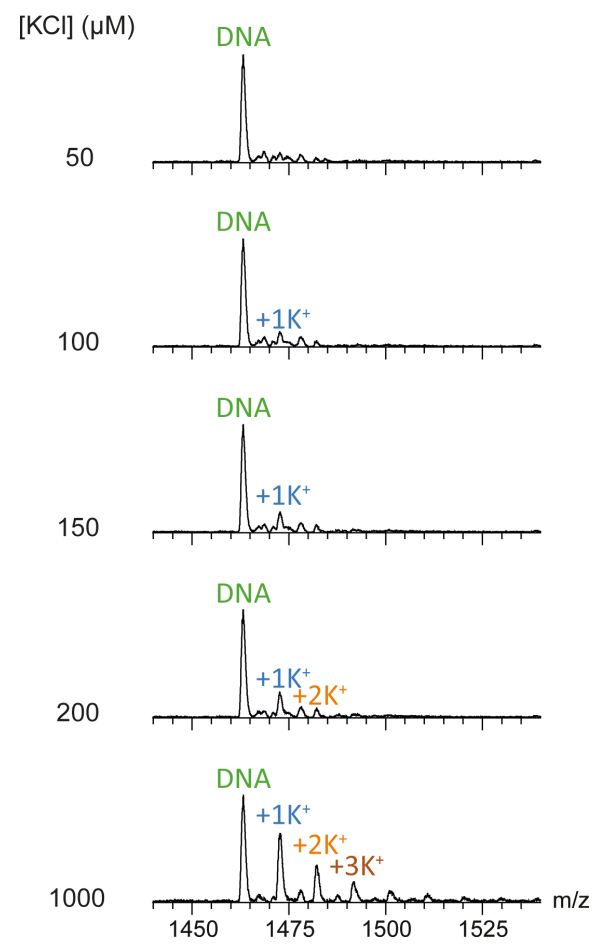

Figure S37. Titration of d(TGCGTTGCGTTGCGTTGCG) by $\mathrm{KCl}(50-1000 \mu \mathrm{M})$, at a $10-\mu \mathrm{M}$ strand concentration, by native ESI-MS. The spectra are focused on the 4-charge state. The number of potassium adducts (non specific; this is a single-stranded control) are indicated above the corresponding peaks.

Table S7. Non-specific adduct quantification. For calculation details, see "Diffusively bound potassium cleaning in native ESI-MS experiments" on p.3

\begin{tabular}{rrrr}
{$\left[K^{+}\right](\mathrm{mM})$} & $+1 K=x$ & $+2 K=y$ & $+3 K=z$ \\
\hline 0.00 & 0 & 0 & 0 \\
0.05 & 0.1022 & 0.0353 & 0.0143 \\
0.10 & 0.1551 & 0.0399 & 0.0185 \\
0.15 & 0.2059 & 0.0614 & 0.0338 \\
0.20 & 0.2434 & 0.0738 & 0.0426 \\
1.00 & 0.7041 & 0.363 & 0.2151 \\
\hline
\end{tabular}



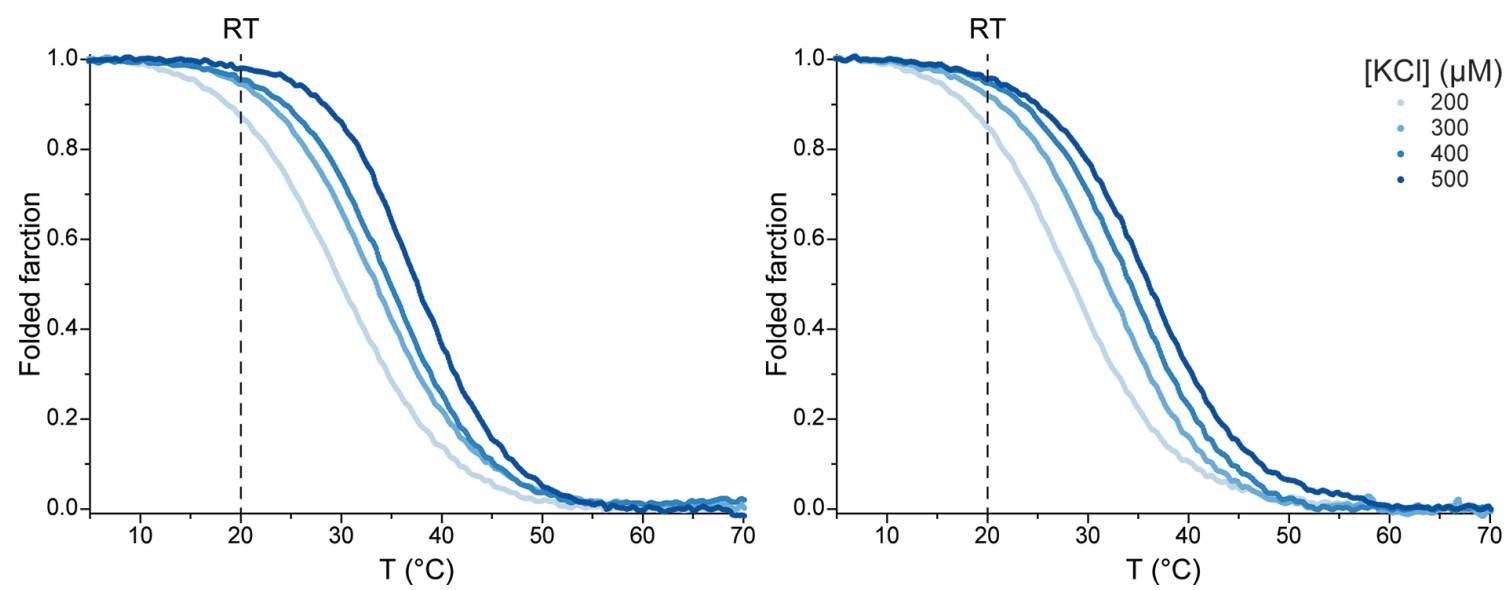

Figure S38. UV-melting curves of 222 (left) and 222T (right), at a $10 \mu \mathrm{M}$ strand concentration, in presence of various submillimolar concentrations of $\mathrm{KCl}$, in lithium cacodylate $(20 \mathrm{mM}, \mathrm{pH} \mathrm{7.2),} \mathrm{and} \mathrm{LiCl}$ (q.s. for a $120 \mathrm{mM}$ salt concentration) (see color code on figure). The dashed line highlights room temperature conditions. 


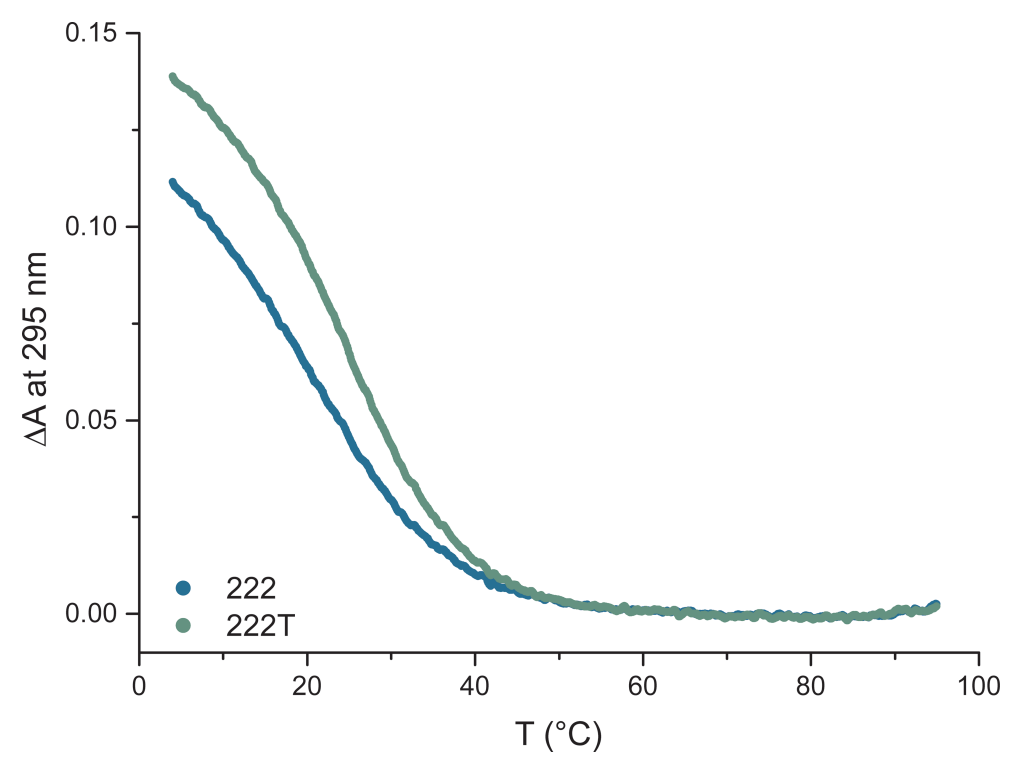

Figure S39. UV-melting curves at $295 \mathrm{~nm}$ of 222 and 222T, at a $10 \mu \mathrm{M}$ strand concentration, in presence of $100 \mu \mathrm{M} \mathrm{KCl}$, lithium cacodylate $(20 \mathrm{mM}, \mathrm{pH}$ 7.2), and LiCl (q.s. for a $120 \mathrm{mM}$ salt concentration). 


\section{2}

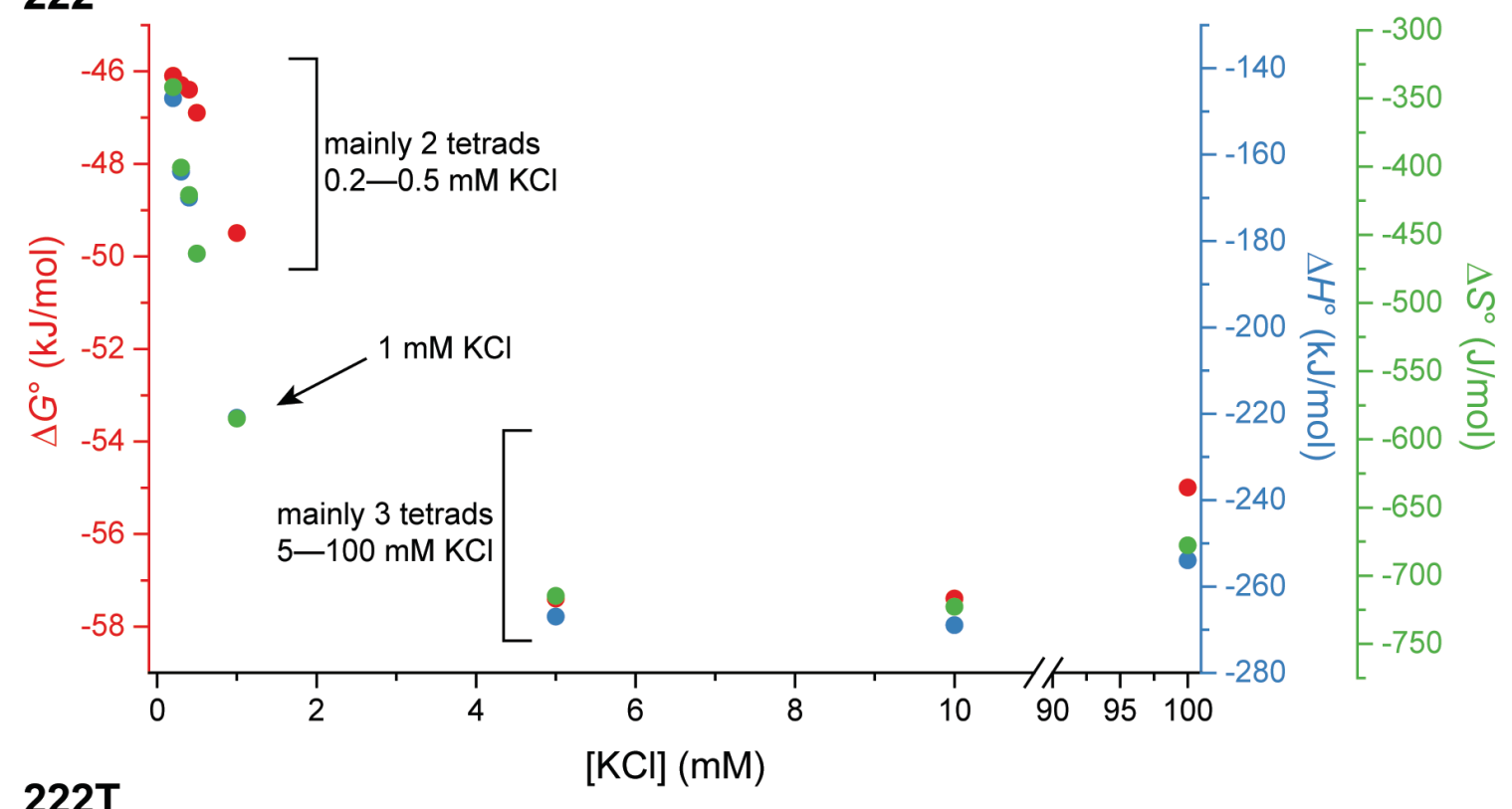

\section{T}

$\mathrm{KCl}](\mathrm{mM})$

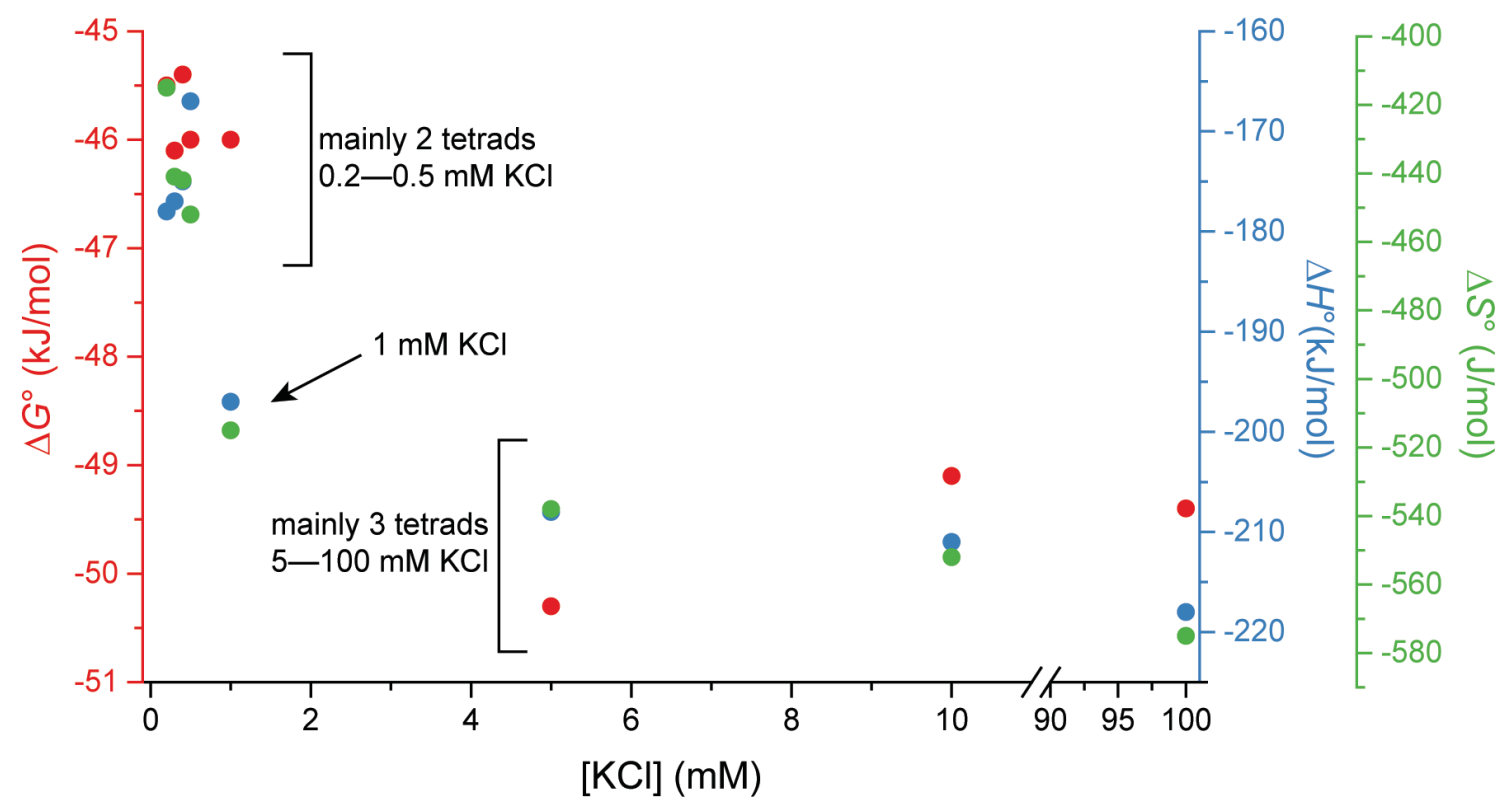

Figure $S 40 . \Delta G^{\circ}, \Delta H^{\circ}$, and $\Delta S^{\circ}$ of folding as a function of $\mathrm{KCl}$ concentration. 
TIME-DEPENDENT CD DATA OF THE FOLDING IN POTASSIUM
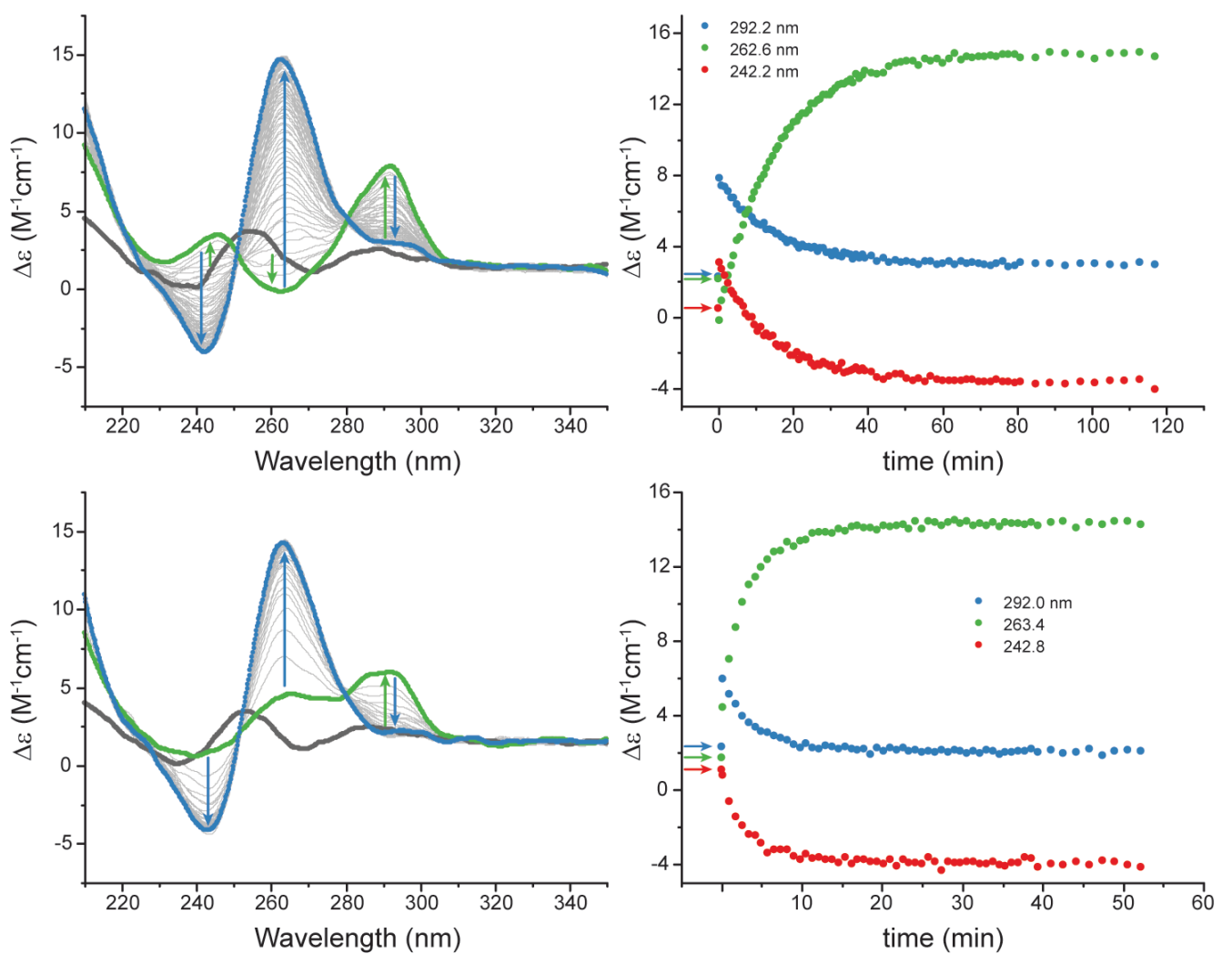

222
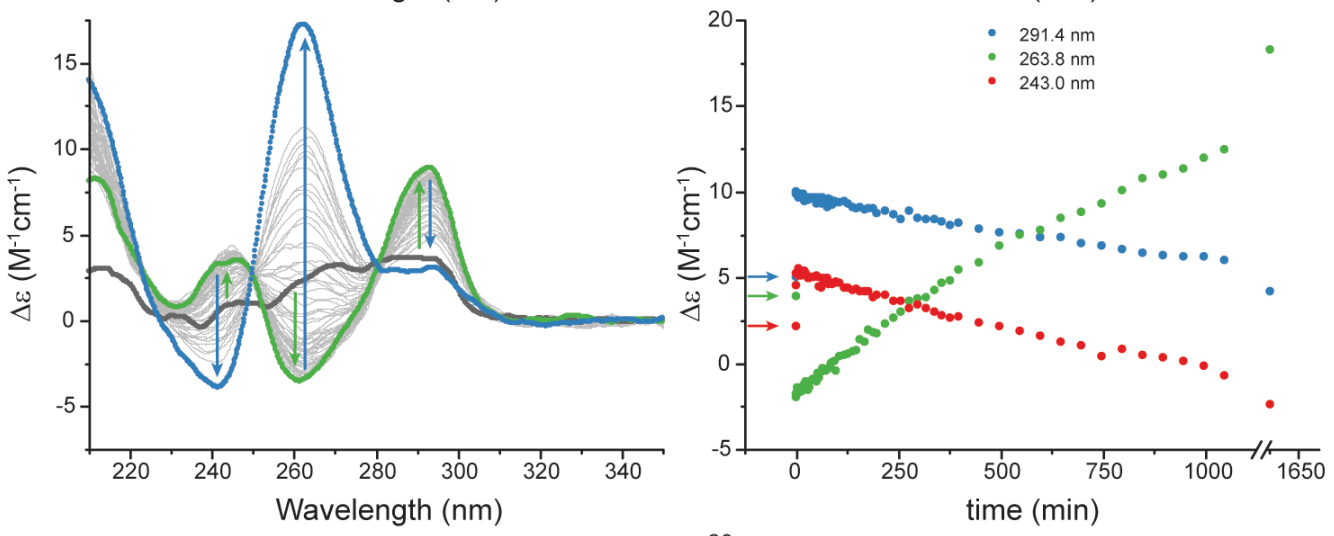

$222 T$
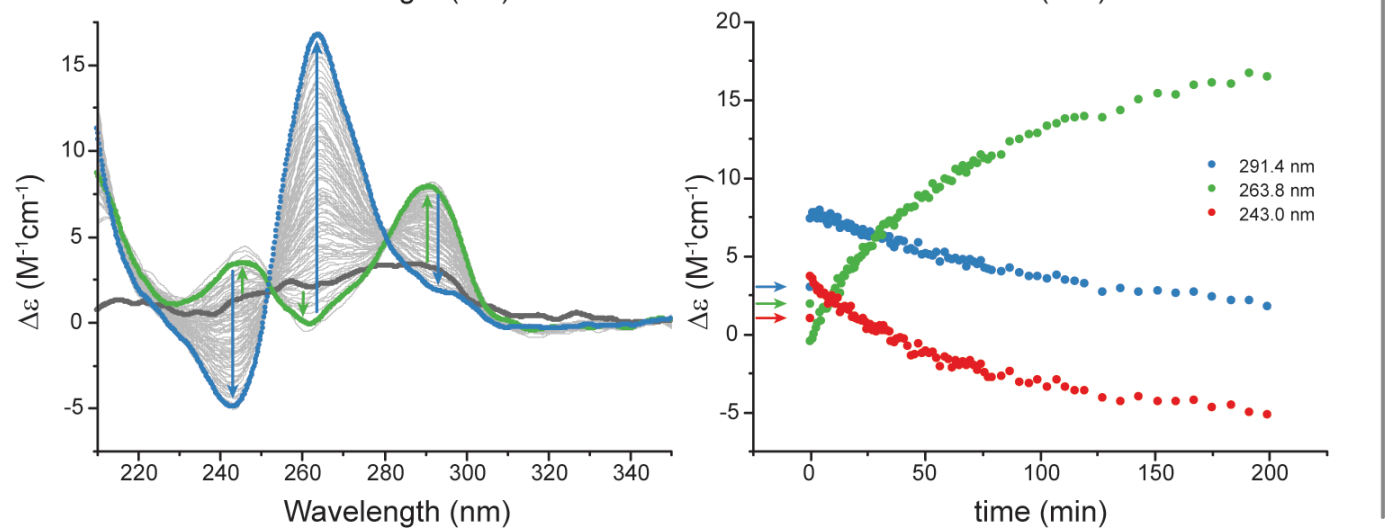

222

$4^{\circ} \mathrm{C}$

222T

Figure S41. Left: Time-dependent CD of 222 and 222T, prepared in TMAA with no other cation (dark grey) after addition of $5 \mathrm{mM} \mathrm{KCl}$, at $20^{\circ} \mathrm{C}$ (top) or $4{ }^{\circ} \mathrm{C}$ (bottom). An antiparallel intermediate (green) is observed after one minute, then converts to a parallel signal (final spectrum: blue). Right: Corresponding plots of the normalized ellipticity at three characteristic wavelengths, where arrows highlight the initial point at $t=0$. 

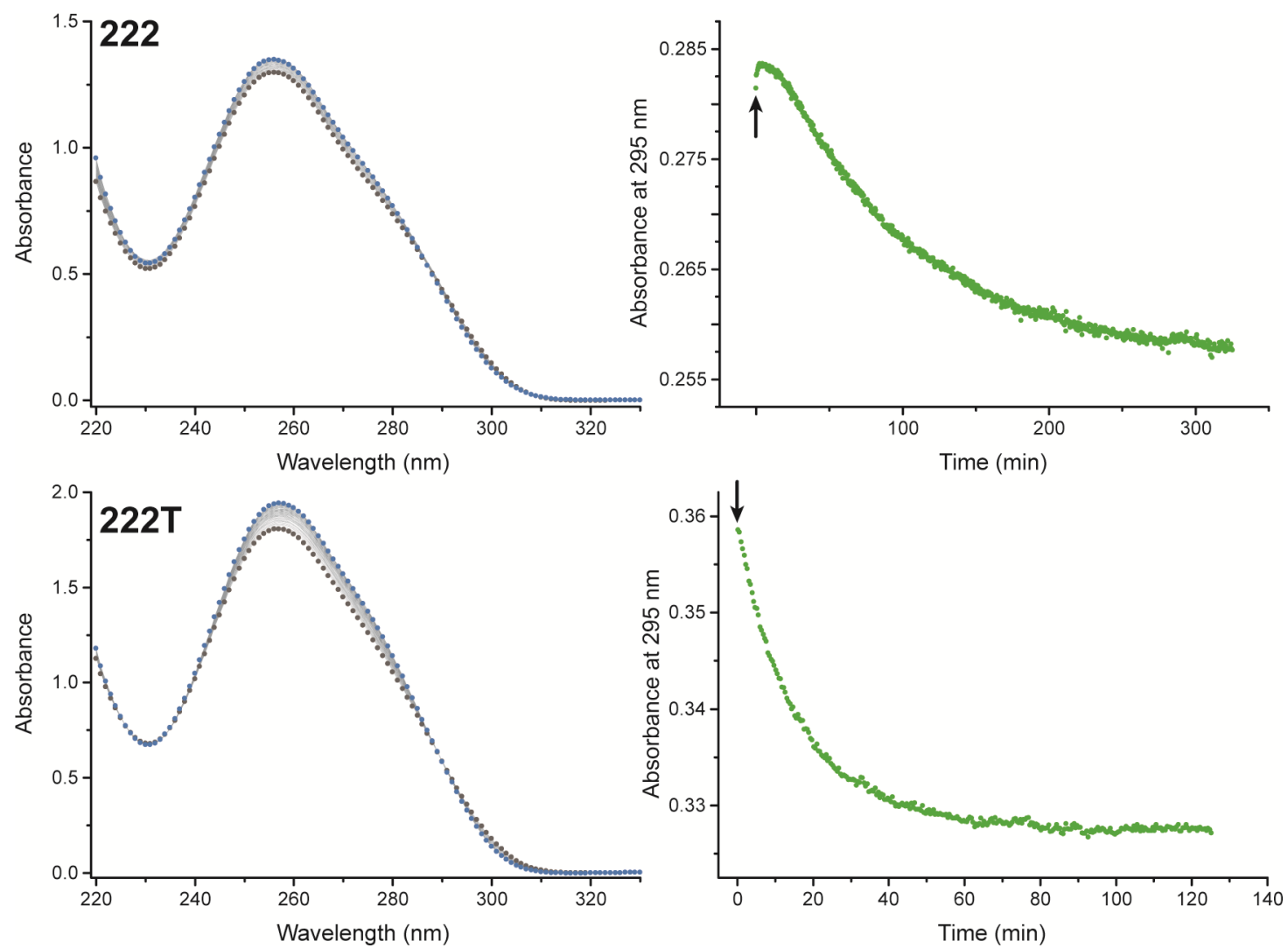

Figure S42. Time-dependent UV-vis spectra of 222 and 222T, prepared in TMAA with no other cation (dark grey) after addition of $5 \mathrm{mM} \mathrm{KCl}$ (final spectra: blue), at $10^{\circ} \mathrm{C}$ (left), and the corresponding plots at $295 \mathrm{~nm}$ (right). Arrows highlight the initial point at $t=0$.
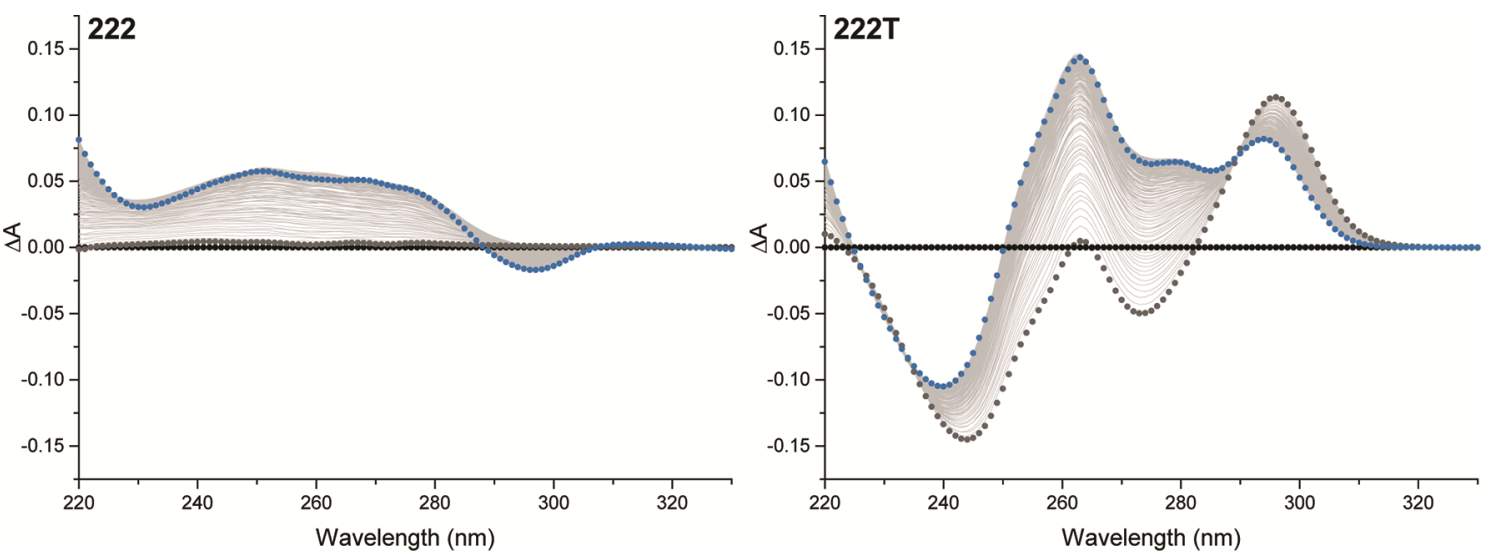

Figure S43. Time-dependent IDS spectra of 222 and 222T, prepared in TMAA with no other cation (black) after addition of $5 \mathrm{mM} \mathrm{KCl}$ (after dead time of 15 seconds: dark grey; final spectra: blue), at 10 ${ }^{\circ} \mathrm{C}$ (left). 
STEADY-STATE STRONTIUM TITRATIONS
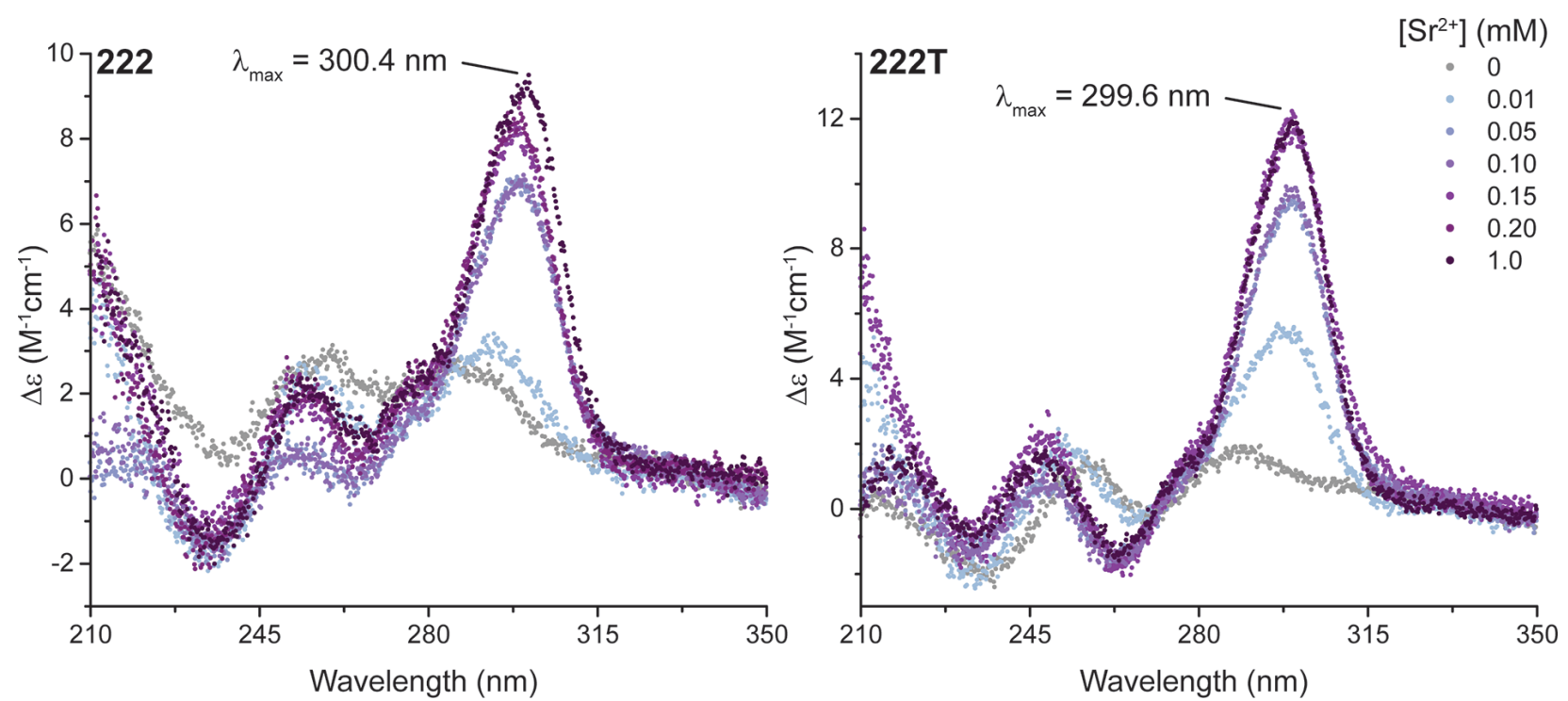

Figure S44. Titration of 222 (left) and $222 \mathrm{~T}$ (right) by SrCl $2(0-1000 \mu \mathrm{M}$; grey to dark purple), at a 10$\mu M$ strand concentration in TMAA (q.s. $120 \mathrm{mM}$ salt concentration), by CD spectroscopy. 
222
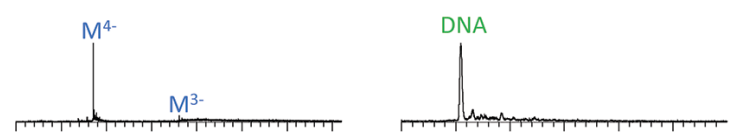

$\left[\mathrm{SrCl}_{2}\right](\mu \mathrm{M})$

0
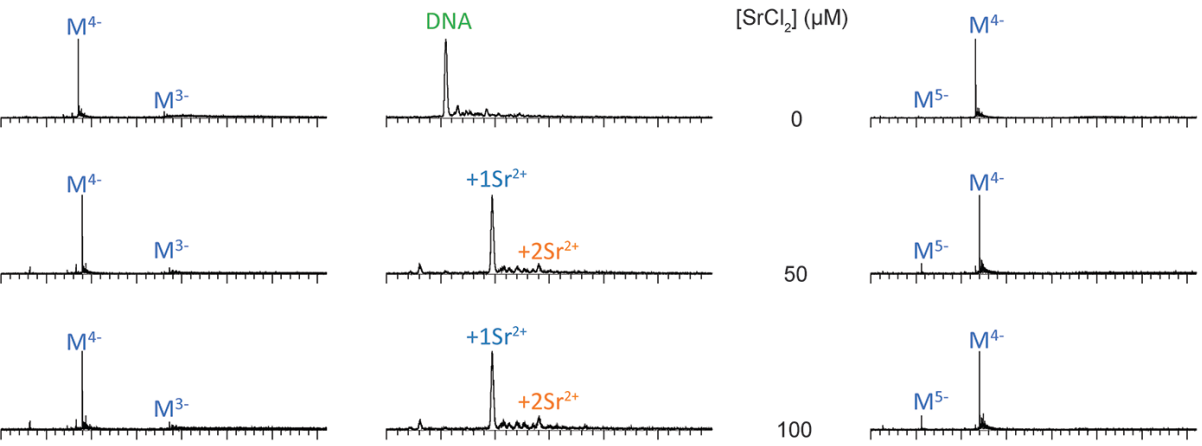

100
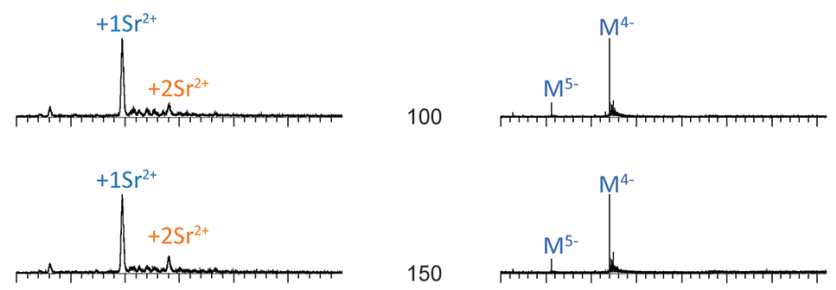

150
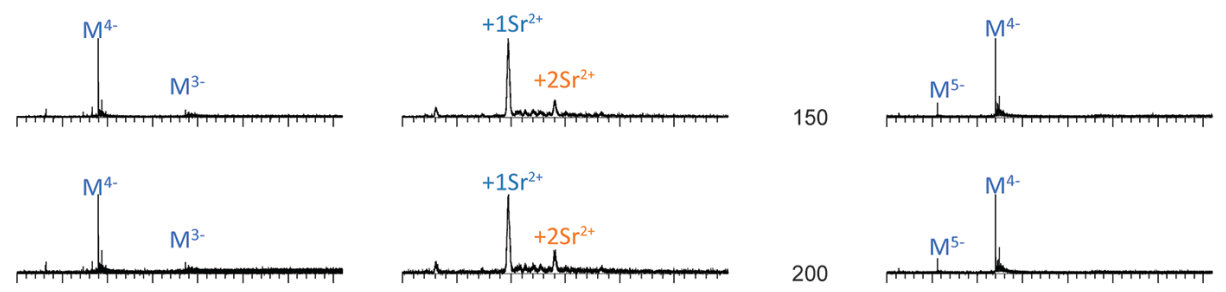

200
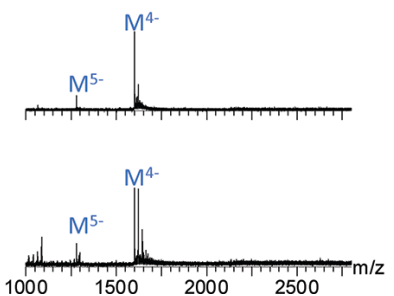
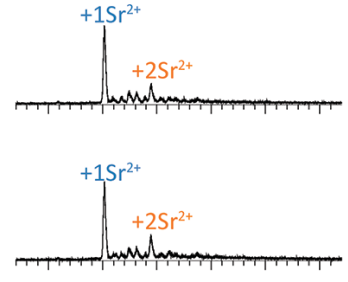

222T
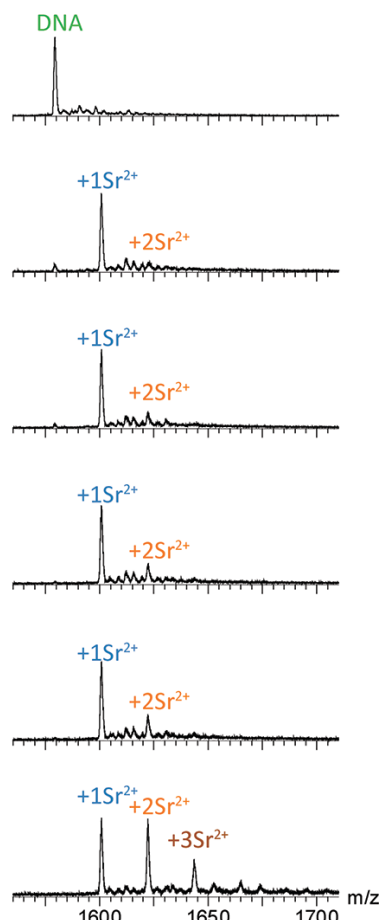

Figure S45. Titration of 222 (left) and $222 \mathrm{~T}$ (right) by $\mathrm{SrCl}_{2}(0-1000 \mu \mathrm{M})$, at a $10-\mu \mathrm{M}$ strand concentration in TMAA (q.s. $120 \mathrm{mM}$ salt concentration), by native ESI-MS. For each oligonucleotide, the left spectra shows the 1000-2750 m/z range, and the right spectra are focused on the 4 charge state. $M$ stands for monomer and $D$ for dimer. The number of strontium adducts is indicated above the corresponding peaks. 


\section{BLAST}

Table S8. 222 and 222T sequences in the human genome (GRCh38 Primary Assembly, 100\% identity). For hits in untranscribed regions, both the upstream and downstream genes are indicated.

\begin{tabular}{|c|c|c|c|c|c|c|c|c|c|}
\hline$\underset{a}{\text { Sequence }}$ & $\begin{array}{c}\text { G- } \\
\text { tracts } \\
b\end{array}$ & $\begin{array}{c}\text { chromosom } \\
\mathrm{e}\end{array}$ & $\begin{array}{l}\text { Accession } \\
\text { number }\end{array}$ & strand & $\begin{array}{c}E \\
\text { value }\end{array}$ & $\begin{array}{c}\text { start } \\
\text { position }\end{array}$ & $\begin{array}{c}\text { end } \\
\text { position }\end{array}$ & gene & features \\
\hline $222 \mathrm{~T}$ & 6 & 12 & NC_000012.12 & plus/minus & 0.008 & 9924440 & 9924469 & CLEC2A & $\begin{array}{l}\text { C-type lectin domain } \\
\text { family } 2 \text { member A } \\
\text { isoform X1; } \\
\text { C-type lectin domain } \\
\text { family } 2 \text { member A }\end{array}$ \\
\hline $222 \mathrm{~T}$ & 4 & 12 & NC_000012.12 & plus/minus & 0.008 & 68918644 & 68918663 & CPM & $\begin{array}{c}\text { carboxypeptidase M } \\
\text { precursor } \\
\text { putative }\end{array}$ \\
\hline $222 \mathrm{~T}$ & 4 & 14 & NC_000014.9 & plus/minus & 0.008 & 99067505 & 99067524 & $\begin{array}{l}\text { C14orf177; } \\
\text { BCL11B }\end{array}$ & $\begin{array}{c}\text { uncharacterized } \\
\text { protein C14orf177; } \\
\text { B-cell } \\
\text { lymphoma/leukemia } \\
\text { 11B isoform 1 }\end{array}$ \\
\hline $222 \mathrm{~T}$ & 4 & 21 & NC_018932 & plus/minus & 0.008 & 41156398 & 41156417 & $\begin{array}{l}\text { BACE2; } \\
\text { DSCAM }\end{array}$ & $\begin{array}{c}\text { beta-secretase } 2 \\
\text { isoform C } \\
\text { preproprotein; } \\
\text { Down syndrome cell } \\
\text { adhesion molecule } \\
\text { isoform X }\end{array}$ \\
\hline $222 \mathrm{~T}$ & 4 & 7 & NC_000007 & plus/plus & 0.008 & 132317249 & 132317268 & PLXNA4 & $\begin{array}{l}\text { plexin-A4 isoform } 1 \\
\text { precursor; } \\
\text { plexin-A4 isoform X3 }\end{array}$ \\
\hline 222 & 4 & 6 & NC_000006.12 & plus/plus & 0.083 & 87229964 & 87229981 & ZNF292 & $\begin{array}{c}\text { zinc finger protein } \\
292\end{array}$ \\
\hline 222 & $5^{c}$ & 14 & NC_000014.9 & plus/minus & 0.083 & 99067501 & 99067523 & $\begin{array}{l}\text { C14orf177; } \\
\text { BCL11B }\end{array}$ & $\begin{array}{c}\text { putative } \\
\text { uncharacterized } \\
\text { protein C14orf177; } \\
\text { B-cell } \\
\text { lymphoma/leukemia } \\
\text { 11B isoform 1 }\end{array}$ \\
\hline 222 & $4^{c}$ & 14 & NC_000014.9 & plus/minus & 0.083 & 99067532 & 99067549 & $\begin{array}{l}\text { C14orf177; } \\
\text { BCL11B }\end{array}$ & $\begin{array}{c}\text { putative } \\
\text { uncharacterized } \\
\text { protein C14orf177; } \\
\text { B-cell } \\
\text { lymphoma/leukemia } \\
\text { 11B isoform 1 }\end{array}$ \\
\hline 222 & 4 & 17 & NC_000017.11 & plus/minus & 0.083 & 75933313 & 75933330 & FBF1 & fas-binding factor 1 \\
\hline
\end{tabular}

${ }^{a}$ Sequence 222 is always contained in $222 T$ matches, and the results are not duplicated in the table except for the chromosome 14 where 222 appears twice.

${ }^{b}$ number of G-tracts is 4 to obtain the minimal G4-forming oligonucleotide sequence.

${ }^{c}$ The two sequences are separated by 8 nucleotides (TCGGGTCG), forming a long G-rich sequence. 


\section{DISCUSSION}

\section{TAGGED OLIGONUCLEOTIDES}

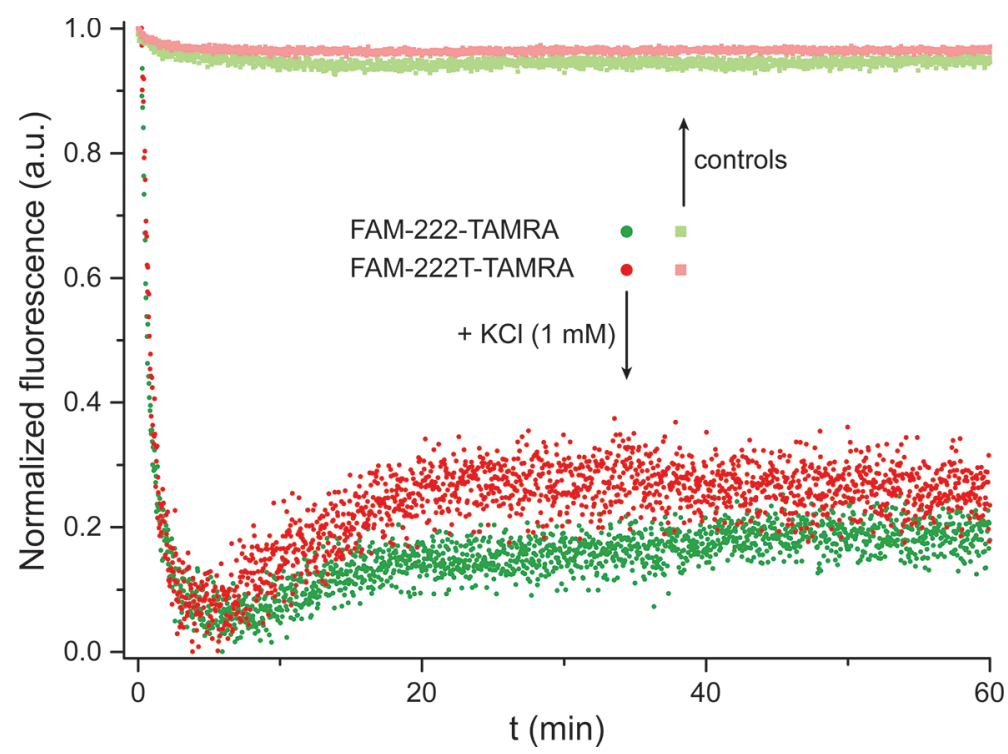

Figure S46. Fluorescence kinetics of FAM/TAMRA-labelled 222 and $222 T$ oligonucleotides (200 nM) in lithium cacodylate $(20 \mathrm{mM}, \mathrm{pH} 7.2)+100 \mathrm{mM} \mathrm{NaCl}$, after addition of $1 \mathrm{mM} \mathrm{KCl}$. Fluorescence was monitored at $\lambda=519 \mathrm{~nm}$ (excitation: $\lambda=490 \mathrm{~nm}$ ), at low temperature $\left(7^{\circ} \mathrm{C}\right.$ ), on a Horiba Jobin Yvon FluoroMax-4 (Longjumeau, France). A control experiment, where no potassium is added, is performed to account for photobleaching of the fluorophores and any other time-dependent phenomena. This control is then subtracted from the potassium dependent data depicted above. Quenching at equilibrium is of roughly $20 \%$. 


\section{REFERENCES}

(1) Pinnavaia, T. J.; Marshall, C. L.; Mettler, C. M.; Fisk, C. L.; Miles, H. T.; Becker, E. D. J. Am. Chem. Soc. 1978, 100, 3625.

(2) Lech, C. J.; Heddi, B.; Phan, A. T. Nucleic Acids Res. 2013, 41, 2034.

(3) Shannon, R. D. Acta Crystallogr., Sect. A: Found. Crystallogr. 1976, 32, 751.

(4) Sun, J.; Kitova, E. N.; Wang, W.; Klassen, J. S. Anal. Chem. 2006, 78, 3010.

(5) Gray, R. D.; Chaires, J. B. Curr. Protoc. Nucleic Acid Chem. 2011, Chapter 17, 17.4.

(6) Mergny, J. L.; Li, J.; Lacroix, L.; Amrane, S.; Chaires, J. B. Nucleic Acids Res. 2005, 33, e138.

(7) Mergny, J. L.; Lacroix, L. Oligonucleotides 2003, 13, 515.

(8) Wallimann, P.; Kennedy, R. J.; Miller, J. S.; Shalongo, W.; Kemp, D. S. J. Am. Chem. Soc. 2003, 125, 1203.

(9) Guédin, A.; Gros, J.; Alberti, P.; Mergny, J.-L. Nucleic Acids Res. 2010, 38, 7858.

(10) Rachwal, P. A.; Brown, T.; Fox, K. R. Biochemistry 2007, 46, 3036.

(11) Balkwill, G. D.; Garner, T. P.; Williams, H. E.; Searle, M. S. J. Mol. Biol. 2009, 385,

1600.

(12) Tran, P. L. T.; Mergny, J. L.; Alberti, P. Nucleic Acids Res. 2011, 39, 3282.

(13) Wang, Y.; Patel, D. J. J. Mol. Biol. 1995, 251, 76.

(14) Tran, P. L. T.; Largy, E.; Hamon, F.; Teulade-Fichou, M.-P.; Mergny, J.-L. Biochimie 2011, 93, 1288.

(15) Largy, E.; Mergny, J. L. Nucleic Acids Res. 2014, 42, e149.

(16) Waller, Z. A.; Sewitz, S. A.; Hsu, S. T.; Balasubramanian, S. J. Am. Chem. Soc. 2009, $131,12628$.

(17) Phan, A. T.; Kuryavyi, V.; Burge, S.; Neidle, S.; Patel, D. J. J. Am. Chem. Soc. 2007, 129, 4386.

(18) Kuryavyi, V.; Phan, A. T.; Patel, D. J. Nucleic Acids Res. 2010, 38, 6757.

(19) Wei, D.; Todd, A. K.; Zloh, M.; Gunaratnam, M.; Parkinson, G. N.; Neidle, S. J. Am. Chem. Soc. 2013, 135, 19319. 